\title{
Influence of snow cover properties on avalanche dynamics
}

THÈSE Nº 6475 (2015)

PRÉSENTÉE LE 26 JANVIER 2015

À LA FACULTÉ DE L'ENVIRONNEMENT NATUREL, ARCHITECTURAL ET CONSTRUIT

LABORATOIRE DES SCIENCES CRYOSPHÉRIQUES

PROGRAMME DOCTORAL EN GÉNIE CIVIL ET ENVIRONNEMENT

ÉCOLE POLYTECHNIQUE FÉDÉRALE DE LAUSANNE

POUR L'OBTENTION DU GRADE DE DOCTEUR ÈS SCIENCES

PAR

\section{Walter STEINKOGLER}

acceptée sur proposition du jury:

Prof. S. Takahama, président du jury

Prof. M. Lehning, Dr B. Sovilla, directeurs de thèse

Prof. C. Ancey, rapporteur

Prof. J. McElwaine, rapporteur

Prof. K. Nishimura, rapporteur

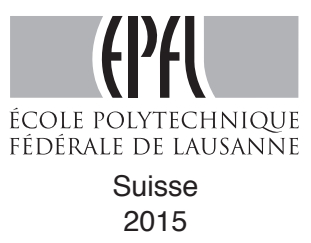



Everything we hear is an opinion, not a fact. Everything we see is a perspective, not the truth. - Marcus Aurelius, Roman emperor and philosopher

To my parents... 



\section{Acknowledgments}

At the end of my $\mathrm{PhD}$ I finally get to write the acknowledgments. Neither work nor private life would be as successful and funny without the people you meet and work with along the way. Therefore, I am indebted to all my friends and colleagues who have supported me during these years. The list would be too long to list all of them, but I would like to especially thank a few individuals.

First I would like to thank my thesis director Michael Lehning for initially bringing me to SLF during my master thesis, giving me the chance to work on many different projects and finally directing my $\mathrm{PhD}$ study. I am grateful for the supervision and guidance of Betty Sovilla. I surely enjoyed the often intense but always fruitful discussions. I am very proud of what we have achieved together, thank you both.

All the people from SLF who create this unique working environment deserve a huge thank you. Especially the members of the Avalanche Dynamics and Risk Management team and colleagues from other groups: Michael, Cesar, Linda, Marc(x2), Martina, Yves, JP, Anselm, James, Claudia, Perry, Lisa(x2), Tom(x2), Philip, Benni, Luki, JT, Ben, Martin, Steph, Gian, Anna, Jürg, Christine, Jan, Florian, Mathias, Berna, Charles, Michi, Henning, Mathias, and many many others. I remember countless unforgettable moments on the mountains but also during supporting my work in many ways (mostly while freezing in the field).

A special thanks goes to the guys \& girls from the 'Ridersplace': Christoph, Jochen, Fabiano, Johan, Benni, Sanni, Sabrina, Kiki, Christiane and Laura. Unforgettable moments that will stay in my head for the rest of my life! I thank all of you for creating a unique atmosphere in which everybody knew that no matter what: we would pick each other up when one fell down. For all your support in work related fields and also in personal things I am deeply grateful.

I am thankful to my parents who always believe in me and always support me in every aspect.

Finally, I thank Maren for her 'all-in support' in every life situation and the wonderful moments we share together. Thanks that you are there! 



\section{Abstract}

Snow avalanches are a direct thread to many mountain communities around the world and already small avalanches can endanger traffic routes and result in loss of life or property. Their destructive power depends, among other things, on the overall mass and the properties of the flowing snow. The variety of flow regimes in avalanches, ranging from powder clouds to slush flows, is mainly controlled by the properties of the snow released and entrained along the path. So far, the knowledge on how snow conditions effect avalanche behavior is limited and hypotheses are not supported by data.

This study aims to provide a first step towards the successful link between snow cover properties and the internal granular composition, which in turn affects the flow dynamics of an avalanche. As a first step, the snow cover properties with most relevance for avalanche dynamics, such as run-out distance and front velocity, are identified. Five avalanches with similar initial mass and topography, but different flow dynamics were selected from the Vallée de la Sionne test site (Western Swiss Alps) database. For each of these avalanches, the snow conditions were reconstructed using the three-dimensional surface process model Alpine3D and the snow cover model SNOWPACK. For the investigated avalanches the data shows that the total mass, mainly controlled by entrained mass, defines run-out distance but does not correlate with front velocity. Yet, a direct effect of snow temperature on front velocity, development of a powder cloud and deposition structures could be observed. A temperature of the flowing snow warmer than approximately $-2^{\circ} \mathrm{C}$ was identified as critical value for changes in flow dynamics.

As a next step field experiments with multiple artificially released avalanches were conducted to quantify the temperature of the flowing snow more accurately and to investigate the magnitudes of different sources of thermal energy. Manually measured snow temperature profiles along the avalanche track and in the deposition area allowed quantifying the temperature of the eroded snow layers. Infrared radiation thermography (IRT) was used to assess the surface temperature before, during and just after the avalanches with high spatial resolution. This data allowed the calculation of the thermal balance, from release to deposition. We found that, for the investigated dry avalanches, the thermal energy increase due to friction was mainly dependent on the elevation drop of the avalanche with a warming of approximately $0.5^{\circ} \mathrm{C}$ per 100 height meters. Contrary, warming due to entrainment was very specific to the individual avalanche and depended on the temperature of the snow along the path and the erosion depth 
ranging from nearly no increase to $1^{\circ} \mathrm{C}$. Furthermore, we could observe that the warmest temperatures are located in the deposits of the dense core.

Especially in cases where the described warming processes cause the temperature of the flowing snow to approach the melting point significant differences in the granular composition of an avalanche can occur. Consequently, the granular structures in the deposition zone of avalanches are often associated with cold or warm avalanches. We therefore conducted experiments on the temperature-dependent granulation of snow. An ordinary concrete tumbler provided a suitable setup to conduct our investigations on intermediate but relevant length scales. In a set of experiments at constant rotation velocity with varying temperatures and water content, we demonstrated that temperature has a major impact on the formation of granules. The experiments showed that granules only formed when the snow temperature exceeded $-1^{\circ} \mathrm{C}$ and thus support the earlier made observations. Depending on the snow temperature and moisture content, different granulation regimes were obtained, which were qualitatively classified according to their properties and size distribution. All experimentally observed granule classes were reproduced by a discrete element model (DEM) that mimicked the competition between cohesive forces, which promoted aggregation, and impact forces, which induced fragmentation. Furthermore, the DEM simulations reproduced the grain size distribution and general behavior observed in the different granule regimes.

In summary the thesis illustrates the importance of snow temperature on the flow dynamics of avalanches with a critical threshold at $-1^{\circ} \mathrm{C}$. The experiments and model results on the granulation of snow allowed to describe granular structures typically observed in the deposition zone of avalanches of different temperature regimes.

Key words: avalanche dynamics, snow cover properties, temperature, granulation 


\section{Zusammenfassung}

Schneelawinen stellen weltweit eine direkte Bedrohung für viele bewohnte Bergregionen dar. Bereits kleinere Lawinen haben das Potential Verkehrswege zu gefährden und den Verlust von Menschenleben und Gütern zu verursachen. Ihre zerstörerische Kraft hängt, unter anderem, von ihrer Masse und den Schneeeigenschaften entlang der Lawinenbahn ab. Lawinen können viele unterschiedliche Fliessregime, von Pulverschneelawinen bis zu 'slush flows', aufweisen. Welches dieser Fliessregime sich ausbildet, ist grossteils von den Schneeeigenschaften im Anriss und denen des aufgenommenen Schnees entlang der Bahn abhängig. Bisher ist das Wissen um den Einfluss der Schneebedingungen auf die Dynamik jedoch sehr beschränkt und bestehende Hypothesen sind nicht durch Daten verifiziert.

Diese Studie hat das Ziel einen ersten Schritt zur Verknüpfung von Schneeeigenschaften mit der internen granularen Struktur von Lawinen und damit deren Fliessdynamik zu erstellen. In einem ersten Schritt werden die Schneedeckenparameter mit der grössten Relevanz für die Lawinendynamik (Auslaufdistanz und Frontgeschwindigkeit) identifiziert. Dazu wurden fünf Lawinen mit ähnlicher Initialmasse und Topographie, jedoch unterschiedlicher Fliessdynamik, aus der Datenbank der Vallée de la Sionne Versuchsfläche (Westliche schweizer Alpen) ausgewählt. Für jede dieser Lawinen wurden die Schneeeigenschaften mit dem drei-dimensionalen Oberflächenprozessmodel Alpine3D und dem Schneedeckenmodell SNOWPACK rekonstruiert. Die Daten der untersuchten Lawinen zeigten, dass die finale Masse, welche hauptsächlich durch die aufgenommene Masse entlang der Bahn bestimmt wird, mit der Auslaufdistanz, jedoch nicht mit den Frontgeschwindigkeiten korreliert. Ein direkter Zusammenhang der Schneetemperatur mit Frontgeschwindigkeiten, der Entwicklung der Pulverwolke und Ablagerungsstrukturen in der Depositionszone konnte beobachtet werden. Als kritischer Wert für Änderungen im Fliessverhalten wurde eine Schneetemperatur des fliessenden Schnees von $-2^{\circ} \mathrm{C}$ identifiziert werden.

Um die Temperatur des fliessenden Schnees genauer zu quantifizieren und die Grössenordnung verschiedener Quellen von thermischer Energie abzuschätzen, wurden in einem weiteren Schritt Feldversuche mit mehreren künstlich augelösten Lawinen durchgeführt. Manuell erstellte Schneetemperaturprofile entlang der Bahn und in der Depositionszone erlaubten die Temperatur der erodierten Schneeschichten zu bestimmen. Infrarot Thermographie (IRT) wurde eingesetzt um die Oberflächentemperatur des Schnees vor, während und nach dem Lawinenabgang mit hoher räumlicher Auflösung zu erfassen. Basierend auf 
diesem Datensatz konnte die thermische Bilanz von der Anrisszone bis zur Ablagerung bestimmt werden. Wir konnten feststellen, dass für die untersuchten trockenen Lawinen die Zufuhr thermischer Energie in Folge Reibung im Wesentlichen von der Fallhöhe der Lawine abhängt und eine Erwärmung von ungefähr $0.5^{\circ} \mathrm{C}$ pro 100 Höhenmeter verursachen kann. Im Gegensatz dazu variierte die Erwärmung durch Erosion von Schnee für die einzelnen Lawinen stark. Massgebend war hier die Temperatur des Schnees in der Lawinenbahn und der Erosionstiefe. Die Bandbreite der thermischen Energiezufuhr durch Erosion reichte von beinahe keiner Erwärmung bis zu $1^{\circ} \mathrm{C}$. Die durchgeführten Messungen zeigten des Weiteren dass die wärmsten Temperaturen in der Ablagerung des Fliessanteils einer Lawine auftreten.

Besonders in Situationen wo die beschriebenen Erwärmungsprozesse die Temperatur des fliessenden Schnees bis nahe dem Schmelzpunkt erwärmen, treten oft deutliche Unterschiede in der granularen Zusammensetzung von Lawinen auf. Aufgrund dessen werden die granularen Strukturen in einer Ablagerung oft intuitiv mit kalten oder warmen Lawinen assoziiert. Wir führten daher Experimente bezüglich der temperaturabhängigen Granulation von Schnee durch. Ein regulärer Betonmischer stellte eine geeignete Methode dar um die involvierten Prozesse auf einer kleineren aber repräsentativen Grössenskala zu untersuchen. Basierend auf einer Reihe von Experimenten bei konstanter Rotationsgeschwindigkeit aber variierender Schneetemperatur und Wassergehalt wird der bedeutende Einfluss der Temperatur auf die Granulatbildung aufgezeigt. Die Experimente zeigten, dass sich Granulare nur bildeten, wenn die Schneetemperatur $-1^{\circ} \mathrm{C}$ überstieg. Abhängig von den Bedingungen konnten unterschiedliche Granulatregime erzeugt werden welche entsprechend ihrer Persistenz und Grössenverteilung qualitativ klassifiziert wurden.

Alle in den Experimenten beobachteten Granularklassen wurden mit einem discrete elemente model (DEM) reproduziert. Das Modell beschreibt dazu die Balance zwischen kohesiven Kräften, welche Aggregation verursachen, und Aufprallkräften, welche Fragmentation verursachen. Die erstellten Simulationen unterstützen die Interpretation der Granulatregime welche in den Experimenten beobachtet wurden. Des Weiteren konnte mit den DE Simulationen die Grössenverteilung und das allgemeine Verhalten der Granulare in den verschiedenen Regimen reproduziert werden.

Diese Arbeit verdeutlicht die Wichtigkeit der Schneetemperatur auf die Fliessdynamik von Lawinen mit einem kritischen Grenzwert bei $-1^{\circ} \mathrm{C}$. Die Ergebnisse aus den Experimenten und den Modellberechnungen erlaubten die granularen Strukturen, welche oft in Ablagerungen von Lawinen mit verschiedenen Temperaturregimen beobachtet werden, zu erklären.

Stichwörter: Lawinendynamik, Schneeeigenschaften, Temperatur, Granulation 


\section{Contents}

$\begin{array}{ll}\text { Acknowledgments } & \text { i }\end{array}$

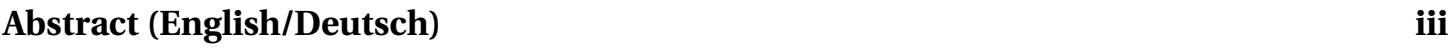

1 Introduction 1

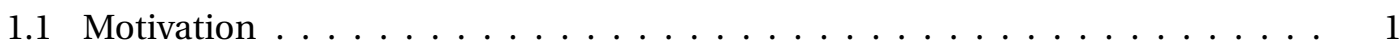

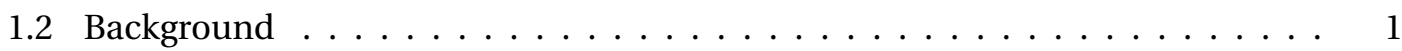

1.2.1 Snow cover mass and other properties influencing avalanche dynamics 3

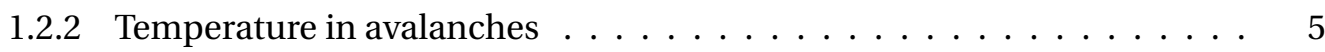

1.2 .3 Granular matter . . . . . . . . . . . . . . . . 6

1.3 Purpose and Outline $\ldots \ldots \ldots \ldots \ldots \ldots \ldots \ldots$

2 Influence of snow cover properties on avalanche dynamics 11

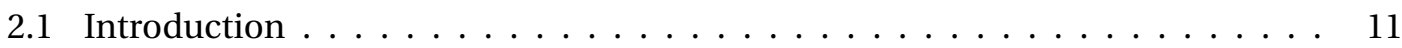

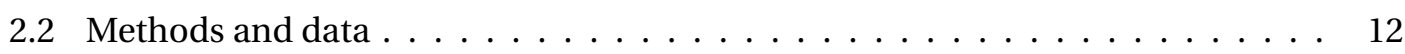

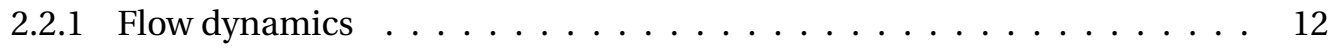

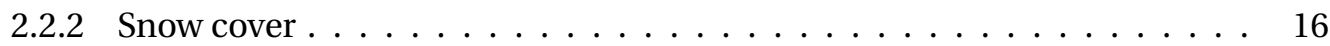

2.2 .3 Mass balance calculations . . . . . . . . . . . . . . . . . . . . 19

2.3 Data synopsis of investigated avalanches . . . . . . . . . . . . . . . 19

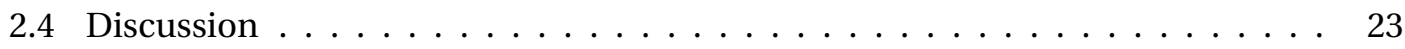

2.4.1 Influence of mass on run-out and front velocity . . . . . . . . . . . . 24

2.4.2 Effects of snow cover properties on front velocity . . . . . . . . . . 25

2.5 Conclusion and outlook $\ldots \ldots \ldots \ldots \ldots \ldots \ldots$

3 Thermal energy in dry snow avalanches 31

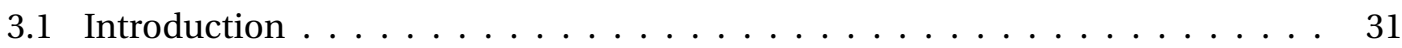

3.2 Methods \& Data . . . . . . . . . . . . . . . . . . . . . 32

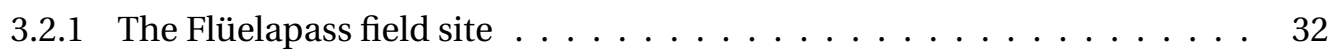

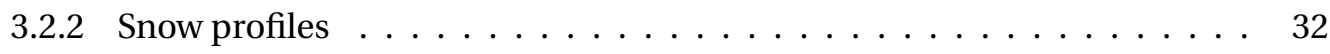

3.2 .3 Lateral temperature profiles . . . . . . . . . . . . . . . . 33

3.2.4 Infrared radiation thermography (IRT) camera $\ldots \ldots \ldots . \ldots 34$

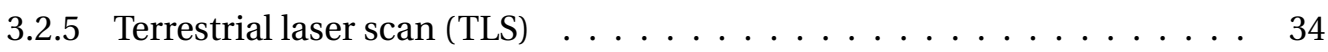

3.3 Investigated avalanches $\ldots \ldots \ldots \ldots \ldots \ldots \ldots \ldots$

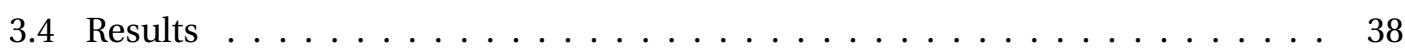


3.4 .1 Temperature distribution $\ldots \ldots \ldots \ldots \ldots \ldots$

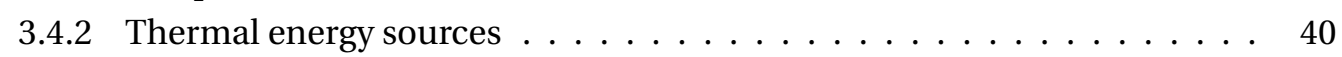

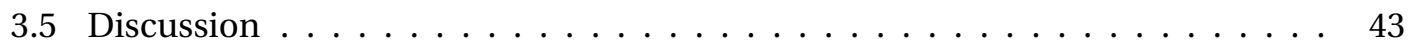

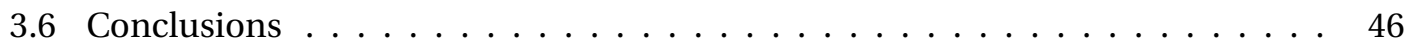

4 Granulation of snow: experiments and discrete element modeling 49

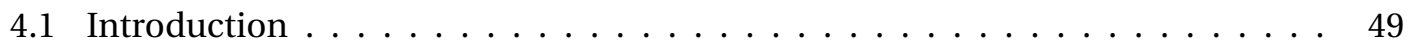

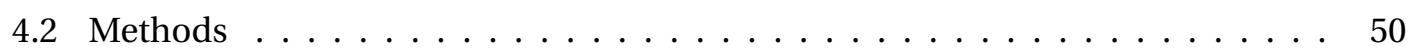

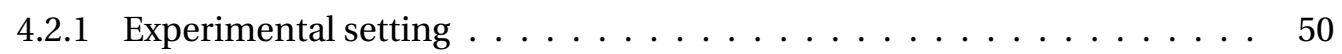

4.2 .2 Discrete Element Modeling . . . . . . . . . . . . . . . . . 54

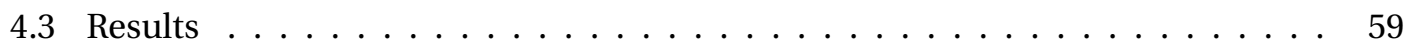

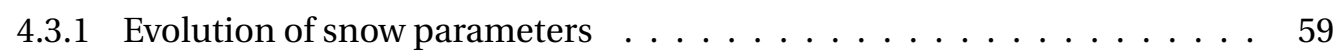

4.3 .2 Granulation classification . . . . . . . . . . . . . . . . 60

4.3 .3 Numerical results . . . . . . . . . . . . . . . . . . . . . . . . 62

4.3.4 Granule size distribution . . . . . . . . . . . . . . . . . 65

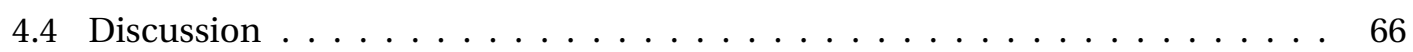

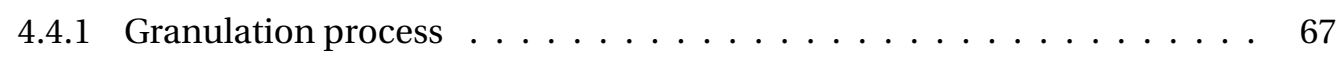

4.4 .2 Main results . . . . . . . . . . . . . . . . . . 67

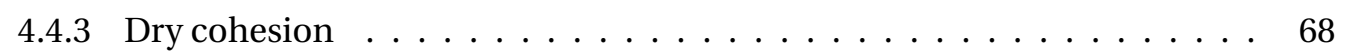

4.4 .4 Wet cohesion . . . . . . . . . . . . . . . . . 69

4.4.5 Translation to DEM and phase diagram . . . . . . . . . . . 70

4.4.6 Limitations of experimental and modeling setup . . . . . . . . . . . 71

4.4 .7 Implications for flow dynamics . . . . . . . . . . . . . . . . . . . . . . . . . . . . . . . . . 72

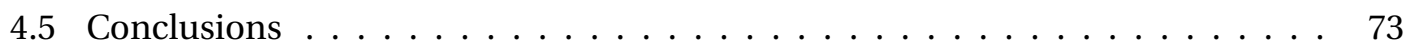

5 Overall summary and conclusions $\quad 75$

6 Outlook $\quad 79$

$\begin{array}{ll}\text { Bibliography } & 95\end{array}$

$\begin{array}{lr}\text { Curriculum Vitae } & 97\end{array}$ 


\section{Introduction}

\subsection{Motivation}

Snow avalanches are a major natural hazard in mountainous regions. The increased development of alpine areas as well as a significant change in safety requirements and risk propensity of the people demand an improved management of avalanche related risks. This refinement and optimization of existing procedures and guidelines has to include a more sophisticated understanding of the different flow behaviors of avalanches. The varying flow regimes, and possible rapid transitions between them, face practitioners, such as forecasters and engineers, with often unexpected run-out distances, velocities and impact pressures. From the researcher perspective, the complex snow cover property dependent rheological characteristics of snow make the modeling of different flow regimes challenging. The aim of this study is to extend and partly quantify the often empirically and 'rule-of-thumb' based knowledge on the influence of snow cover properties on avalanche dynamics with a special focus on the effects of snow temperature.

\subsection{Background}

Snow avalanches threaten mountain communities, tourism destinations and traffic routes in many mountain regions around the world. They possess a threat in basically every area with mountain ranges that receive high amounts of snow (Fig. 1.1). Especially densely inhabited mountain areas in the European Alps and other countries such as Norway, USA, India, Pakistan, Japan or New Zealand have often seen catastrophic avalanche accidents in history. In Austria around 6000 and Switzerland 20000 relevant avalanche paths are recorded [Rudolf-Miklau and Sauermoser, 2011].

The increased demand to access mountainous regions all year long and independently of the snow and weather conditions has required the continuous investment of substantial financial efforts. Switzerland invested around CHF 1.5 billion between 1950 and 2000 in technical avalanche risk reduction measures $[S L F, 2000]$. Despite these investments approximately 1350 


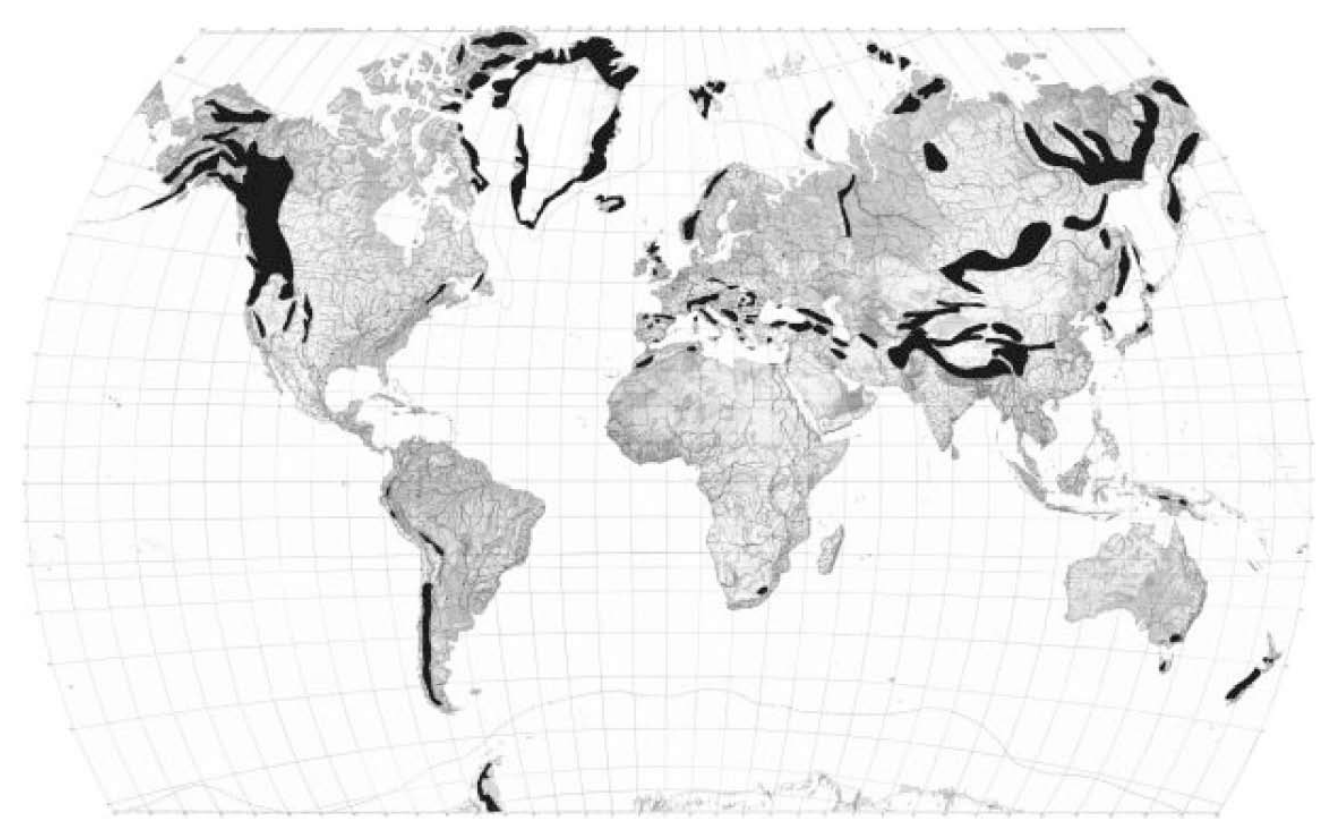

Figure 1.1: Overview worldmap of mountain regions with areas endangered by snow avalanches (black areas). From Rudolf-Miklau and Sauermoser [2011], based on Glazovskaya [1998].

avalanches causing 17 human deaths inside buildings or on roads and an estimated direct and indirect loss of 750 million CHF were caused during the last catastrophic avalanche cycle in the European Alps in February 1999 [Fuchs et al., 2007]. Overall though, permanent measures and the avalanche-hazard mapping procedure developed in Switzerland since the last extreme avalanche winter in 1951 proved to work for the extreme avalanche winter 1999: in most cases the avalanches stopped within the avalanche-hazard zones [Gruber and Margreth, 2001]. This last extreme winter verified that avalanche protection measures, both permanent and temporary, are an essential factor in the economic evolution of alpine regions.

The most prominent avalanche paths have been mitigated with permanent structures, yet numerous avalanche paths remain and pose a danger for roads, railways and ski resorts. Since permanent structures are very expensive and thus socio-economical not cost-effective, measures with temporary protective effect (observation, detection and warning, artificial avalanche release) became very popular over the course of the last decades and developed rapidly [Rudolf-Miklau and Sauermoser, 2011; Stoffel, 2013]. Systems for the artificial release of avalanches are increasingly applied to secure ski resorts, roads and railway tracks since they are more cost effective than permanent measures (defensive structures, galleries, tunnels) and provide the possibility to release the avalanche at a defined point of time.

Yet, the latter point demands a constant monitoring and evaluation of the avalanche danger by experts, e.g. by a local avalanche commission. This puts a lot of pressure on local authorities since they are urged to keep closure times to a minimum, but ensure that avalanche mitigation work is conducted when needed. Generally, it is already challenging to assess release location 
and time window of an avalanche, but in many cases it is even harder to predict its run-out distance. However, to decide on road closures, it is essential for local avalanche safety services to know whether the avalanche will reach the road or stop above. These decisions are often very difficult as multiple elements need to be equally considered: a correct interpretation of the weather forecasts, the evolution of snow cover stability and its structure and finally the influence of the snow cover parameters on avalanche dynamics and thus run-out distances [Blattenberger and Fowles, 1995]. Many of these decisions are not based on defined procedures, but rather on the experience of the local safety personnel. An improved and more quantitative link between the individual elements in the decision chain has the potential to considerably improve the safety management of avalanche related risks, justify the decisions of practitioners and allow the easier transfer of avalanche mitigation concepts to new sites.

Guidelines for hazard mapping [BFF and EISLF, 1984; Rudolf-Miklau and Sauermoser, 2011] were originally created for extreme avalanches which are usually dry avalanches that release after or during extraordinary new snow events. Especially for smaller and often more frequent avalanches it is essential to consider variations in snow cover properties of the flowing snow in order to accurately estimate run-out and flow behavior. Literature on the direct influence of snow characteristics on avalanche dynamics are sparse and mostly describe the link between new snow amounts and run-out for extreme avalanches [Eckert et al., 2010; Naaim and Durand, 2012].

\subsubsection{Snow cover mass and other properties influencing avalanche dynamics}

The variability in the nature of snow avalanches is vast and complex. Their evolution and motion is mainly defined by three independent contributions: the amount of snow, the morphology of the avalanche path (slope, curvature) and the rheological properties of the snow [Naaim et al., 2013].

The overall amount of snow inside an avalanche is composed of the released mass and the entrained snow the avalanche erodes along the path. The importance of the entrainment process, which can increase the mass substantially, was clearly demonstrated by Sovilla et al. [2006, 2007]. Similar observations were made by Schweizer et al. [2009] who found in their data that the run-out distances of avalanches were related to the difference in snow depth over the last three days. Their results also suggested that the entrainment of snow was favored by weak basal layers in the avalanche track and might therefore have contributed to the larger run-out distances.

Bates et al. [2014] noted that entrainment may or may not significantly affect the dynamics of the flow, e.g. resulting in increased run-out distances. Observations have shown that different avalanches can form with similar initial conditions and on the same avalanche path depending on the snow cover properties. Ultimately, the rheological properties of the snow will determine which flow regime will develop. 
Snow avalanches can exhibit many different behaviors [Ancey, 2001], such as a sheared and fluid-like layer, a plug flow or a dilute suspended powder cloud [Gauer et al., 2008]. In most cases different regimes exist at the same time at different locations inside an avalanche [Sovilla et al., 2008]. Typical pressures and velocities can be associated to the individual flow regimes and are taken into account for practical applications such as hazard mapping or the design of structures close to the avalanche path [BFF and EISLF, 1984; Salm et al., 1990].

As soon as the avalanche is released the slab disintegrates into smaller pieces, erosion along the track adds additional mass and, in the case of a dry avalanche, a powder cloud develops that obscures the processes and other flow regimes inside the avalanche [Nishimura and Ito, 1997]. Powder clouds rapidly grow in height up to $200 \mathrm{~m}$ and reach frontal speeds up to 100 $\mathrm{m} \mathrm{s}^{-1}$ [Sovilla et al., submitted]. Even though the impact pressure in the dilute front region is relatively small, it is powerful enough to damage tall objects such as tree tops, break windows (2-4 kPa), or weaken doors, walls and roofs (3-6 kPa). Zones with the highest impact pressures are located in the area behind the front and in the dense core. There, impact pressures can reach sufficient levels to destroy wooden and brick structures (12-24 kPa and 25-45 kPa, respectively), level mature forests $(\sim 100 \mathrm{kPa})$, or displace large rocks ( $>200 \mathrm{kPa})$ [Sovilla et al., submitted].

Multiple observations and measurements have indicated the presence of a fluidized intermediatedensity layer (often also called a "saltation layer"). Although not fully investigated and understood, it may have important consequences in hazard mapping and the design of countermeasures. The high mobility of the fluidized flow regime allows it to reach areas that cannot be reached by the dense flow [Gauer et al., 2008]. A substantial mass fraction of mixed dry-snow avalanches is flowing in this fluidized regime and can reach front velocities around $30-50 \mathrm{~m} \mathrm{~s}^{-1}$ and impact pressures ranging between 10 to $70 \mathrm{kPa}$ [Issler and Gauer, 2008; Issler et al., 2008].

In contrast to dry avalanches [Kern et al., 2010], wet-snow avalanches are much slower [Takeuchi et al., 2003], yet they can exhibit a serious danger to forests, infrastructure and traffic routes. Also slushflows [Onesti, 1987], a flowing mixture of water and snow, cause damage every year to man and property in arctic and mountainous regions Uaedicke et al., 2008]. According to historical documentation, slushflows and snow avalanches are almost equally responsible for both damage and economic losses [Hestnes, 1998].

Depositional structures in the run-out zone of avalanches are often interpreted as indicators for the flow regime of an avalanche. Dry avalanches typically feature a fan-shaped deposition zone with an approximately log-normal granule size distribution, similar to many natural sediment deposits [Bartelt and McArdell, 2009]. On the contrary, wet-snow avalanches tend to produce more large granules than dry avalanches [De Biagi et al., 2012; Kobayashi et al., 2000] and often flow-fingers and levee formation [Bartelt et al., 2012a] can be observed.

As for other geophysical mass flows multiple different model approaches were developed to simulate the motion of snow avalanches [Harbitz, 1998; Pudasaini and Hutter, 2007]. Initially, statistical approaches were used [Lied and Bakkehøi, 1980; McClung and Lied, 1987] before 
deterministic approaches, commonly called avalanche dynamics models, were developed [Hutter and Kirchner, 2013; Pudasaini, 2012; Salm et al., 1990; Sampl and Zwinger, 2004; Voellmy, 1955]. Yet, all these avalanche dynamics models face the difficult problem to account for the rheological properties of the snow [Ancey, 2001]. Since many of those models, e.g. RAMMS [Christen et al., 2010], are calibrated for extreme dry avalanches they often produce unsatisfactory results for run-out distances of small- and mid-sized avalanches, which may still produce problems for infrastructure. New model modifications [Vera et al., 2012] seem to be very promising for the calculation of small-sized avalanches and in defining different flow regimes [Bartelt et al., 2011; Gauer et al., 2007]. Bartelt et al. [2014] concluded that in future, avalanche dynamics models must reflect the variability of the natural snow conditions to improve the accuracy of model calculations.

In summary these observations allow the conclusion that snow cover properties are highly important for the avalanche flow behavior. Especially for avalanches close to the melting point and as soon as liquid water is present significant and unexpected changes can occur.

\subsubsection{Temperature in avalanches}

Even though the importance of entrainment on the evolution of an avalanche has been known for long, the properties of the eroded snow were largely neglected so far. Nevertheless, many studies [Hopfinger, 1983; Kern et al., 2009] and reports from practitioners [Jones et al., 2014] describe the challenges caused by avalanches at different temperatures. Despite its importance, not many direct investigations on the temperature distributions and heat sources in snow avalanches exist. Miller et al. [2003] used thermocouples in an avalanche path and measured a temperature increase at the running surface of flowing snow. Only recent studies on the effect of snow properties on flow dynamics showed the significant influence of snow temperature [Naaim et al., 2013; Sovilla and Bartelt, 2002; Vera et al., 2012]. Naaim et al. [2013] found an increasing trend with temperature and density for the static friction coefficient. Additionally, certain thermal regimes are associated with characteristic granular structures in the deposition zone of avalanches [Bartelt and McArdell, 2009]. Granular structures might therefore provide the link between different snow cover properties and the corresponding flow dynamics of the different avalanche types (cold, warm, slush). Yet, critical thresholds that define their formation and properties are missing.

Measuring the snow temperature prior to an avalanche release or afterwards in the deposition area is a challenging task. Often the measurements cannot be conducted due to safety concerns or only too late after the release so that significant temperature changes occurred already. Therefore, direct in-flow measurements at the mast at the Vallée de la Sionne field site [Kern et al., 2009; Sovilla et al., 2008] and the recent application of non-contact and nonintrusive infrared radiation thermography (IRT) technologies in the snow science domain [Schirmer and Jamieson, 2013; Shea and Jamieson, 2011] represent promising tools to quantify the temperature distribution and potential sources of thermal energy. Additionally, snow cover models allow to supplement these measurements or can be used to reproduce snow cover in- 
formation for historical avalanches [Naaim et al., 2013]. State-of-the art physics-based model approaches, such as the model chain SNOWPACK/Alpine3D [Lehning et al., 2002a, 2006], allow to calculate a local, one-dimensional evolution of the seasonal snow cover (SNOWPACK) and to spatially distribute it on mountainous topography (Alpine3D).

Generally, a snow temperature close to the melting point and the presence of liquid water due to meltwater or rain can result in substantially different avalanche flow dynamics. A better understanding on the conditions and transition between different avalanche flow regimes would also allow for a more accurate design of structural measures in the path and run-out zone of avalanches. These findings could then increase the performance of tools and concepts which were originally created for dry and cold conditions when they are applied to other climate regions, such as warmer maritime coastal regions in Alaska or Norway. Yet, also in typically cold regions drastic changes in the snow cover properties along the path can occur, especially for avalanches with large elevation drops.

\subsubsection{Granular matter}

Numerous studies on mono- and bi-disperse materials pointed out the relation between the mobility of a granular flow, i.e. its ability to move faster and further, and the particle size distribution [GDR MiDi, 2004; Moro et al., 2010]. This concept could possibly be extended to account for varying flow forms of snow avalanches as the studies in the deposition zone of full-scale avalanches showed that wet-snow avalanches tended to produce a different size distribution than dry-snow avalanches [Bartelt and McArdell, 2009; De Biagi et al., 2012; Kobayashi et al., 2000]. A comprehensive description under which conditions a certain particle size distribution forms is still lacking. As a second effect, the properties of the granules need to be accounted for since the dissipation of kinetic energy upon granule collisions and frictional processes between them might be different for dry or wet granules [Bartelt et al., 2006].

In addition, extensive studies on granular flow dynamics in laboratory experiments exist. Typically, artificial grains, e.g. glass ballotini [Caccamo et al., 2012; Faug et al., 2009; Schaefer and Bugnion, 2013], PMMA particles [Ancey et al., 2013], sand [Holyoake and McElwaine, 2012] or ping-pong balls [McElwaine and Nishimura, 2001], are used. Nevertheless, these experimental setups generally do not account for inter-particle cohesion or changes in size distribution. Since it has to be assumed that these effects are particularly important for snow avalanches and their different flow regimes, the results of these studies can only be applied for avalanches to a limited extent. Experiments with natural snow and pre-existing granules were conducted on snow chutes [Kern et al., 2004; Nishimura, 1991]. In fact, the assumption that an avalanche, or at least its dense core, can be approximated as granular flow [Roche et al., 2011] was made in multiple studies and has been modeled with dry granular theory [Andreotti et al., 2013; Faug et al., 2012; Louge et al., 2011].

Even though granular media are involved in many industrial and geophysical applications it has to be mentioned that no complete theoretical framework is available to describe the 
variety of behaviors observed, even in the ideal case of a medium consisting of identical spherical particles. Andreotti et al. [2013] listed the main difficulties as:

1) Granular media are composed of a large number of particles: This makes it hard to account for the properties and movement of each individual grain. Often averaged quantities of the granular media of interest are therefore described and continuum approaches are used to model its behavior.

2) Lack of scale separation: The microscopic scale, i.e. the individual grains, significantly influences the macroscopic scale, i.e. the size of the flow, and can not be separated.

3) Complex interactions between the grains: At the grain level, the contact between two particles involve non-trivial and highly non-linear phenomena. This is of especial importance for snow with varying temperature and liquid water content.

4) Granular media easily dissipate energy: Depending on the granular properties significant amounts of their kinetic energy can be dissipated by collisions and friction between them.

5) Different states of manner: Depending on how it is agitated and handled, granular material can behave like a solid, a liquid or a gas (Fig. 1.2). These different flow regimes might coexist in a single phenomenon, e.g. a snow avalanche.

Especially for snow, as a medium which is close to its melting point and can therefore considerable change its mechanical properties, these findings must not be neglected. However, up to now, very few investigations exist which address the granulation of snow [Nohguchi et al., 1997; Turnbull, 2011], i.e. the generic name for particle size enlargement [Walker, 2007].

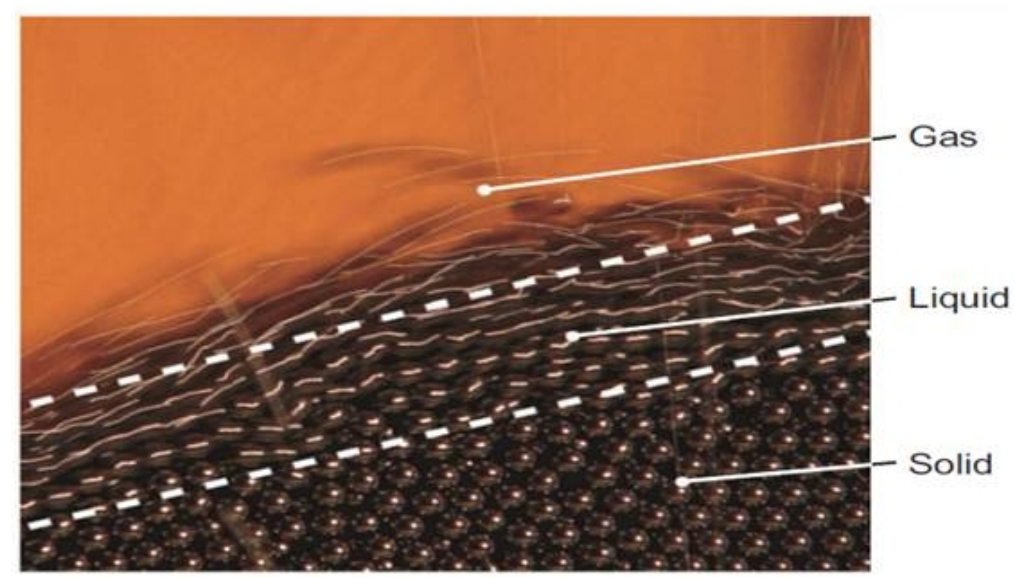

Figure 1.2: An illustration of the solid, liquid, and gas flow regimes obtained by pouring steel beads on a pile. From [Forterre and Pouliquen, 2008].

The granulation of a variety of materials in rotating drums is a key process in many industrial applications including medicinal and pharmaceutical [Kristensen and Schaefer, 1987; Vervaet and Remon, 2005], ceramics [Reed, 1995] and mineral processing as well as fertilizers production. Extensive research on granulation processes [Pietsch, 2003] and the characterization on the granule properties and size distributions took place in the last five decades [Ennis et al., 
1991; Ouchiyama and Tanaka, 1975]. Also studies on mixtures of granular material with liquid water, which usually makes the system even more complex, were conducted with respect to microscopical properties as well as their dynamics [Herminghaus, 2005, and references therein] .

From a modeling view point, numerical studies of cohesive powder flows in rotating drums generally use the discrete element method [Cundall and Strack, 1979] and mainly focus on the mixing behavior [Chaudhuri et al., 2006; Sarkar and Wassgren, 2010, 2009] rather than the evolution of granule sizes. DE simulations were also used recently to model the dense flow of cohesive granular materials by Rognon et al. [2008a] who studied the effect of cohesion on the flow mobility and showed that a plug region could develop if the cohesion is high enough. However, to our knowledge, DE modeling has never been used to describe granulation effects in snow avalanches which are often described using cohesionless granular materials [Faug et al., 2009].

\subsection{Purpose and Outline}

The intention of this study is to improve the understanding of the effects of snow cover properties on the flow dynamics of snow avalanches. This demands an initial identification of relevant snow cover parameters by reconstructing the snow cover with models for well documented avalanches at the Vallée de la Sionne field site. Consequently field measurements are presented which allow to quantify the temperature distribution at the surface and inside an avalanche and identify the main sources of thermal energy. The granulation behavior of snow in the identified temperature range is investigated in granulation experiments in a controlled environment of a concrete tumbler. The three main objectives of this $\mathrm{PhD}$ study can be outlined as follows:

1. Identification of the most relevant snow cover properties influencing avalanche regime and motion for measured real-scale avalanches

2. Measurement of the temperature distribution inside an avalanche and identification of sources of thermal energy in an order of magnitude estimation

3. Establishment of an initial link between the snow cover and avalanche dynamics by granulation experiments

These three objectives were treated in three peer-reviewed journal articles. In this thesis, each publication is presented in a separate Chapter: 
Chapter 2: Influence of snow cover properties on avalanche dynamics

Steinkogler W., Sovilla B., Lehning M. (2014) Influence of snow cover properties on avalanche dynamics. Cold Regions Science and Technology.

In this chapter, we discuss observed differences in flow dynamics and link them to simulated snow cover properties. We first summarize the data, model and methods. Flow dynamical and snow cover data are used to quantify the characteristics of the individual avalanches. Observed differences between the avalanches and the influence of snow cover parameters are discussed.

Chapter 3: Thermal energy in dry snow avalanches

Steinkogler W., Sovilla B., Lehning M. (Submitted) Thermal energy in dry snow avalanches. The Cryosphere.

In this chapter, we identify the distribution of temperature at the surface of a moving avalanche as well as in the deposition zone by manual profiles and the application of infrared radiation thermography. This data set also allows to quantify sources of thermal energy by partitioning the overall warming into contributions of friction and entrainment of warmer snow.

\section{Chapter 4: Granulation of snow}

Steinkogler W., Gaume, J., Löwe, H., Sovilla B., Lehning M. (Submitted) Granulation of snow: from tumbler experiments to discrete element simulations. Journal of Geophysical Research Earth Surface.

In this chapter, we describe relevant snow cover parameters and thresholds that control the size and properties of granules for different types of snow that formed in a rotating tumbler by ways of laboratory experiments and numerical simulations. We then compare those results to measurements in the deposition of real-scale avalanches and suggest a diagram of the granulation regimes. We discuss our results in view of the commonly used terminology of granulation processes. Applications of the results and future avenues of research are discussed.

The individual methods are presented in each chapter or publication respectively. An overall summary and the conclusions are presented in Chapter 5. The limitations of this study and an outlook on potential future research are presented in Chapter 6. 



\section{Influence of snow cover properties on avalanche dynamics}

Steinkogler W., Sovilla B., Lehning M. (2014) Influence of snow cover properties on avalanche dynamics. Cold Regions Science and Technology.

\subsection{Introduction}

While it is already challenging to assess release location and time window for a snow avalanche threatening, for example, a road, it is often impossible to predict the run-out distance. However, to decide on road closures, it is essential for local avalanche safety services to know whether the avalanche will reach the road or stop above. Such decisions are often very difficult as they demand the ability to correctly interpret weather forecasts, link the evolution of snowpack stability and its structure and finally evaluate the influence of the snow cover on avalanche dynamics and thus run-out distances [Blattenberger and Fowles, 1995]. Literature on the direct influence of snow characteristics on avalanche dynamics are sparse and mostly describe the link between new snow amounts and run-out for extreme avalanches [Eckert et al., 2010; Naaim and Durand, 2012].

Schweizer et al. [2009] analyzed a dataset of 54 avalanches for an avalanche path above Davos, Switzerland. They found that the run-out distances of avalanches are related to the difference in snow depth over the last three days. Furthermore, their investigations suggest that weak basal layers in the avalanche track were favorable for strong snow entrainment, i.e. the process of adding snow along the avalanche track by erosion, and might have contributed to the larger run-out distances.

The importance of snow cover entrainment on the run-out distance was clearly demonstrated by Sovilla et al. [2006]. They showed that avalanches following identical paths, having similar release volumes and eroding snow with identical characteristics (the avalanches released within a few hours) had different run-out due to different entrainment depths. However, they could not asses what the influence on run-out would be if the snow cover conditions had changed between the avalanches. 
Until now most avalanche dynamics models, e.g. RAMMS [Christen et al., 2010], are calibrated for extreme avalanches and often produce unsatisfactory results for run-out distances of smalland mid-sized avalanches (defined as avalanches with a total mass of approximately $10^{5} \mathrm{~kg}$ to $10^{7} \mathrm{~kg}$ or size 2 to 4 according to Canadian Avalanche Association [2007]), which may still produce problems for infrastructure. New approaches and model modifications seem to be very promising for the calculation of small-sized avalanches and in defining different flow regimes [Bartelt et al., 2011; Gauer et al., 2007]. A better understanding of the influence of snow cover properties on avalanche dynamical parameters would be of great interest for further improvements of these models. Since information on the snow cover properties in the release zone and along the track are often not possible to acquire due to safety concerns and do not exist for many historic avalanches, snow cover models can be used to reproduce this data. Recent advances in modeling the snow cover in mountainous terrain allow for the first time to accurately reconstruct and investigate the snow properties at the time of avalanche release. In several studies the three-dimensional atmospheric and surface process model Alpine3D [Lehning et al., 2006] was successfully applied to model the snow cover distribution on the catchment scale [Bavay et al., 2009; Mott et al., 2010].

In this paper, we discuss observed differences in flow dynamics and link them to simulated snow cover properties. In section 4.2 we first summarize the data, models and methods. Flow dynamical (section 2.2.1) and snow cover (section 2.2.2) data are used to quantify the characteristics of the individual avalanches in section 2.3. Observed differences between the avalanches and the influence of snow cover parameters are discussed in section 2.4. We conclude and give a general outlook on, as the authors believe, necessary future research in section 2.5.

\subsection{Methods and data}

Avalanches with similar release zone and release mass which followed the same topography but showed different flow dynamics were selected from the database of the Vallée de la Sionne (VDLS) field site (Fig. 2.1) located in the Western Swiss Alps. Selecting only avalanches that fulfill these criteria allow the neglect of topography effects on the flow dynamical behavior of individual avalanches. All selected avalanches (Fig. 2.1) in our dataset released from the Crêta Besse 1 (CB1) release zone, followed the main gully and the main run-out zone of the VDLS field site. The avalanches we analyzed in this work are \#5274 (05 February 2003), \#509 (07 February 2003), \#628 (19 January 2004), \#816 (06 March 2006) and \#917 (26 March 2008). The numbering of the avalanches is in accordance to the VDLS data base to allow easier comparison with previous publications.

\subsubsection{Flow dynamics}

A common method of characterizing avalanche flow dynamics is the comparison of run-out distances. Yet, in the case of VDLS large avalanches are usually deflected by the counter slope 


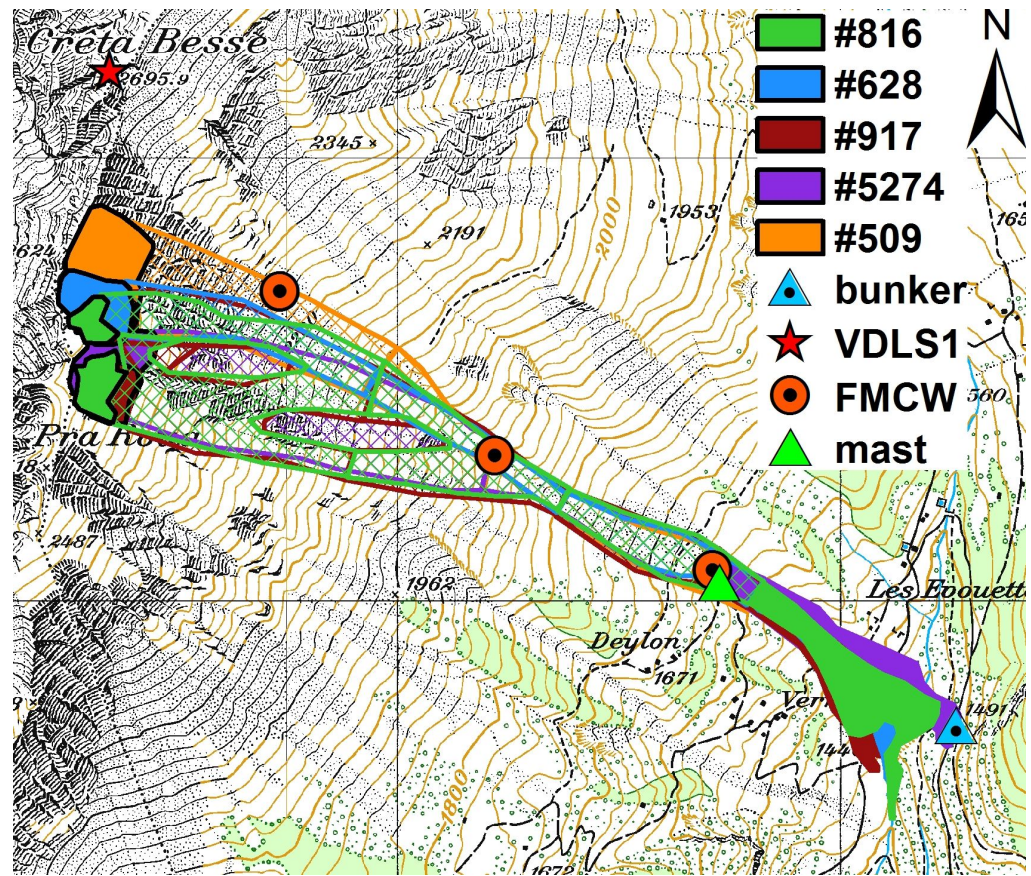

Figure 2.1: Overview of Vallée de la Sionne (VDLS) field site and all investigated avalanches. All avalanches released from Crêta Besse 1 (filled areas with black outlines), followed the main gully and entrainment area (hatched areas) and stopped at the bottom of the slope (filled area). Avalanches are color-coded according to \#816=green, \#628=blue, \#509=orange, \#917=red and \#5274=violet. Furthermore the positions of the FMCW radars (red circles), the VDLS 1 automatic weather station (red star) on the ridge, the measurement mast (green triangle) and the observation bunker (blue triangle) are marked. The underlying grid has a size of $1 \mathrm{xl} \mathrm{km}$.

(Fig. 2.1) and the deposits of previous avalanches reaching the creek of the 'La Sionne' river can significantly change the topography for subsequent flows. We used the run-out information as a rough size-criterion and ranked the individual avalanches depending whether debris was deposited at the observation bunker (blue triangle in Fig. 2.1) or it only was hit by the powder cloud. Following this criteria we introduced a variable named ranked size (see Table 2.1) where \#5274 was the largest avalanche (size 5) and \#917 was the smallest (size 1). Note that the introduced size criterion only ranks the selected avalanches investigated in this study and the value does not correspond to any quantitative scale, e.g. as had been suggested by the Canadian Avalanche Association [2007]. Additional measurements, i.e. front velocities and FMCW radar data, were consequently used to quantify the flow dynamical differences between the avalanches in more detail.

Stereoscopical videos (Fig. 2.3a-d) allowed calculation of front velocities of the investigated avalanches [Vallet et al., 2004]. Front lines were measured with an accuracy of $\pm 10 \mathrm{~m}$ in the upper part of the avalanche and $+/-5 \mathrm{~m}$ in the lower part. A frame rate of $5 \mathrm{~s}$ allowed calculation of average front velocity between the measurement points (Fig. 2.4). Pictures were additionally used to observe the formation of deposition structures as soon as the avalanches 

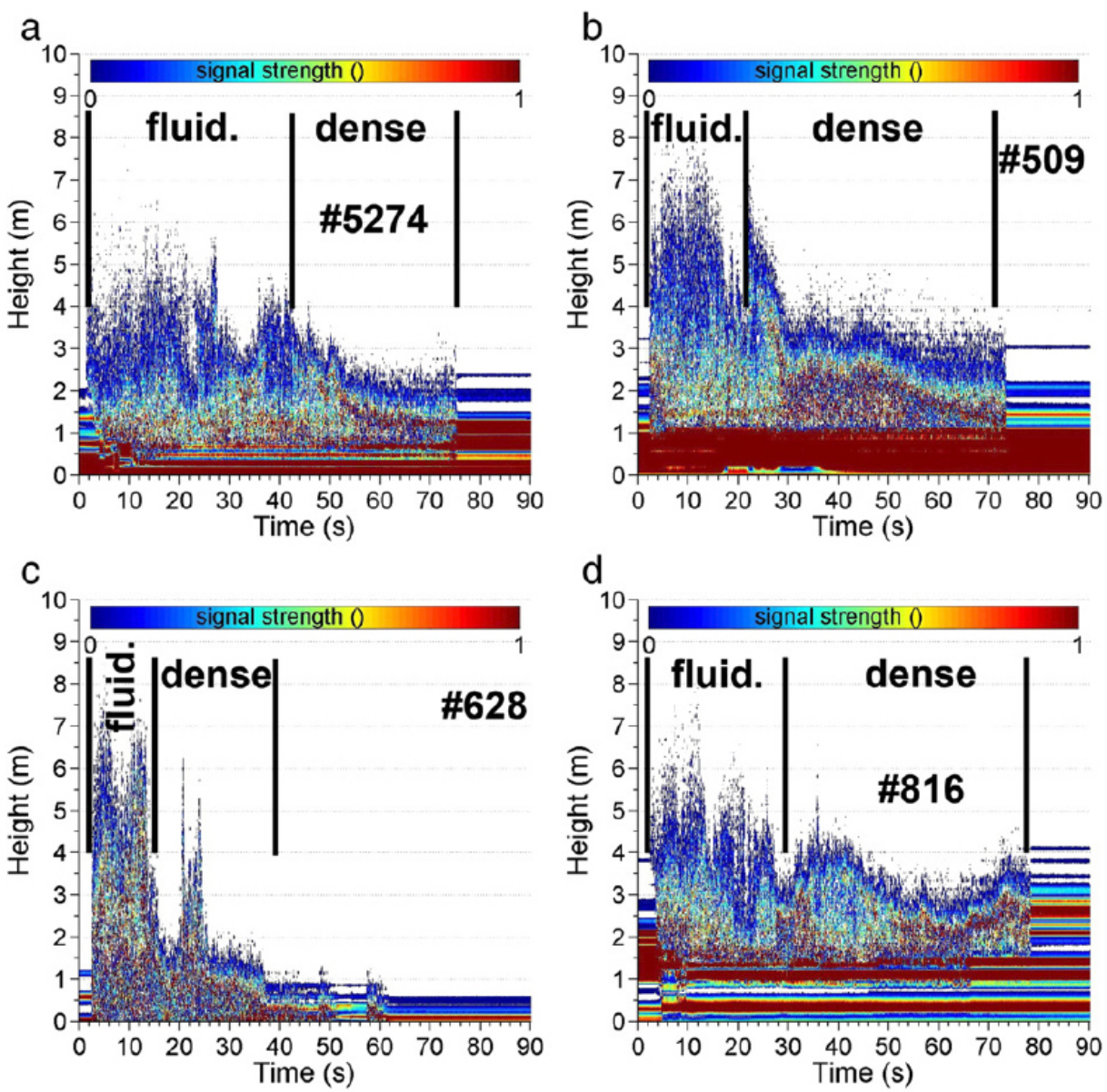

Figure 2.2: FMCW radar at location B (1896 m. a. s. l.) for avalanches (a) \#5274, (b) \#509, (c) \#628 and (d) \#816. Scaled to maximum signal strength of respective avalanche. Fluidized front and dense flow layer are indicated with black lines. No FMCW radar data are available for avalanche \#917.

stopped (Fig. 2.3e-h) since granular structures and size distributions in the deposition zone are often interpreted as indirect indicators for the internal flow dynamical characteristics of an avalanche [Bartelt and McArdell, 2009; Issler et al., 2008].

In order to identify internal flow structures and flow regimes we used frequency-modulated, continuous wave (FMCW) radars buried in the ground along the avalanche path, which looked upwards in a slope-normal orientation (red circles in Fig. 2.1). The signal strength, scaled to the respective maximum signal of each avalanche, is interpreted in a qualitative way. Although increased signal intensity can be associated with larger granules, moister or denser snow, the layers near the ground can influence the reflected signal from the flowing avalanche above [Gubler and Hiller, 1984]. The duration and development of the flow regimes of the individual avalanche can be compared through the flow depth (y-direction) and in time (all plots are cut to a measuring time window of $90 \mathrm{~s}$ ). 
a
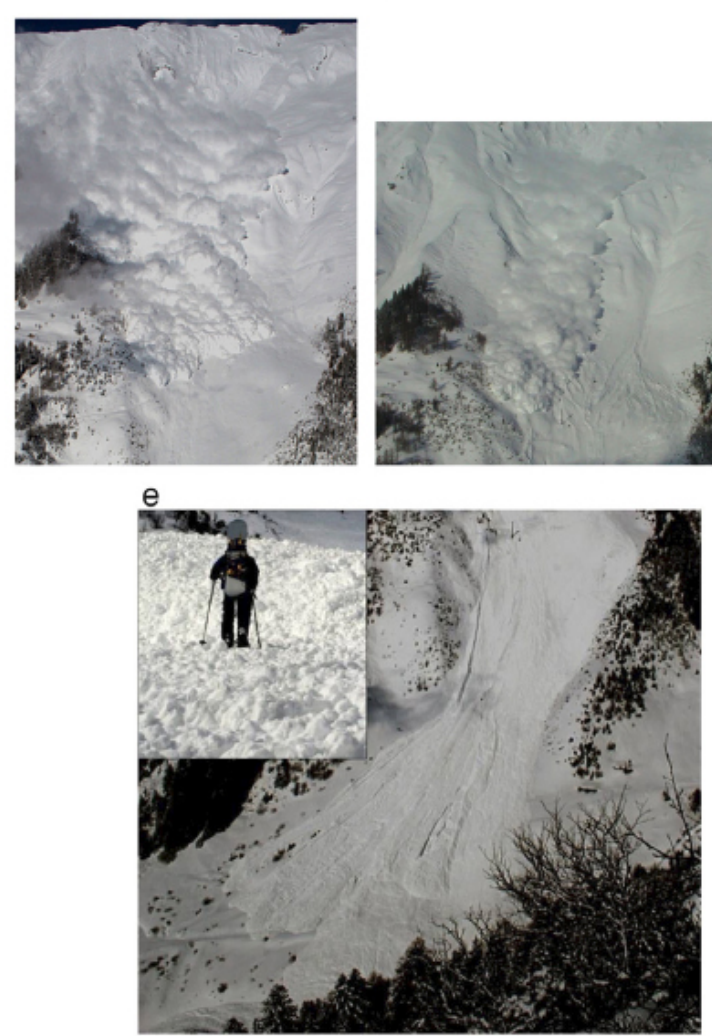

g

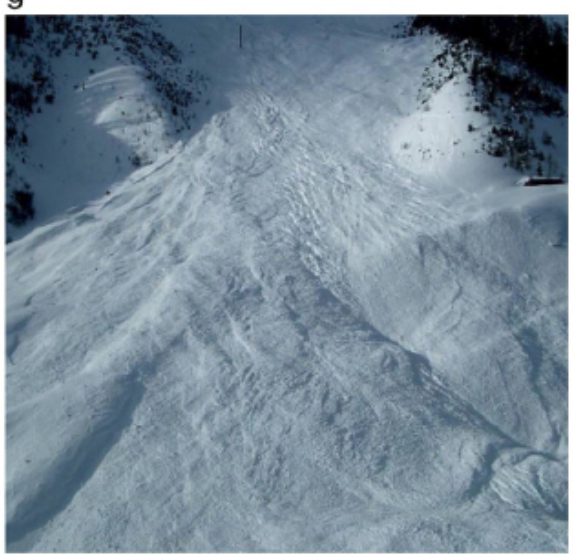

c

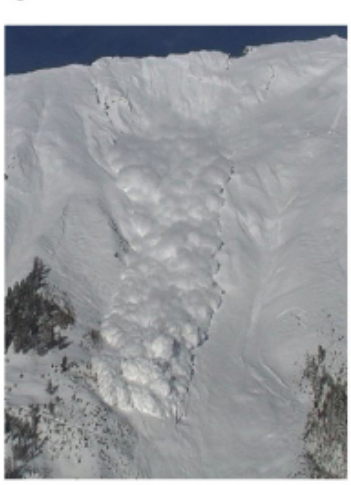

d
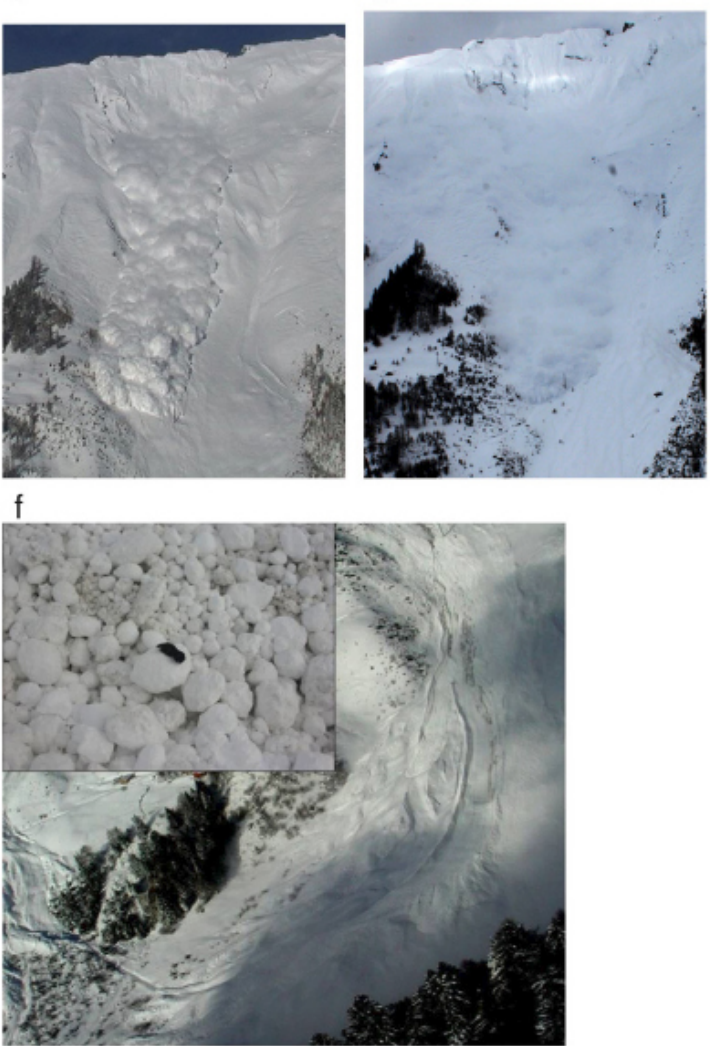

$\mathrm{h}$

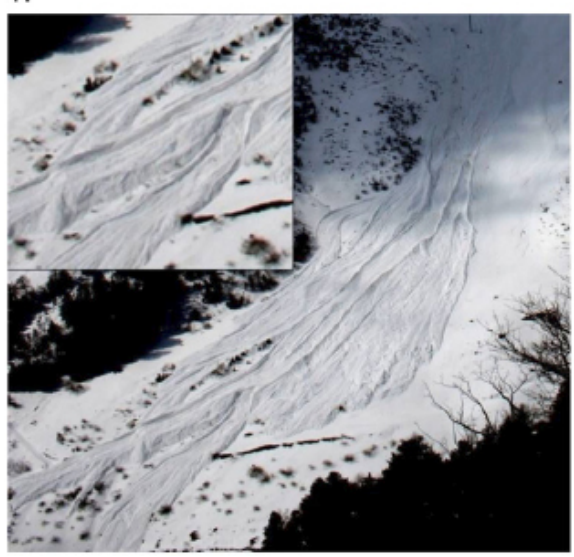

Figure 2.3: Powder clouds of avalanches (a) \#816, (b) \#628, (c) \#509 and (d) \#917 as they reach the measurement mast (same position as FMCW-C). Deposition area of avalanches (e) \#816, (f) \#628, (g) \#509 and (h) \#917 including a closeup view of the deposited granules.

A basic flow regime classification (see Gauer et al. [2008] for more details on flow regimes) is shown in Figure 2.2. The fluidized avalanche front (e.g. Fig. 2.2b, avalanche \#509, 5-20 s) exhibits a frayed signal (in y-direction) whereas dense flow parts (e.g. Fig. 2.2b, avalanche \#509, 30-70 s) have a (relatively) stronger signal and a sharper transition in signal strength. No flow regime classification could be performed for the upper part of the track since the investigated 


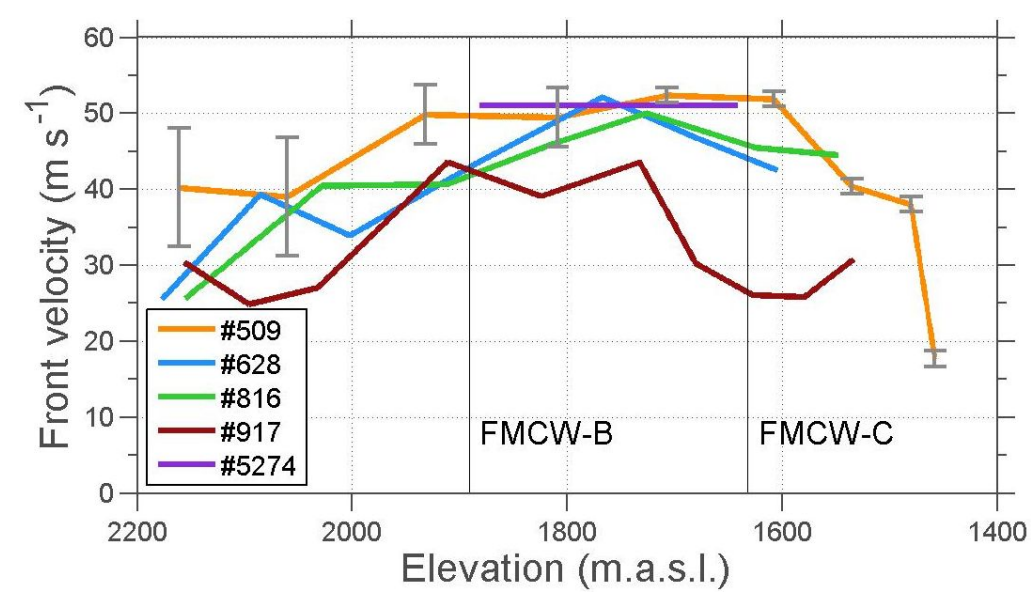

Figure 2.4: Front velocities of all investigated avalanches. The elevation of the FMCW radars along the avalanche path are indicated as FMCW-B (1896 m. a.s. l.) and FMCW-C (1642 m. a. s. l.). Error bars based on measurement accuracy are given for avalanche \#509.

avalanches released from $\mathrm{CB} 1$ and did not completely pass FMCW-A. Also for FMCW-C the signal did not always provide reliable data due to a moist layer at the soil-snow interface or technical issues. Therefore, FMCW-B provided most useful data and was mainly used in this study. Supplementary data such as new snow heights and images aided the interpretation of FMCW signals.

\subsubsection{Snow cover}

To investigate the released and entrained snow layers and their properties in more detail, information on the snow cover was extracted from simulations conducted with the onedimensional numerical snow cover model SNOWPACK [Lehning and Fierz, 2008]. Since the nearest automatic weather station (VDLS2), that would provide all required data to run SNOWPACK is $2 \mathrm{~km}$ away, the necessary meteorological input data, such as air temperature and precipitation, were spatially interpolated with the three-dimensional surface process model Alpine3D [Lehning et al., 2006] which allows investigation of the spatial distribution and seasonal evolution of snow cover properties for the whole VDLS catchment (Fig. 2.5). Both Alpine3D and SNOWPACK were already successfully applied for studies on spatial snow distribution [Lehning et al., 2008; Mott et al., 2010, 2011], avalanche forecasting [Bellaire et al., 2011; Hirashima et al., 2008], climate change [Bavay et al., 2009; Rasmus et al., 2004], hydrology [Bavay et al., 2013; Magnusson et al., 2011] and have shown to successfully model snow cover parameters [Lehning et al., 2002b]. In this study, four automatic weather stations, located at or close to the VDLS field site and installed at elevations from 482 to $2696 \mathrm{~m}$. a. s. l., provided data for Alpine3D.

SNOWPACK was then run at four different positions along the avalanche path (Fig. 2.5f). RELEASE is the location of an automatic weather station at the ridge of VDLS (VDLS1, $2691 \mathrm{~m}$. a. s. l.) (Fig. 2.1). Since VDLS1 is not equipped with all necessary sensors to run SNOWPACK directly, 

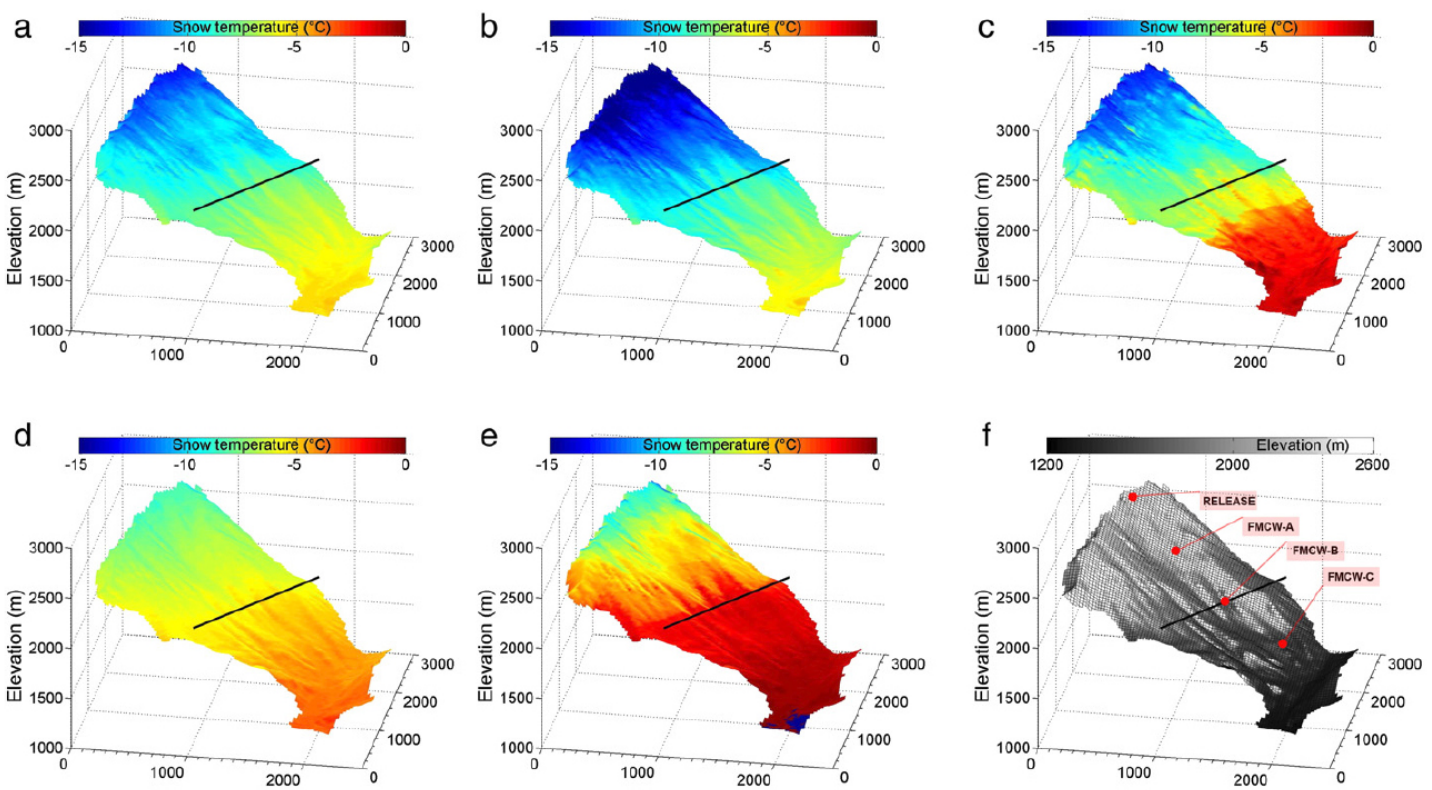

Figure 2.5: Modeled snow temperature $40 \mathrm{~cm}$ below snow surface for avalanches (a) \#5274, (b) \#509, (c) \#628, (d) \#816 and (e) \#917 at time of release. Black line indicates 1900 m. a. s. 1. and corresponds with elevation of FMCW-B. (f) shows digital elevation model with $25 \mathrm{~m}$ grid resolution and locations of SNOWPACK simulations (RELEASE, FMCW-A, FMCW-B and FMCW-C).

interpolated data from Alpine3D was used to supplement the data set. The model results at this point represent the release area of Crêta Besse 1 (CB1). FMCW-A (2246 m. a. s. 1.), FMCW-B (1896 m.a.s. l.) and FMCW-C (1642 m.a.s. l.) represent the locations of the buried FMCW radars along the avalanche path. The FMCW radar data presented in section 2.2.1 furthermore allowed assessing the amount of locally eroded snow $d_{e}$ and to detect if ground erosion occurred (Fig. 2.2). The combination of full SNOWPACK output with erosion depth $d_{e}$, acquired with FMCW radar data facilitated the investigation of snow cover properties of the released and entrained snow along the complete path. In cases where no FMCW data was available, the entrainment depth $d_{e}$ was estimated by using pictures, measured and modeled new snow heights. Release depths $d_{r}$ were calculated from airborne laser scans or photogrammetry. Previously occurring avalanches had to be taken into account since they might have significantly influenced the snow cover in the avalanche path in several ways. First, they can change the overall potentially erodible snow depth and second the erosion and deposition of snow along the track will affect the properties of subsequent snow layers (e.g. on bare ground it would be expected to warm more quickly). To accurately estimate the amount and properties of the entrained snow, Alpine3D was re-initialized with the corresponding, remaining snow height at the date of the latest avalanche that significantly influenced the snow cover. This has been necessary for avalanches \#628, \#509 and \#5274 were erosion by previous avalanches took place (see section 2.3 for further details on the individual avalanches).

Whether the new snow is deposited on bare ground or on the undisturbed snow cover is 
illustrated for two different snow cover scenarios for \#628 in Fig. 2.6. Most of the snow cover was eroded by natural avalanches occurring few days before \#628 was artificially released. The new snow was deposited on an icy surface in the avalanche track. The resulting snow cover consists of $0.9 \mathrm{~m}$ of precipitation particles and decomposed forms (lime green and dark green colors in left grain type column in Fig. 2.6) on top the icy layer at the bottom (light blue layer). If previous avalanches had not eroded the snow cover, the new snow would have been deposited on top an already existing snow cover of $0.7 \mathrm{~m}$ (right grain type column in Fig. 2.6). This would have changed the snow temperature profiles significantly (blue and black line in Fig. 2.6). Assuming the same entrainment depth of $0.9 \mathrm{~m}$ for both cases, the averaged snow temperature would have been $-4.9^{\circ} \mathrm{C}$ (average over solid black line) instead of $-3.7^{\circ} \mathrm{C}$ (average over blue line). Assuming an erosion of the entire snow cover would result in an averaged snow temperature of $-2.8^{\circ} \mathrm{C}$ (average over solid and dashed black line).

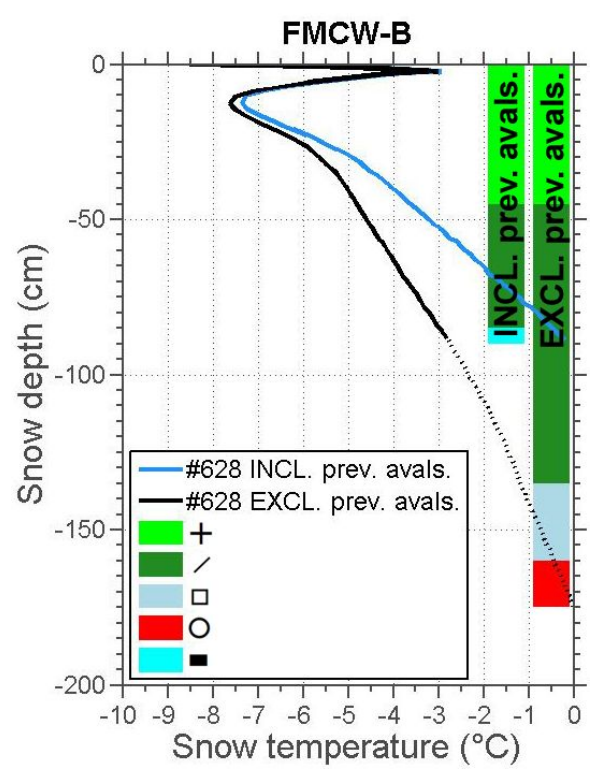

Figure 2.6: Effect of previous avalanches on snow cover properties for avalanche \#628 at the position of FMCW-B. Modeled snow height, grain type (color-coded according to Fierz et al. [2009]) and snow temperature curves including (black line and left grain type column) and excluding (blue line and right grain type column) previous avalanches. To directly compare the snow temperature profiles, the top, i.e. $0 \mathrm{~cm}$, corresponds to the snow surface.

The corresponding results on modeled snow height, grain type and erosion depth along the path for all avalanches are shown in Figure 2.7. Snow temperature profiles at positions along the track are illustrated in Figure 2.8. For easier interpretation and comparison between the individual avalanches, the model results were then averaged to obtain mean values of temperature (Fig. 2.9) and density (Fig. 2.10) over the varying entrainment depths at different locations and elevations (Table 2.1). 

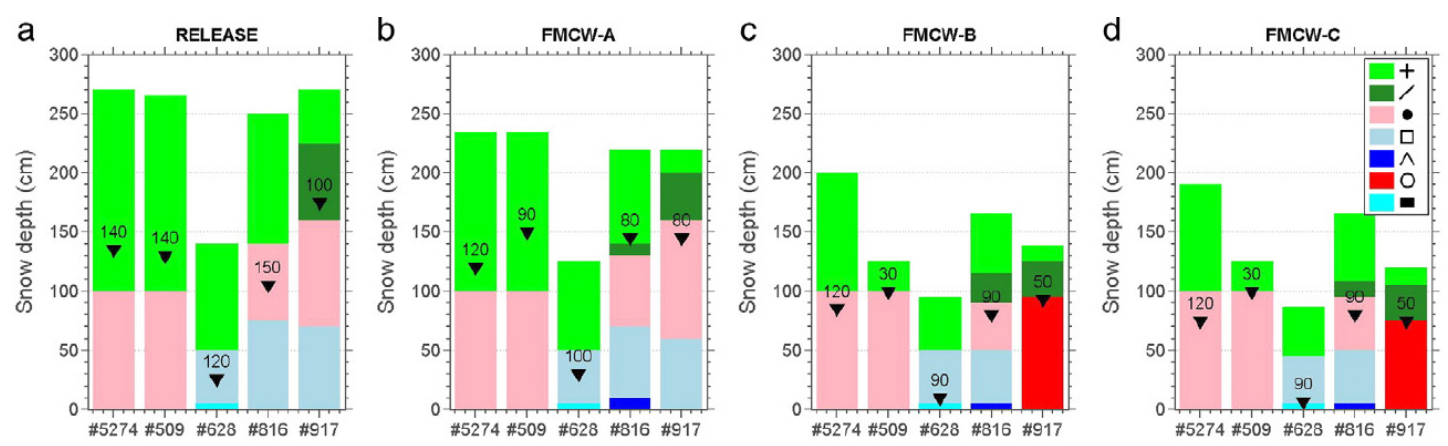

Figure 2.7: Modeled snow height and grain type (color-coded according to Fierz et al. [2009]) for four locations along the track ((a) release area, (b) FMCW-A, (c) FMCW-B and (d) FMCW-C). Previous avalanches were taken into account and Alpine3D was re-initialized with corresponding avalanche deposit. Black triangles indicate amount of released $d_{r}$ or eroded snow $d_{e}(\mathrm{~cm})$, determined with FMCW radar.

\subsubsection{Mass balance calculations}

Another common approach to illustrate differences between avalanches is to investigate and compare their respective mass balance, which consists of the initial release mass $M_{r}$, the entrained snow along the track $M_{e}$ and the terminal deposition mass $M_{d}$. To compare the mass balances of all investigated avalanches a 'growth index' $I_{g}$ as described by Sovilla et al. [2006] is calculated. This index defines the avalanche mass increase due to snow entrainment by calculating the ratio of deposited mass $M_{d}$ to released mass $M_{r}$ :

$$
I_{g}=\frac{M_{d}}{M_{r}}
$$

The release mass $M_{r}$ is calculated by acquiring the release area and the fracture depth (averaged over release area) from photogrammetric or airborne laser scans. In many cases it is not possible to conduct measurements in the release zone due to safety issues, therefore often typical snow density values were assumed to calculate the release mass. We use modeled values calculated with the snow cover model SNOWPACK as described in section 2.2.2. Note that, this may cause slightly different values of release mass and consequently growth index compared to previous publications using this data (see for example Sovilla et al. [2006]).

\subsection{Data synopsis of investigated avalanches}

The methods presented in section 2.2 were used to quantify the key characteristics of the individual avalanches, such as front velocities (Fig. 2.4). FMCW radar data (Fig. 2.2) was used to identify internal flow regimes in more detail and Fig. 2.5 allowed to classify them as 'cold', i.e. negative snow temperatures, or 'warm', i.e. close to $0^{\circ} \mathrm{C}$, avalanches. Information on necessary model re-initialization of SNOWPACK to account for previous avalanches is given in Table 1 and below. Deposition structures are briefly summarized and links to publications 
which contain further data on the respective avalanche are listed. More detailed data on snow temperatures and densities, mass balance and erosion features can also be found in Table 2.1.
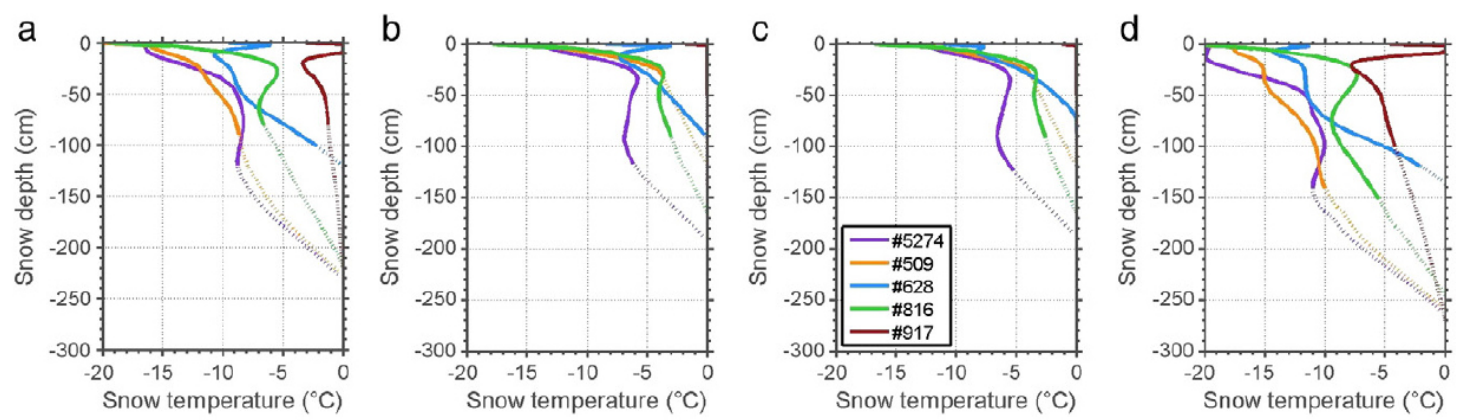

Figure 2.8: Modeled snow temperature profiles at different elevations along the path. (a) RELEASE, (b) FMCW-A, (c) FMCW-B, (d) FMCW-C for all investigated avalanches. Solid lines represent erosion depths. Temperatures of $\# 917$ are isothermal at $0^{\circ} \mathrm{C}$ at location FMCW-B and FMCW-C.

\section{Avalanche \#5274:}

On 5 February 2003 a mixed avalanche, indicating the presence of a dense core and a powder cloud, released naturally from the southern part of CB 1 and Pra Roua (PR) (Fig. 2.1). The avalanche entrained a large amount of snow (see $I_{g}$ in Table 2.1) and covered the bunker (Fig. 2.1, blue triangle). Therefore, \#5274 can be classified as the largest avalanche in our dataset (Table 2.1). FMCW radar data (Fig. 2.2d) showed a $25 \mathrm{~s}$ long fluidized front followed by a short and denser tail. Even though \#5274 released spontaneously the extent and volume could be well approximated based on the photogrammetric measurements that were performed two days later for avalanche \#509. No direct front velocity measurements or pictures during the avalanche are available. Yet, an average velocity of $51 \mathrm{~m} \mathrm{~s}^{-1}$ could be calculated for the region between FMCW-B and FMCW-C (Fig. 2.4) by relating the time the avalanche travelled between the two FMCW radar positions and the corresponding distance [Sovilla et al., 2006]. Previous to avalanche \#5274 an avalanche was artificially released on 31 January 2003 and eroded large parts of the snow cover along the track. Therefore, SNOWPACK was initialized with $1 \mathrm{~m}$ of compacted snow and re-started on 31 January 2003. Sub-surface snow temperatures along the path (Fig. 2.5) show negative values for the whole VDLS catchment. Consequently, \#5274 is classified as a 'cold' avalanche.

\section{Avalanche \#509:}

On 7 February 2003 09:59 a mixed avalanche was artificially released from the southern part of CB1. The avalanche attained a maximum front velocity of $52 \mathrm{~m} \mathrm{~s}^{-1}$ and maintained this velocity from 1950 to $1650 \mathrm{~m}$. a. s. l. (Fig. 2.4), reached the valley bottom and a small powder component reached the observation bunker (Fig. 2.1, blue triangle). FMWC radar data (Fig. 2.2c) showed a very well-developed and $15 \mathrm{~s}$ long fluidized front followed by a pronounced and $40 \mathrm{~s}$ long tail that shows much higher densities (more intense signal compared to front). 
Two days before \#509 an avalanche (\#5274) released naturally between CB1 and Pra Roua (to the orographic right of CB1). This avalanche mainly followed the same path as \#509, partly removed snow along the track below an elevation of FMCW-B (Fig. 2.1) and deposited densified avalanche debris. The snow cover in the upper part of the track was also partly influenced by the artificial release of avalanche \#504 on 31 January 2003. SNOWPACK was initialized with 1 $\mathrm{m}$ of consolidated avalanche snow on 31 January 2003 for the upper part (VDS1, FMCW-A) and on 5 February 2003 for the lower part (FMCW-B, FMCW-C). \#509 was classified as a 'cold' avalanche since snow temperatures were negative for the complete avalanche path (Fig. 2.5). The debris in the deposition area showed a wide, fan-shaped structure (Fig. 2.3g).

\section{Avalanche \#628:}

A mixed avalanche was artificially released from the southern part of CB1 on 19 January 2004 10:31. The avalanche attained a maximum front velocity of $52 \mathrm{~m} \mathrm{~s}^{-1}$ (Fig. 2.4) and reached the observation bunker in the run-out zone. Three natural avalanches (releasing on 12 January 2004 and 13 January 2004) significantly influenced the avalanche track by creating a very icy surface before avalanche \#628. Basal erosion by avalanche \#628 down to this icy layer is visible as darker areas in the avalanche track in Fig. 2.3f and in the FMCW radar plots (Fig. $2.2 \mathrm{~b}$ ). Due to this icy surface, \#628 entrained only the deposited new snow (Table 2.1). Even though a short but distinct fluidized front can be observed, the tail of the avalanche is not very pronounced (Fig. 2.2b). Strong levee formation created by the preceding avalanches could be observed before the release of \#628. The flowing part mainly followed these old levees and deposited well-developed granules of various sizes (Fig. 2.3f). The granules were more distinct than for avalanche \#816 or \#509. This might be attributed to the widespread ground erosion and thus entrainment of warmer snow below an elevation of $1650 \mathrm{~m}$ (FMCW-C in Fig. 2.1). The modification of the snow cover by previously occurring avalanches was taken into account by initializing SNOWPACK with a bottom ice layer of $0.02 \mathrm{~m}$ and re-starting the simulation at the time of the preceding avalanche. Figure 2.5 indicates that snow temperatures were negative for most parts of the track. Therefore, \#628 was classified as 'cold' avalanche.

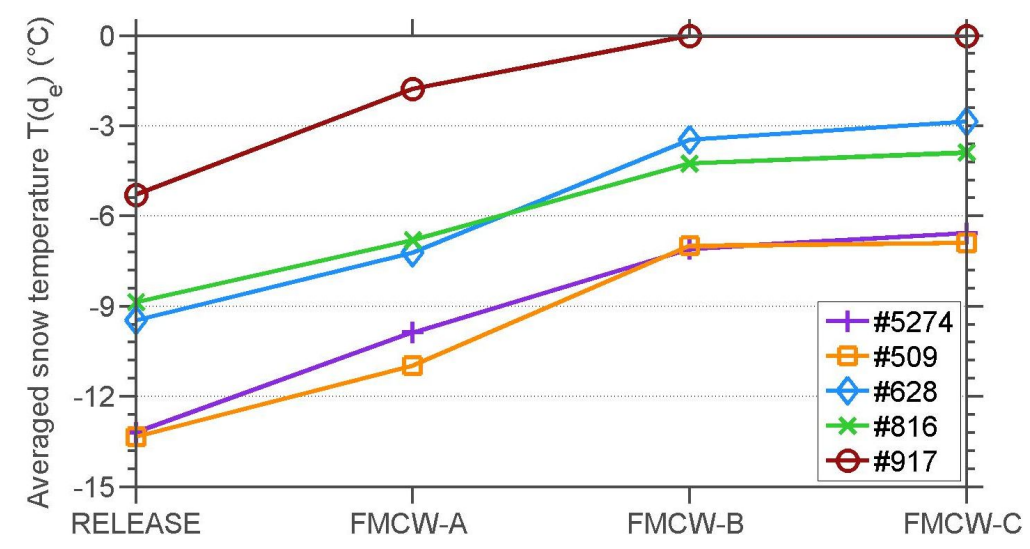

Figure 2.9: Modeled snow temperatures averaged over fracture depth $d_{r}$ or local entrainment depth $d_{e}$ for different elevations (RELEASE, FMCW-A, FMCW-B, FMCW-C). 
Table 2.1: Summary of investigated avalanches. Release zone: release area $A_{r}$, fracture depth $d_{r}$, release volume $V_{r}$, depth averaged snow density in release area $\rho_{r}$, release mass $M_{r}$ and snow temperature averaged over release depth $\overline{T s\left(d_{r}\right)}$. Entrainment zone: potential entrainment area $A_{e}$, depth averaged snow density averaged for the whole avalanche path $\rho_{e}$, averaged entrainment depth $d_{e}$ and calculated entrained mass $M_{e}$. Snow temperature averaged over local entrainment depth at corresponding FMCW position $\overline{T s\left(d_{e}\right)} @ F M C W_{A}$. Deposition zone: deposition mass $M_{d}$ and deposition snow density $\rho_{d}$. The growth index is defined as $I_{g}=\frac{M_{d}}{M_{r}}$. $A_{e-a b o v e B}$ and $M_{e-a b o v e B}$ only consider areas above FMCW-B. '-' indicates that no data was available or could not be analyzed. * indicates modeled values. ${ }^{a}$ indicates that no FMCW radar data was available and $d_{e}$ was assessed by using modeled and measured new snow heights and pictures. Calculated values were rounded.

\begin{tabular}{|c|c|c|c|c|c|}
\hline Nr. & \#5274 & \#816 & \#509 & \#628 & $\# 917$ \\
\hline Date of release & 05 February 2003 & 06 March 2006 & 07 February 2003 & 19 January 2004 & 26 March 2008 \\
\hline Time of release & $08: 40$ & 09:03 & $09: 59$ & $10: 31$ & $12: 45$ \\
\hline Release type & spontaneous & artificial & artificial & artificial & artificial \\
\hline Type & cold & cold & cold & cold & warm \\
\hline Influence by prev. avalanches & yes & partly & yes & yes & no \\
\hline Powder cloud to bunker & yes & yes & yes & yes & no \\
\hline Deposition at bunker & yes & yes & no & no & no \\
\hline Ranked size (based on run-out) & 5 & 4 & 3 & 2 & 1 \\
\hline \multicolumn{6}{|l|}{ Release zone } \\
\hline$A_{r}\left(\mathrm{~m}^{2}\right)$ & 26500 & 18800 & 42200 & 18000 & 21000 \\
\hline$d_{r}(\mathrm{~m})$ & 1.4 & 1.5 & 1.4 & 1.19 & 1 \\
\hline$V_{r}\left(\mathrm{~m}^{3}\right)$ & 37000 & 28200 & 59100 & 21500 & 20900 \\
\hline$\rho_{r}\left(\mathrm{kgm}^{-3}\right)$ & $130^{*}$ & $180^{*}$ & $160^{*}$ & $200^{*}$ & $190 *$ \\
\hline$M_{r}(\mathrm{~kg})$ & $4700 \times 10^{3}$ & $5100 \times 10^{3}$ & $9300 \times 10^{3}$ & $4400 \times 10^{3}$ & $4100 \times 10^{3}$ \\
\hline$\overline{T s\left(d_{r}\right)}\left({ }^{\circ} \mathrm{C}\right)$ & -13.2 & -8.9 & -13.3 & -9.5 & -5.3 \\
\hline \multicolumn{6}{|l|}{ Entrainment zone } \\
\hline$A_{e}\left(\mathrm{~m}^{2}\right)$ & 280400 & 292800 & 243100 & 146900 & 252700 \\
\hline$\rho_{e}\left(\mathrm{kgm}^{-3}\right)$ & $170^{*}$ & $190^{*}$ & $150^{*}$ & $220^{*}$ & $240^{*}$ \\
\hline$d_{e}(\mathrm{~m})$ & 0.75 & 0.41 & 0.38 & 0.28 & - \\
\hline$M_{e}(\mathrm{~kg})$ & $35800 \times 10^{3}$ & $23200 \times 10^{3}$ & $13600 \times 10^{3}$ & $9100 \times 10^{3}$ & - \\
\hline$d_{e} @ F M C W_{A}(\mathrm{~m})$ & $1.2^{a}$ & 0.8 & 0.9 & $1.0^{a}$ & $0.8^{a}$ \\
\hline$d_{e} @ F M C W_{B}(\mathrm{~m})$ & 1.2 & 0.9 & 0.3 & 0.9 & $0.5^{a}$ \\
\hline$d_{e} @ F M C W_{C}(\mathrm{~m})$ & $1.2^{a}$ & $0.9^{a}$ & $0.3^{a}$ & $0.9^{a}$ & $0.5^{a}$ \\
\hline$\overline{T s\left(d_{e}\right)} @ F M C W_{A}\left({ }^{\circ} \mathrm{C}\right)$ & -9.9 & -6.8 & -11.0 & -7.2 & -1.8 \\
\hline$\overline{T s\left(d_{e}\right)} @ F M C W_{B}\left({ }^{\circ} \mathrm{C}\right)$ & -7.1 & -4.3 & -7.0 & -3.5 & 0 \\
\hline$\overline{T s\left(d_{e}\right)} @ F M C W_{C}\left({ }^{\circ} \mathrm{C}\right)$ & -6.6 & -3.9 & -6.9 & -2.9 & 0 \\
\hline \multicolumn{6}{|l|}{ Deposition zone } \\
\hline$M_{d}(\mathrm{~kg})$ & $40500 \times 10^{3}$ & $28400 \times 10^{3}$ & $22900 \times 10^{3}$ & $13500 \times 10^{3}$ & - \\
\hline$\rho_{d}\left(\mathrm{kgm}^{-3}\right)$ & 400 & 400 & 400 & 400 & - \\
\hline$I_{g}$ & 8.60 & 5.52 & 2.45 & 3.09 & - \\
\hline \multicolumn{6}{|l|}{ Above FMCW-B zone } \\
\hline$M_{e-\text { aboveB }}(\mathrm{kg})$ & $21300 \times 10^{3}$ & $14300 \times 10^{3}$ & $7300 \times 10^{3}$ & $4300 \times 10^{3}$ & - \\
\hline$M_{e-a b o v e B}+M_{r}(\mathrm{~kg})$ & $26000 \times 10^{3}$ & $19400 \times 10^{3}$ & $16700 \times 10^{3}$ & $8600 \times 10^{3}$ & - \\
\hline Levee formation & no & no & no & no & yes \\
\hline Basal erosion-FMWC-A & no & no & no & no & - \\
\hline Basal erosion-FMCW-B & no & no & no & yes & - \\
\hline Basal erosion-FMCW-C & no & no & no & yes & yes \\
\hline Basal erosion-runout & no & no & no & yes & yes \\
\hline Basal erosion-general & no & partly & no & yes & - \\
\hline
\end{tabular}


Avalanche \#816:

On 6 March 2006 09:03 a mixed avalanche was artificially released (Fig. 2.1) from CB1 and parts from Pra Roua (PR). Parts of the released mass entered a secondary gully to the South. This mass was not taken into account in this study since the deposition did not contribute to the main deposition area. The avalanche reached a maximum front velocity of $50 \mathrm{~m} \mathrm{~s}^{-1}$ (Fig. 2.4). A pronounced fluidized front, sustaining for about $15 \mathrm{~s}$, and a distinct flowing part with high densities at the tail can be observed in the FMCW radar plot in Fig. 2.2a. Preceding avalanches (occurring on 3 March 2006 and 4 March 2006) partly influenced the snow cover in the upper part of the track to an elevation of $2450 \mathrm{~m}$. a. s. 1. . The lower part of the track did not show any significant influence by previous avalanches. Therefore, no modifications to the input had to be conducted. \#816 was classified as 'cold' avalanche since snow temperatures (Fig. 2.5) were negative for the whole VDLS catchment. Parts of the powder cloud and debris reached the observation bunker. The debris in the deposition area showed a wide and fanshaped structure. Granule size followed a log-normal distribution with a small median grain size [Bartelt and McArdell, 2009]. No distinct levee formation could be observed. Additional information on avalanche \#816 is published in Sovilla et al. [2010a] and Sovilla et al. [2008].

Avalanche \#917:

Mixed avalanche \#917 was artificially released on 26 March 2008 12:45 from CB 1 and parts of PR. The extent of the release area was similar to \#816 and parts of the released mass entered a secondary gully to the South. This mass was not taken into account in this study since the deposition did not contribute to the main deposition area. In the upper part of the path the avalanche quickly developed a distinct powder cloud (Fig. 2.3d) and accelerated to a maximum velocity of $44 \mathrm{~m} \mathrm{~s}^{-1}$ (Fig. 2.4). Yet, as soon as it approached the run-out zone, the powder cloud showed a rapid collapse and quickly disappeared before reaching the valley bottom. Shortly after the flowing part of the avalanche became visible and the avalanche formed levees and flow-fingers, which are typical for 'warmer' avalanches (Fig. 2.3h). The avalanche did not reach the counter slope. The snow cover along the avalanche path was not influenced by previous avalanches. Figure 2.5 indicates negative snow temperatures for the upper part. Below FMCW-B (black line in Fig. 2.5) the snow cover was isothermal at $0{ }^{\circ} \mathrm{C}$ (Fig. 2.9). \#917 was therefore classified as 'warm' avalanche. No reliable FMCW radar data is available since the signal could not penetrate the very warm and wet snow cover at lower elevations.

\subsection{Discussion}

Based on the individual characteristics of the investigated avalanches (section 2.3), differences between them are pointed out and the influence of mass (section 2.4.1) and effects of individual snow cover properties (section 2.4.2) on flow dynamical characteristics such as run-out, front velocity and flow regime are discussed. 


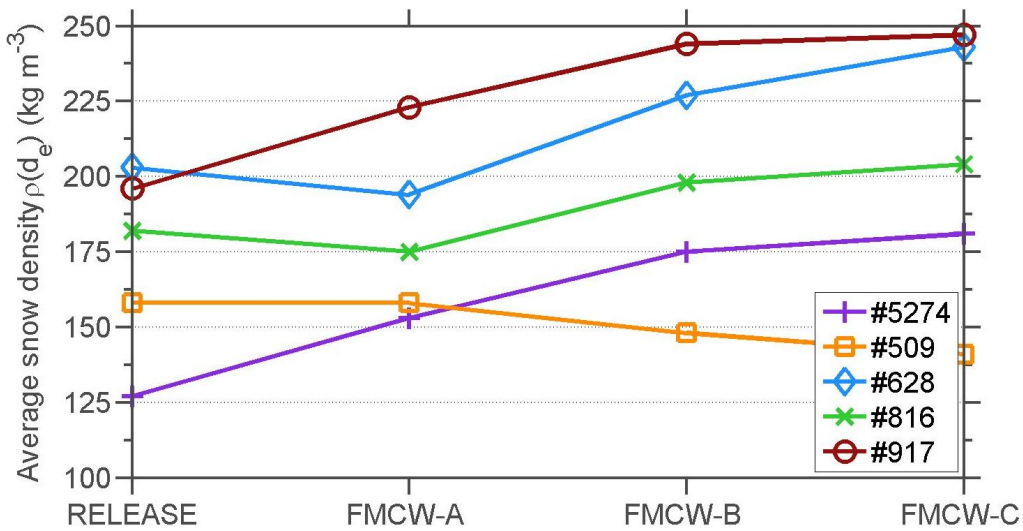

Figure 2.10: Modeled snow densities averaged over fracture depth $d_{r}$ or entrainment depth $d_{e}$ for different elevations (RELEASE, FMCW-A, FMCW-B, FMCW-C).

\subsubsection{Influence of mass on run-out and front velocity}

As described in section 2.2 only avalanches that released at similar release zones and with similar initial conditions were selected for this investigation. Figure $2.7 \mathrm{a}$ shows that all avalanches released primarily in new snow and release depths ranged from $1.0 \mathrm{~m}$ to $1.5 \mathrm{~m}$. The variations in release mass $M_{r}$, ranging from $4100 \times 10^{3} \mathrm{~kg}$ to $9300 \times 10^{3} \mathrm{~kg}$, were relatively small compared to the entrained mass $M_{e}$, ranging from $9100 \times 10^{3} \mathrm{~kg}$ to $35800 \times 10^{3} \mathrm{~kg}$.

A major reason for the observed variations in the mass balances of the individual avalanches, reflected in growth indices $I_{g}$ ranging from 2.45 to 8.6, is due to the snow available for entrainment. All avalanches mostly entrained new snow that accumulated over the days before the release. For example, as described in section 2.3, avalanche \#5274 released two days before \#509 and eroded most of the new snow in the lower part of the track. This resulted in approximately $1 \mathrm{~m}$ of compacted avalanche debris and \#509 could only entrain $0.3 \mathrm{~m}$ of freshly deposited snow (Fig. 2.2b and Fig. 2.7c,d). Increased entrainment due to weak basal layers, as indicated by Schweizer et al. [2009], could not be observed for the investigated avalanches.

Even though our data set is limited we calculated some basic correlations to illustrate the observed trends. Figure 2.11 shows released, entrained and deposited mass versus the size classification (see section 2.2.1), with larger numbers indicating larger run-out. The results reflect the findings of Sovilla et al. [2006] that adding mass by entrainment of snow along the track can significantly influence run-out distance. In addition to that, Fig. 2.11 shows that the release mass does not correlate to run-out. Comparing the total entrained mass $M_{e}$, the mass that was entrained until the elevation of FMCW-B $M_{e-a b o v e B}$ and the deposition mass $M_{d}$ furthermore shows that most mass is entrained in the upper part of the track.

Despite the differences in entrained mass among the investigated avalanches they all reach a maximal front velocity of $44 \mathrm{~m} \mathrm{~s}^{-1}$ to $52 \mathrm{~m} \mathrm{~s}^{-1}$ at an elevation of $1700 \mathrm{~m}$. a. s. l. between location of FMCW-B and FMCW-C (Fig. 2.4). No correlation between released or entrained mass and front velocity at FMCW-B could be observed (Fig. 2.12). These findings indicate that, at least 


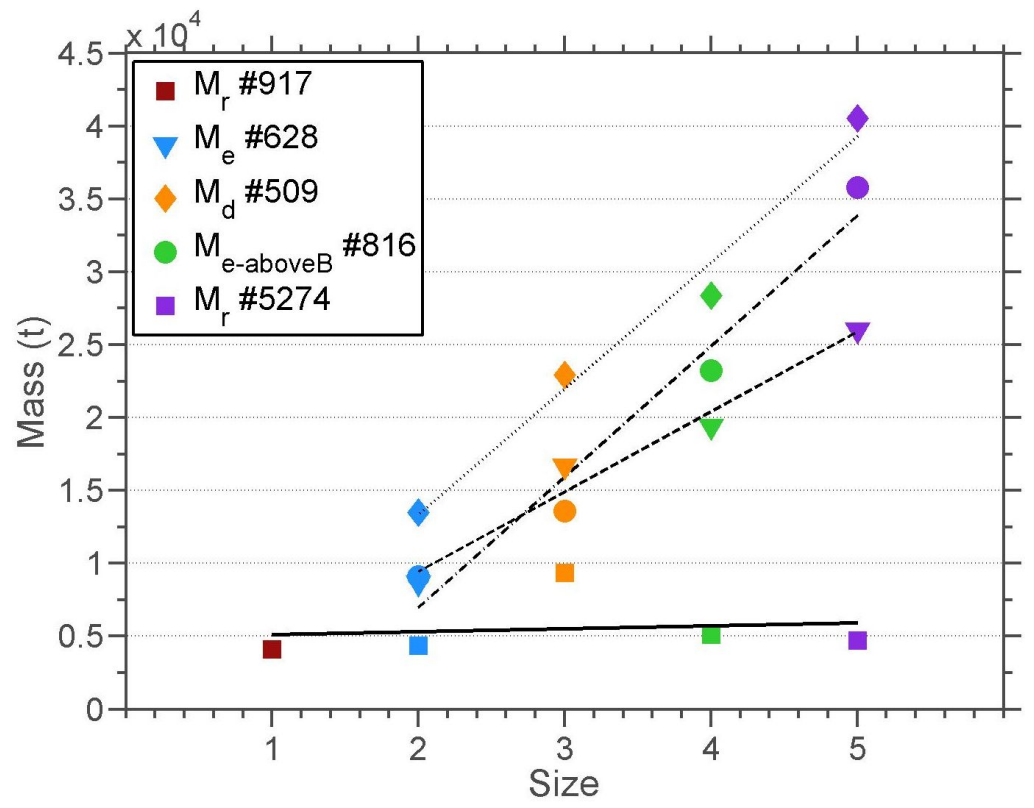

Figure 2.11: Correlation between avalanche size ( 5 is largest and 1 is smallest) and release mass $M_{r}$ (squares), total entrained mass $M_{e}$ (triangles), entrained mass until elevation of FMCW-B $M_{e-a b o v e B}$ (circles) and deposition mass $M_{d}$ (diamonds). Symbols are color-coded according to \#816=green, \#628=blue, \#509=orange, \#917=red and \#5274=violet.

for avalanches investigated in this study, mass inside an avalanche correlates to the run-out distance but not to front velocities.

Furthermore, FMCW radar data reveals that all avalanches developed a distinct fluidized front that can be observed in Fig. 2.2 from 5-30 s for \#816, 3-15 s for \#628, 3-30 s for \#509 and 3-30 s for \#5274. However, a distinct dense flow layer at the tail can only be observed for avalanche \#816 (40-75 s), \# 509 (30-75 s) and \#5274 (45-75 s) but not for \#628. Despite these differences in flow regimes all avalanches reached similar maximal front velocities (Fig. 2.4). These findings point out that front velocity measurements are representing the fluidized front of an avalanche but do not allow to draw conclusions on the dense-flow dynamics behind the front (Fig. 2.2).

\subsubsection{Effects of snow cover properties on front velocity}

Even though all avalanches showed similar maximal front velocities, a fluidized front and a distinct powder cloud in the upper part of the avalanche path, differences between the avalanches could be observed for the lower part.

Especially avalanche $\# 917$ showed a strong deceleration in front velocity at the start of the run-out zone at $1700 \mathrm{~m}$. a. s. l. (Fig. 2.4) and in the pictures of the avalanche and its powder cloud (Fig. 2.3d).

Since all investigated avalanches mostly released and entrained new snow (Fig. 2.7), their 


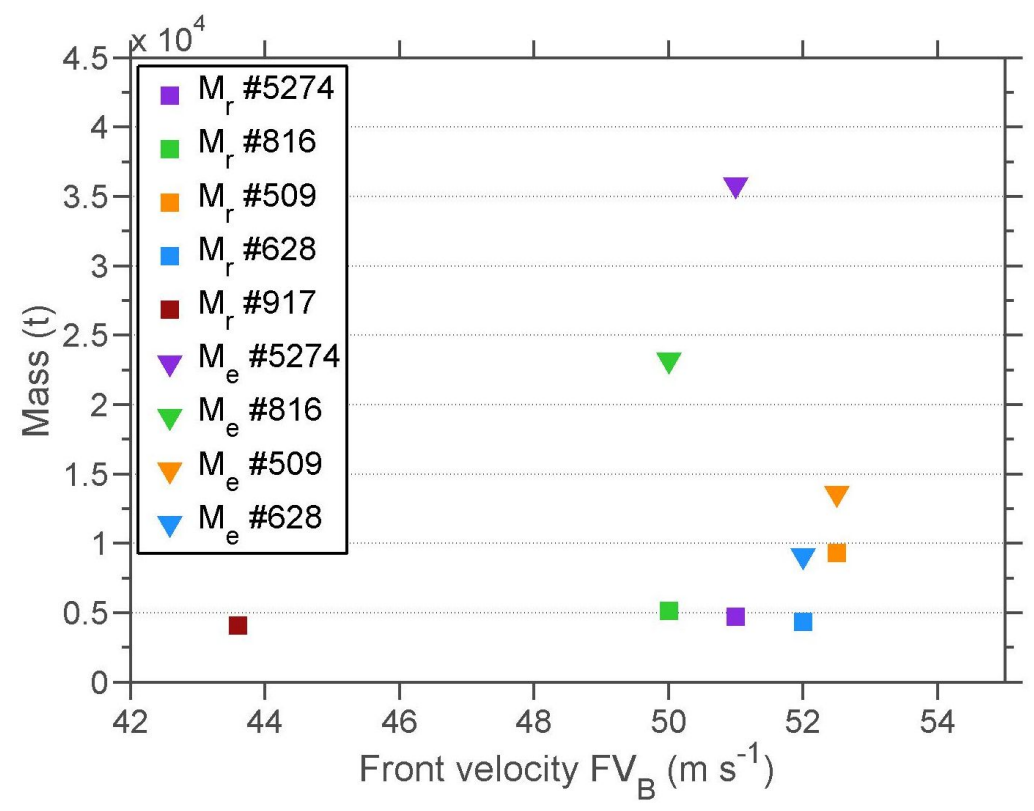

Figure 2.12: Correlation between front velocity at FMCW-B $F V_{B}$ and release mass $M_{r}$ (squares) and entrained mass $M_{e}$ (triangles). Symbols are color-coded according to \#816=green, \#628=blue, \#509=orange, \#917=red and \#5274=violet.

properties are initially depending on the atmospheric conditions during the snow fall. Yet, large variations in snow temperature at time of avalanche release (Fig. 2.5 and Fig. 2.9) prevailed along the track for the individual avalanches.

It becomes evident in Fig. 2.9 that all avalanches entrained relatively 'cold snow', i.e. below $-2{ }^{\circ} \mathrm{C}$, until half way along the path (marked by black line in Fig. 2.5f). In the lower part of the path (at and below FMCW-B) avalanches \#5274, \#816, \#628 and \#509 continued to entrain snow with negative temperatures between $-7^{\circ} \mathrm{C}$ and $-3^{\circ} \mathrm{C}$ (Fig. 2.9), whereas the simulations for avalanche \#917 show warmer temperatures, i.e. isothermal at $0^{\circ} \mathrm{C}$. The entrainment of warm snow for avalanche \#917 in the lower part (Fig. 2.5e) fits the rapid decrease in front velocities and the rapidly 'starving' powder cloud. Yet, the avalanche kept flowing with very small front velocity and formed 'flow-fingers' and levees, i.e. elongated walls in the debris that develop due to segregation and shear processes [Bartelt et al., 2012b] which are usually only observed for 'warm avalanches', before stopping completely. Avalanches \#816, \#628 and \#509 on the other hand reached and maintained a maximum front velocity of $45 \mathrm{~m} \mathrm{~s}^{-1}$ to $52 \mathrm{~m} \mathrm{~s}^{-1}$ and the powder cloud covered the whole valley bottom. In contrast to \#917 the deposited granules in the run-out zone of avalanches \#816 and \#509 show a fan-shaped, wide deposition field, no strong levee formation and a homogeneous granular size distribution [Bartelt and McArdell, 2009]. The visible levees for avalanche \#628 were created by previous avalanches.

Correlations between front velocities and snow temperatures indicate a general decreasing trend with a rapid transition (indicated with black dashed line in Fig. 2.13) in flow dynamics as snow with temperatures warmer than $-2^{\circ} \mathrm{C}$ is entrained. Snow temperature furthermore 
seems to have a strong impact on observed granule size distribution in the deposition area (Fig. 2.3e-f). This indicates that granulation, i.e. the generic name for particle size enlargement [Walker, 2007] and thus the process of forming granules and their inherent properties, is controlled by temperature. These findings are consistent with recent laboratory experiments by Steinkogler et al. [2013]. They showed that snow temperature appears to be a controlling factor on the granulation process of snow and their results indicate a transition in granulation around $-1^{\circ} \mathrm{C}$. At colder temperatures no distinct granules were formed. Also Gauer et al. [2008] concluded that in snow avalanches, the particle size is non-uniform and changes over time. Studies on mono- and bi-disperse material in granular flow show a strong relation between mobility, i.e. its ability to move faster and further, and the granular size distribution [Moro et al., 2010]. Therefore, the mobility of avalanches with similar initial conditions can strongly change depending on the internal granular distribution and their inherent properties, e.g. deformability and bonding potential. Our results indicate that granulation has the potential to link the effects of different snow properties with flow dynamics.

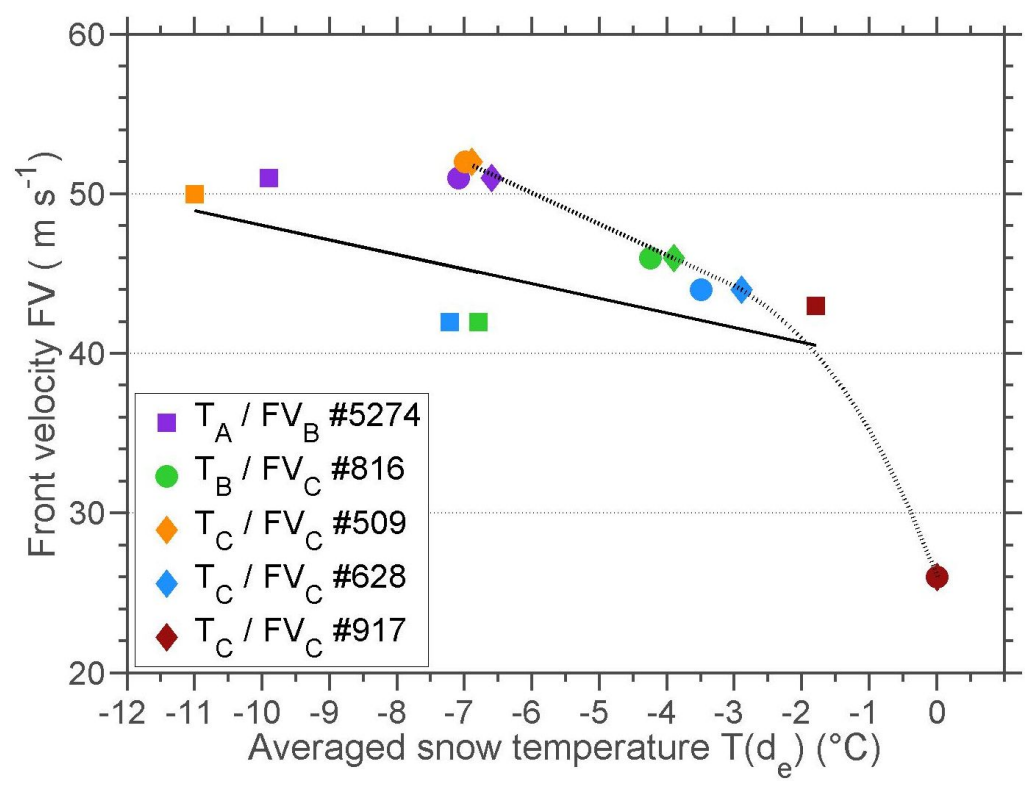

Figure 2.13: Correlation between front velocities at FMCW-B or FMCW-C with averaged snow temperatures for different elevations $T_{A}$ (squares), $T_{B}$ (circles) or $T_{C}$ (diamonds). Symbols are color-coded according to \#816=green, \#628=blue, \#509=orange, \#917=red and \#5274=violet.

Also rapid changes in powder cloud development can be attributed to entrainment of snow with a critical temperature close to $-2^{\circ} \mathrm{C}$ since in those cases the prerequisite of a cold and weakly cohesive snow cover [Louge et al., 2011] is not given anymore. More investigations by correlating powder snow heights, temperature of entrained snow and (if possible) temperature of the powder cloud are needed to quantitatively understand the involved processes and better define the critical snow temperature value. Despite our limited data set the described effects, namely decrease in front velocity, starving of powder cloud and levee formation are a first step in systematically investigating the influence of snow properties, in particular temperature, on 
flow dynamics.

No direct correlation between run-out or front velocity and snow densities (Fig. 2.10) could be observed. Since the avalanches mostly entrained new snow the observed snow density variations are strongly dependent on the snow temperature and warming caused the snow to decompose and settle fast, e.g \#917 in Fig. 2.7. Though entrainment of snow at higher densities could possibly also cause a degradation of the powder cloud we associate this to the warm snow temperature in these areas. Due to negative snow temperatures for most avalanches, liquid water (LWC) was only present for avalanche \#917 (4\% LWC for most of entrained snow below elevation of FMCW-B) and insignificantly for \#628 (isolated layers up to $3 \% \mathrm{LWC}$ at elevations below FMCW-C). Yet, occurring only at snow temperatures at $0^{\circ} \mathrm{C}$ or in rain-on-snow events, the presence of a substantial amount of liquid water could facilitate levee formation and a transition in flow dynamics towards wet or slush flows.

\subsection{Conclusion and outlook}

Five avalanches from the avalanche test site Vallée de la Sionne with similar initial mass, release area and topography were selected for this investigation. Our data on front velocities, run-out, flow regimes and powder clouds reveal that different avalanches can form for similar initial conditions and on the same avalanche path.

The three-dimensional surface process model Alpine3D was used to interpolate meteorological input data at the VDLS field site and provide data at four locations along the path for the one-dimensional snow cover model SNOWPACK. The combination of full SNOWPACK output at selected points and FMCW radar information allowed for detailed investigations of the properties, e.g. snow temperature, density or grain type, of the eroded snow layers. This facilitated the reconstruction of the snow cover properties for all avalanches and to identify relevant snow cover parameters that can have a significant influence on the flow dynamics. Our study shows that Alpine3D and SNOWPACK can be applied to reconstruct the snow cover and its properties for historical avalanche data sets. For detailed investigations and research purposes the models allow to calculate different scenarios, e.g. for 'warm' and 'cold' snow temperatures. Operating such models as now-casting and forecasting tools has the potential to support local avalanche safety services by providing information on the prevailing snow cover and imminent new snow events. Model results for different elevations show that single point measurements, i.e. single weather stations, are not sufficient to accurately represent the spatial distribution of the snow cover and its properties since they fail to reproduce altitudinal gradients and thus would not allow to explain the observed differences in flow dynamics.

The results confirm that released mass is not the main contribution to the deposition mass of an avalanche and entrainment of mass plays a crucial role. A clear correlation could be found between total mass and run-out, with larger mass resulting in larger run-out distance. Yet, the maximal front velocities did not show any correlation with mass or the development of internal flow regimes and are therefore only representative for the fluidized front of an 
avalanche. This is of crucial importance since many avalanche dynamics models show a significant dependency of run-out on the initial release volume [Fischer, 2013]. Yet, our findings question the assumption of mass-dependent (front) velocity calculation and validation [Christen et al., 2010] in such models.

Significantly different development of front velocities in the lower part of the path as well as the different deposition structures indicate the temperature of the entrained snow to be the controlling parameter. A snow temperature warmer than $-2^{\circ} \mathrm{C}$ could be identified as critical value where large changes in the flow dynamics take place. We therefore conclude that, in addition to total mass, the temperature of the entrained snow will determine avalanche dynamic behavior especially in the transition range towards melting. Even though our data set is too small for a rigorous quantification of the temperature influence and future work is required, our findings agree with Naaim and Durand [2012] which recently showed based on model calculations that the static friction coefficient increases with increasing snow temperature. No direct correlation between flow dynamical parameters and snow density could be observed in our investigations. Yet, we have shown that previous avalanches can significantly influence the amount of snow available for entrainment and its inherent properties.

Especially the influence of snow temperature on granulation and consequently on the flow dynamics of an avalanche seems to play a crucial role. Further studies on the granulometry of avalanche deposits for real scale avalanches as well as a more profound understanding of the granulation process by laboratory experiments [Steinkogler et al., 2013] should be made as a result of our investigation. These results will allow to better quantify to which extent granulation and thus the granule size distribution depends on the flow internal temperature. Implementation of the knowledge on the evolution of granular properties based on the properties of the entrained snow in existing avalanche dynamics models, e.g. RAMMS [Christen et al., 2010] could greatly improve their performance, especially for non-extreme avalanches. New model developments [Bartelt et al., 2012a; Vera et al., 2012] already allow to partly include snow cover properties (e.g. snow density, snow temperature).

\section{Acknowledgment}

Funding for this research has been provided through the Interreg project STRADA by the following partners: Amt für Wald Graubünden, Etat du Valais, ARPA Lombardia, ARPA Piemonte, Valle d'Aosta, Regione Lombardia. The authors would like to thank Mathias Bavay (WSL Institute for Snow and Avalanche Research SLF) for support with Alpine3D. We are grateful for the comments of Barbara Turnbull and one anonymous reviewer, that significantly helped to increase clarity and quality of this paper. 



\section{Thermal energy in dry snow avalanches}

Steinkogler W., Sovilla B., Lehning M. (Submitted) Thermal energy in dry snow avalanches. The Cryosphere.

\subsection{Introduction}

Avalanches can exhibit many different flow regimes [Gauer et al., 2008] depending on 1) the released and entrained amount of snow, 2) the properties of the snow and 3) the topography (slope, curvature) [Naaim et al., 2013]. Studies showed that avalanches can increase their mass due to entrainment by multiple factors [Bates et al., 2014; Sovilla et al., 2007] which in turn influences the run-out distance. Even though important, the amount of snow entrained is not the main controlling factor that determines the flow form of the avalanche [Bartelt et al., 2012a]. The flow regimes and in turn mobility are strongly influenced by the properties of the entrained snow [Steinkogler et al., 2014a]. Data on front velocities, run out, flow regimes and powder clouds revealed that different avalanches can form with similar release conditions and on the same avalanche path depending on the inherent snow cover properties.

Recently, it has been shown that snow temperature inside an avalanche can significantly change its flow dynamics [Naaim et al., 2013; Steinkogler et al., 2014a], mainly by changing the granular structure of the flow [Steinkogler et al., 2014b]. Laboratory studies on the granulation of snow showed a distinct dependency on snow temperatures with a fundamental change in snow structure at a threshold of $-1^{\circ} \mathrm{C}$. Therefore, significant changes in flow dynamics can be expected with relatively small changes in temperature around this threshold.

Measuring temperature inside a flowing avalanche or in its deposit with traditional methods has proven to be difficult due to technical constraints or because measurements can not be conducted due to safety reasons. In addition to manual snow profiles we therefore investigate the application potential of infrared radiation thermography (IRT) technologies. IRT is a non-contact, non-intrusive technique, which enables us to see surface temperature in a visible image. Meola and Carlomagno [2004] give an overview on existing work and describe the most relevant industrial and research applications of IRT. 
The emissivity of a surface is a function of many factors, including water content, chemical composition, structure and roughness [Snyder et al., 1998] as well as the viewing angle between observer and measurement object. Even though many technical challenges and shortcomings of IRT are known, possible applications on the field of snow science have recently been discussed [Shea and Jamieson, 2011]. Shea et al. [2012] and Schirmer and Jamieson [2014] applied IRT to measure spatial snow surface temperatures on snow pit walls. It was found that fast and large temperature changes resulting from surface energy balance processes must be expected [Schirmer and Jamieson, 2014]. These energy balance processes between air and snow are particularly important during windy conditions, clear skies and large temperature differences between air and snow. These findings indicate that measuring the snow surface temperature of avalanche deposits or erosion layers along the track must be carried out as fast as possible. IRT can therefore be seen as a useful qualitative tool for snow applications whose quantitative operation still needs further verification.

The aim of this study is to identify the spatial temperature distribution in an avalanche and to quantify potential sources of thermal energy in an order of magnitude estimation. This is achieved by field measurements and the application of an IRT camera. Furthermore, the acquired IRT videos allow to observe the avalanche phenomenon from a mainly qualitative but nevertheless unique point of view.

\subsection{Methods \& Data}

\subsubsection{The Flüelapass field site}

Multiple dry avalanches were artificially released during winters 2012-13 and 2013-14 at the Flüelapass field site above Davos (Switzerland). Here we will discuss three avalanches, \#1 (23 January 2013), \#2 (05 February 2013) and \#3 (31 January 2014), out of this data base (Fig. 3.1).

The avalanche path is a north-east facing slope covering 600 vertical meters. Deposits of larger avalanches typically reach a lake located at $2374 \mathrm{~m}$ a.s.l. at the bottom of the slope (Fig. 3.2). Observations and remote measurements can safely be conducted from the road at the pass. The slope angle ranges from $50^{\circ}$ in the rock face in the upper part to $20^{\circ}$ at the beginning of the run-out zone with an average of $30^{\circ}$ of the open slope around $2600 \mathrm{~m}$ a.s.l..

\subsubsection{Snow profiles}

To assess the properties of the released and entrained snow, manual snow profiles according to Fierz et al. [2009] were conducted in the release zone $\left(P_{\text {release }}\right)$, i.e. just below the rock face, along the track $\left(P_{\text {track }}\right)$, in the deposition zone $\left(P_{\text {depo }}\right)$ and in the undisturbed snow cover in the run out zone ( $\left.P_{\text {runout }}\right)$ (Fig. 3.2). The profile location of the initially released cornice is refereed to as $P_{\text {cornice }}$. In combination with release and erosion depths, the acquired snow profiles allowed to identify which layers were entrained into the avalanche. 

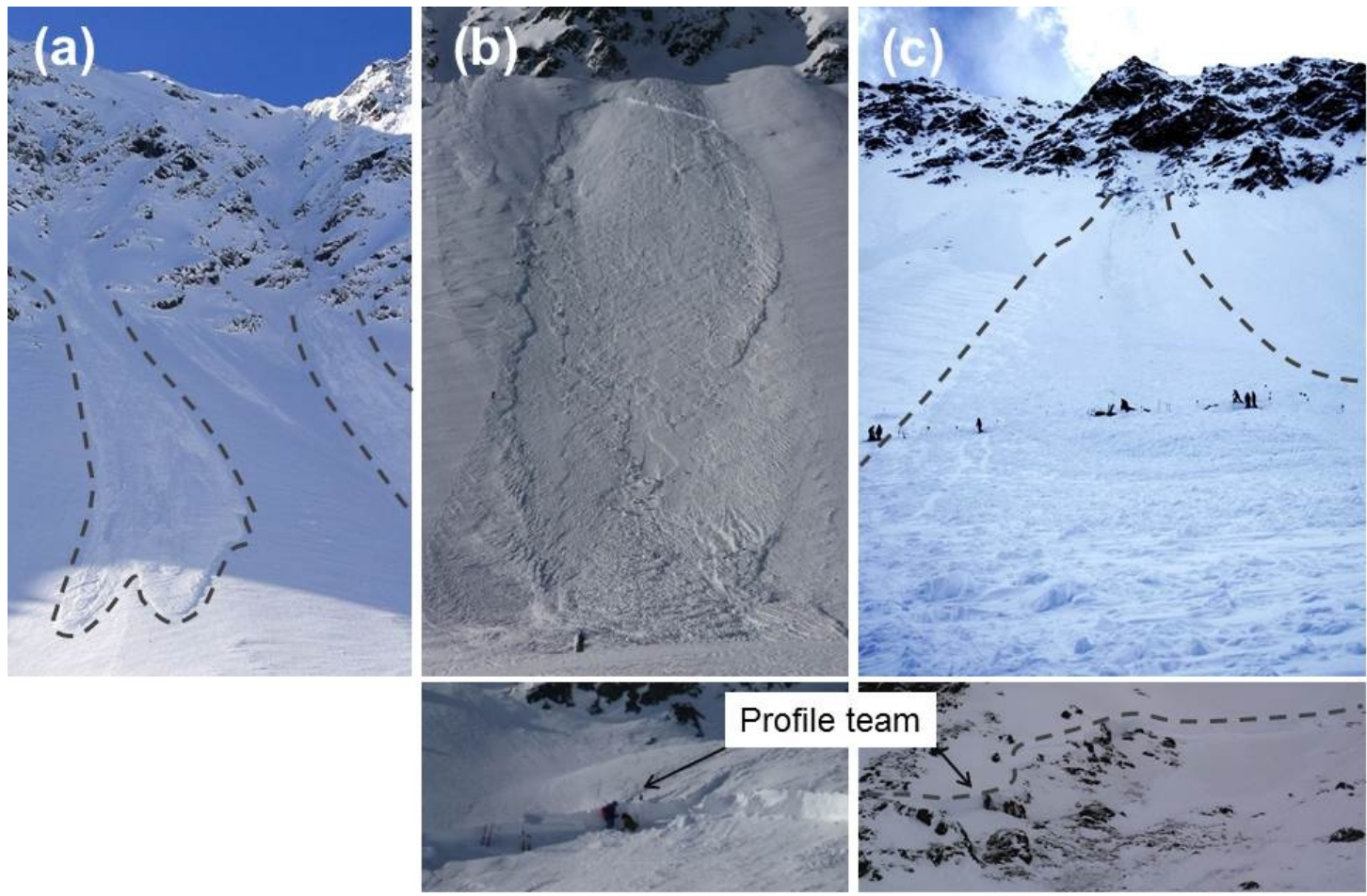

Figure 3.1: Avalanches at the Flüelapass field site released by artificial triggering of the cornices on the ridge. Avalanche \#1a and \#1b (a) were released on 23 January 2013, \#2 (b) on 05 February 2013 and \#3 (c) on 31 January 2014. Note the significant step-down and entrainment of deeper layers below the rock face for (b) avalanche \#2 and (c) avalanche \#3.

All profiles were conducted as fast as possible after the avalanche stopped. Yet, especially for the profiles in the release area and the track, it took around 30 minutes to reach the profile locations. The temperature measurements close to the surface must therefore be interpreted carefully due to a rapid adaptation to the ambient conditions.

\subsubsection{Lateral temperature profiles}

In addition to the regular snow profiles, trenches were dug in the deposition zone and modified avalanche probes were used to measure lateral temperature gradients. The modified temperature probes (BTS) are regular avalanche probes for which the tip was replaced by a thermistor. BTS probes are usually used for permafrost applications [Brenning et al., 2005; Lewkowicz and Ednie, 2004] to measure the temperature at the interface between soil and snow. Their application allowed to measure the temperature of snow layers without exposing them to the ambient air temperature. As for the thermometers used for regular snow profiles (Section 3.2.2) they measure the snow temperature with an accuracy of $\pm 0.1^{\circ} \mathrm{C}$. As for the regular snow profiles the upper most layers need to be interpreted carefully in this investigation due to an expected change in temperature over time. 
The lateral temperature measurements were conducted to the left and right side of snow profile $P_{d e p o}$, which was situated in the center of the deposition zone (Fig. 3.2).

\subsubsection{Infrared radiation thermography (IRT) camera}

The snow temperature measurements acquired from profiles where supplemented with an infrared radiation thermography (IRT) camera which allowed to record snow surface temperatures before, during and after the avalanche (Fig. 3.3 and 3.5). Time-lapse measurements after the avalanche stopped allowed to follow the temporal evolution of surface temperatures (Fig. 3.4) and videos of the moving avalanche provided a qualitative yet illustrative point of view (provided as supplementary material).

We used an InfraTec VarioCAM hr $384 \mathrm{sl}$ and a VarioCAM HD $980 \mathrm{~s}$ that both operate in the long wave infrared spectral range (LWIR) covering 7.5 to $14 \mu \mathrm{m}$. According to the manufacturer the cameras measure with an absolute accuracy of $\pm 1.5^{\circ} \mathrm{C}$ and a resolution of $0.05^{\circ} \mathrm{C}$. The measurements were either conducted with a $15 \mathrm{~mm}$ or a $30 \mathrm{~mm}$ lens.

Even though in our study we use the IRT measurements mainly in a qualitative way, a basic verification was conducted. The snow surface temperatures recorded with the IRT camera (solid lines in Fig. 3.4) were compared to manually measured snow surface temperatures (dots in Fig. 3.4) at the corresponding snow profile locations (Fig. 3.2). The snow surface temperatures of the release ( $\left.I R T_{\text {release }}\right)$ was compared to the corresponding layer in the snow profile in the undisturbed snow $\left(T_{-} P_{\text {release }}\right.$ at $\left.0 \mathrm{~min}\right)$ and measured surface temperatures with a digital thermometer ( $T_{-} P_{\text {release }}$ at $45 \mathrm{~min}$ ). The same was conducted for the surface temperature along the erosion layer in the avalanche path $\left(T_{-} P_{\text {track }}\right)$. Both measurements are in fairly good agreement with an absolute difference of about plus/minus $\pm 1^{\circ} C$.

\subsubsection{Terrestrial laser scan (TLS)}

A terrestrial laser scanner (Riegl LPM-321) was operated from the Flüelapass road (Fig. 3.2) to acquire digital surface models before and after the avalanche releases. The measurements facilitated to calculate release and erosion depths along the path. A complete set of terrestrial laser scans is available for avalanche \#3 only. For avalanche \#2 the scan before the avalanche is only available for the release zone (Fig. 3.2). No information from terrestrial laser scanning was available for avalanche \#1.

\subsection{Investigated avalanches}

This section summarizes the key characteristics and available data (Table 3.1) of the avalanches. All avalanches were released after a snow storm by triggering the cornices at the ridge at $2900 \mathrm{~m}$ a.s.l. with explosives. Therefore, most of the released snow was new snow. Yet, two of the avalanches, avalanche \#2 and \#3 (Fig. 3.1b and c), entrained significant amounts of 


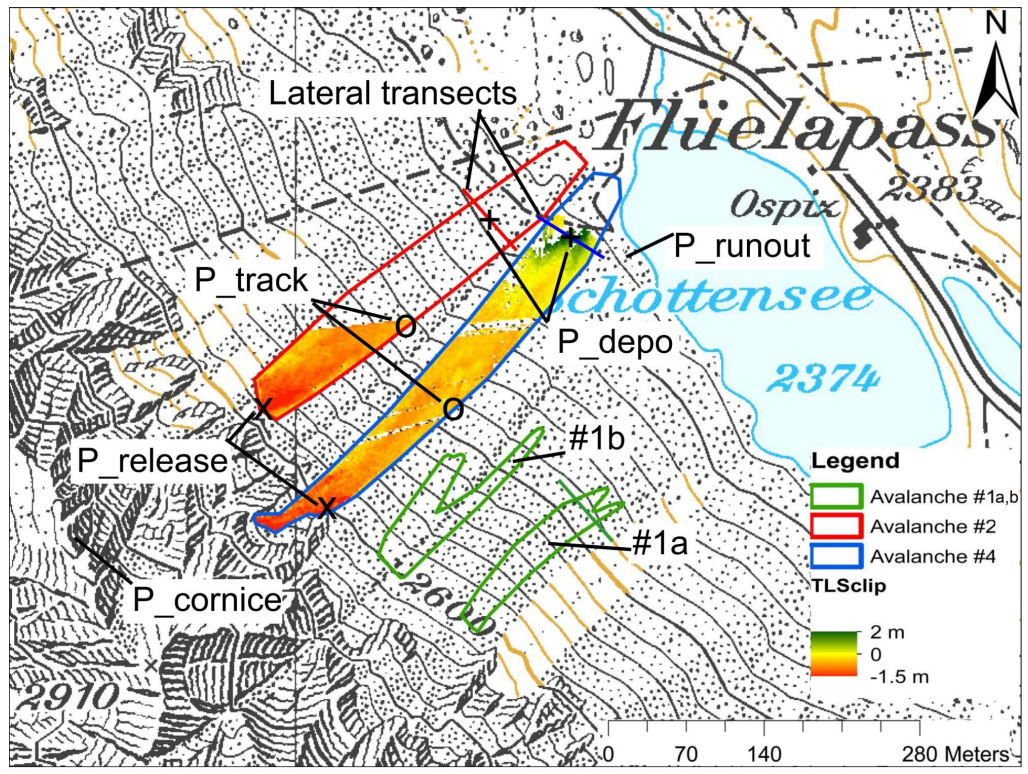

Figure 3.2: Flüelapass field site close to Davos (Switzerland). Outlines of avalanche \#1a and \#1b (green), \#2 (red) and \#3 (blue). The colorbar shows differences between terrestrial laser scans before and after the individual avalanches. $P_{\text {release }}$ and $P_{\text {track }}$ indicate locations of snow profile in the release and along the path, respectively. Red and blue lines indicate positions of lateral investigations and deposition snow profile $P_{\text {depo }}$.

snow from deeper layers due to a step-down, i.e. a secondary release to a deeper weak layer, below the rock face. Since the main mass contribution can be assumed to be defined by the secondary releases below the rock face and the entrainment along the path, we focused our investigations on these snow masses. Mass contributions by the cornices are usually relatively small compared to entrained snow on the open slope below. Furthermore, entrainment of snow in the gullies of the rock face is not assumed to contribute a significant amount since regularly occurring (small) avalanches and slides continuously erode the snow cover. In this study we use the word release to refer to profile locations at the secondary release below the rock face (Fig. 3.2).

\section{Avalanche \# 1a and \#1b (23 January 2013):}

In the days previous to the avalanche experiment $10 \mathrm{~cm}$ of new snow were recorded and snow drift accumulations formed due to strong southerly winds. The national avalanche bulletin reported a moderate avalanche danger (level 2) and identified the fresh snow drift accumulations as the main danger. During the experiment clear sky conditions prevailed and the automatic weather station (AWS) at the Flüelapass (FLU2) measured an air temperature of $-10^{\circ} \mathrm{C}$. Multiple charges were exploded on the ridge to the lookers-left (South) of the summit resulting in two independent small powder avalanches which followed the gullies (Fig. 3.1a and Fig. 3.3). Due to the relatively small release mass and no significant entrainment both avalanches, \#1a and \#1b, stopped half way down the open slope. Even though the avalanches 

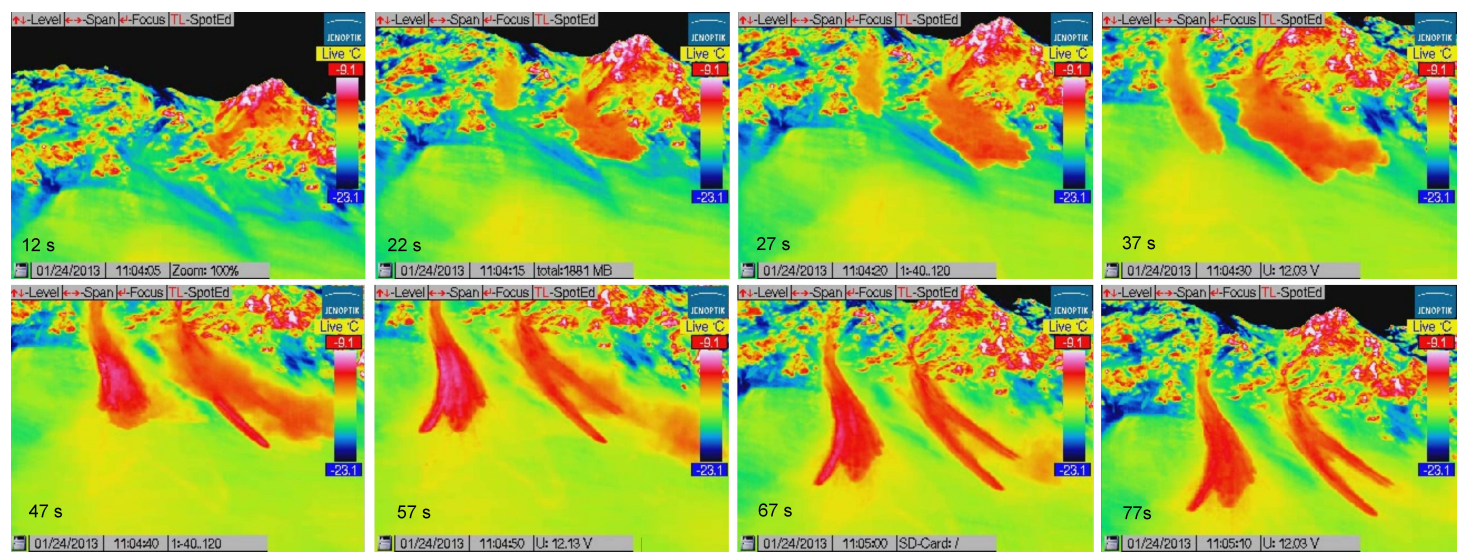

Figure 3.3: Screenshot of IRT camera videos for avalanche \#1a and \#1b. The first picture was taken $12 \mathrm{~s}$ after the avalanche released.

Table 3.1: Summary of measurements for the investigated avalanches. * indicate that erosion and deposition depths were too small.

\begin{tabular}{lccc}
\hline Avalanche & $\begin{array}{c}\text { \#1a } \\
\text { Date }\end{array}$ & $\begin{array}{c}\text { \#2 } \\
\text { 23 Jan. 2013 }\end{array}$ & $\begin{array}{c}\text { 05 Feb. 2013 } \\
\text { 31 Jan. 2014 }\end{array}$ \\
\hline IRT camera model & hr 384 sl & hr 384 sl & HD 980 s \\
\hline Terrestrial laser scan & no & partly & yes \\
Snow profiles lateral & $-*$ & yes & yes \\
Snow profiles track & $-*$ & yes & yes \\
IRT video & yes & yes & no \\
IRT pictures & yes & yes & yes \\
\hline Released mass (t) & - & 502 & 818 \\
Entrained mass (t) & - & 1857 & 1302 \\
Deposited mass (t) & - & 2359 & 2120 \\
\hline
\end{tabular}

were small and a full data set of field measurements is not available, they are retained in this study since they provide good quality IRT data (Fig. 3.3). We excluded the snow profile measurements from the analysis since the erosion and deposition depths were very small, around $0.1 \mathrm{~m}$, and the manual measurements were conducted more than 1 hour after the release. The deposition zone was not accessible before due to safety reasons. The TLS could not be completed due to technical problems.

\section{Avalanche \#2 (25 February 2013):}

$20 \mathrm{~cm}$ of fresh snow that covered older snow drift accumulations resulted in a considerable (level 3) avalanche danger. Furthermore, the bulletin noted that avalanches in isolated cases could be released deeper within the snowpack. The AWS at Flüelapass measured $-12^{\circ} \mathrm{C}$ and a partly cloudy sky prevailed during the experiment. 


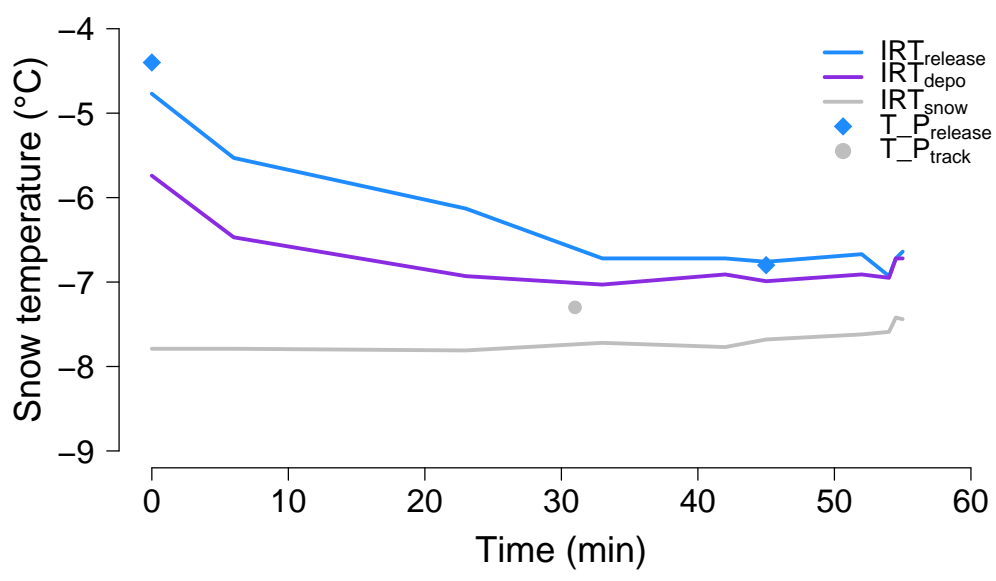

Figure 3.4: Temporal evolution and comparison of snow temperatures using a IRT camera and manually measured data. Solid lines represent regular IRT measurements in the release $\left(I R T_{\text {release }}\right)$, the deposition area $\left(I R T_{\text {depo }}\right)$ and the undisturbed snow $\operatorname{cover}\left(I R T_{\text {snow }}\right)$ which are compared to manual measurements at the profile locations $\left(T_{-} P_{\text {release }}\right.$ and $\left.T_{-} P_{\text {track }}\right)$.

Explosions along the ridge and to the lookers-left (South) side of the summit only produced small avalanches that stopped shortly below the rock face. A single explosion that triggered the cornice to the right side of the summit caused another small powder avalanche that followed the gully and triggered a secondary release at the start of the open slope (Fig. 3.1b). Even though the avalanche almost stopped after entering the open slope, the additional mass which was entrained resulted in an re-acceleration resulting in a long running medium-sized avalanche (deposition mass $2357 \mathrm{t}$ ) which only stopped in the flat part close to the lake.

\section{Avalanche \#3 (31 January 2014):}

Multiple consecutive smaller snowfalls and strong southerly winds created snow accumulations close to ridges. The national avalanche bulletin issued a considerable (level 3) danger level and that the weak old snowpack could cause avalanches to be released in near-ground layers. Moderate winds with gusts up to $60 \mathrm{~km} / \mathrm{h}$ from the South and cloudy to overcast conditions prevailed during the experiment. The automatic weather station FLU2 recorded $-6^{\circ} \mathrm{C}$ with steadily increasing temperatures during the experiment.

Two small spontaneous avalanches already released before the experiment. Initial bombing of the main gully and to the lookers-left (South) of the summit did not produce any significant avalanches. Yet, the bombing of the cornice to the lookers-right (North) of the summit resulted in a small powder avalanche which triggered a second slide at the lower end of the rock face (similar to avalanche \#2). Consequently a significant amount of snow was eroded and resulted in a medium-sized avalanche (deposition mass $2120 \mathrm{t}$ ) that stopped in the flat run out zone (Fig. 3.1c). The secondary release nearly entrained all layers to the bottom of the snowpack (1.6 m). For avalanche \#3 snow temperature measurements were also available for the cornice at the ridge. 


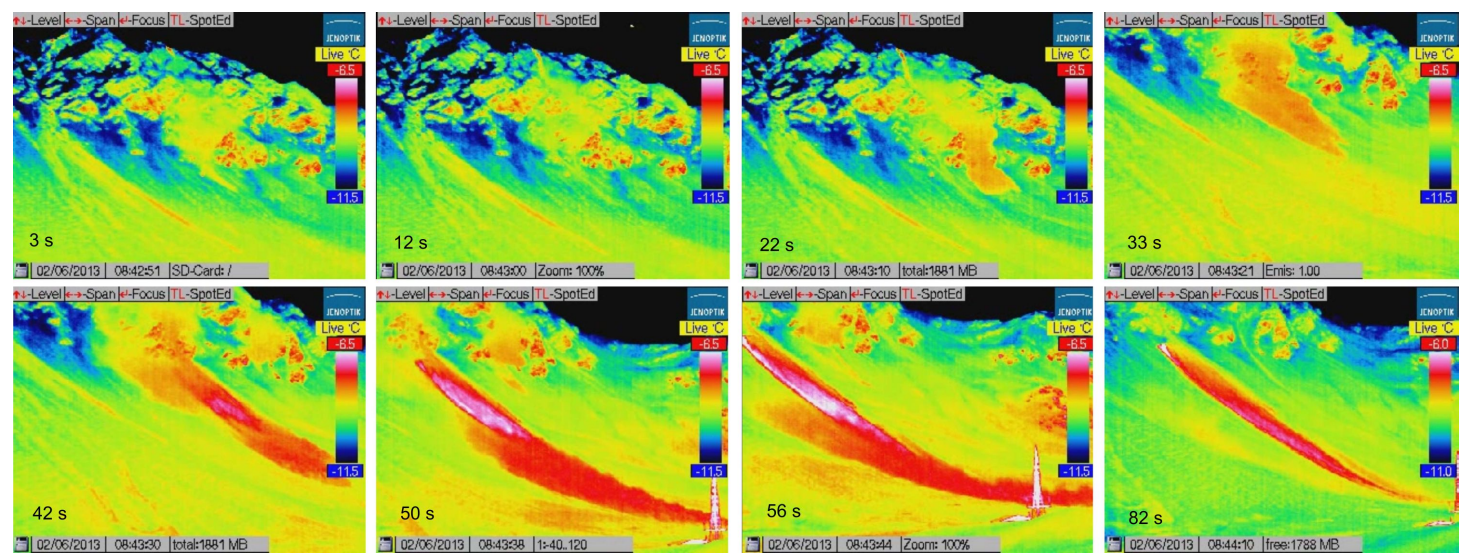

Figure 3.5: Screenshot of IRT camera videos for avalanche \#2. The first picture was taken $3 \mathrm{~s}$ after the avalanche released. Note that the temperature scale was changed by $0.5^{\circ} \mathrm{C}$ for the last shown image (82 s).

\subsection{Results}

Based on these measurements we present observed temperature distributions during the avalanche motion as well as at the surface and inside the deposition zone (Section 3.4.1). In a second step potential sources of thermal energy are identified and quantified (Section 3.4.2).

\subsubsection{Temperature distribution}

\section{Avalanches in motion}

The use of the IRT camera gave very interesting qualitative insights into the temperature behavior of a moving avalanche (Fig. 3.3 and 3.5). Especially plume formation, entrainment of warmer snow and the stopping of the avalanche as the powder cloud starved and drifted aside could be very well observed. (See supplementary material for the videos).

Even though avalanche \#la was small, a significant powder cloud developed shortly after the release (Fig. 3.3). After the avalanche entered the open slope (37 s), plume formation stopped, accompanied by a visible decrease in velocity, and the powder cloud drifted to the up-hill looking right side ( $47 \mathrm{~s}$ ) due to the prevailing wind, revealing the until then obscured dense core (57 s). After that a rapid cooling of the surface of the dense core could be observed (from pink colors at $57 \mathrm{~s}$ to orange at $77 \mathrm{~s}$ ).

The IRT video of avalanche \#2 (Fig. 3.5) is of special interest since a distinct acceleration of the avalanche can be observed as it approaches the open slope below the rock face (33 s). This can be explained by the entrainment of mass of the secondary release (42 s). The powder cloud 

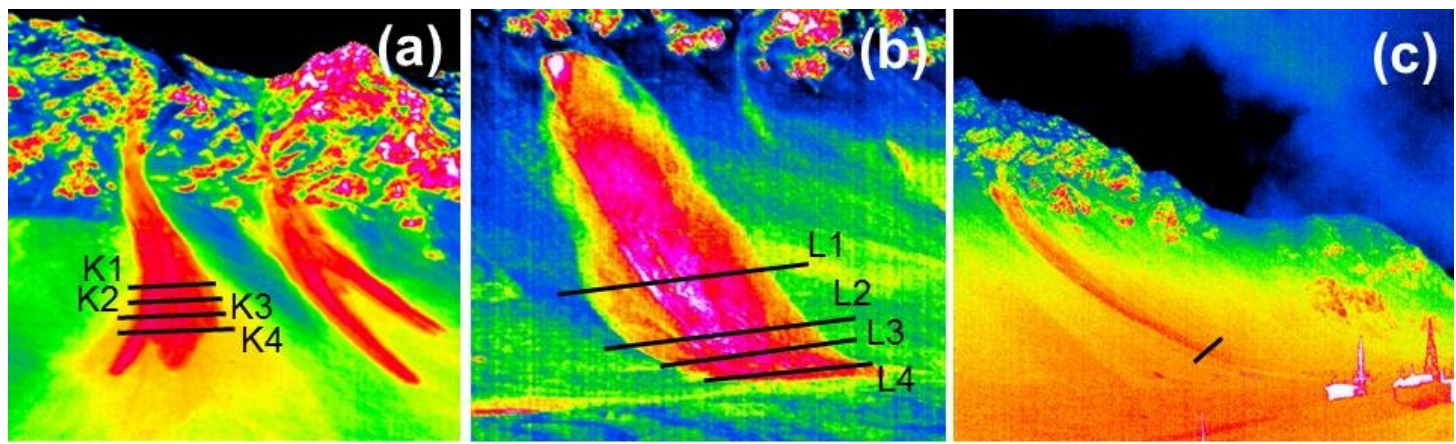

Figure 3.6: IRT camera images for avalanches (a) \#1a and \#1b, (b) \#2 and (c) \#3. Note the different temperature scales amongst the avalanches. Black lines indicate positions of lateral snow temperature transects and profiles.

shows higher temperatures than during the first phase (50 s) and the eroded surface becomes visible after the powder cloud drifts aside (56 - $82 \mathrm{~s}$ ).

\section{Surface temperature distribution}

The IRT camera images acquired shortly after the avalanches stopped (Fig. 3.6) allowed to identify exposed deep, and thus warmer, layers in the release and along the path as well as in the deposited snow. In Fig. 3.6b the secondary release, below the steep rock part, showed a much deeper erosion in the, looking up-hill, left corner. In the lower part of the track erosion was spatially rather homogenous for all avalanches.

Lateral IRT surface temperature transects in the deposition area of avalanche \#1 and \#2 (black lines in Fig. 3.6) revealed that the warmest part of the avalanche is located in the center and therefore in its dense core (Fig. 3.7a and c). In both cases a distinct difference in surface temperature of multiple degree Celsius between undisturbed snow cover and warmer core of the avalanche is evident. Figure 3.7b shows lateral profiles (L1 and L2 in Fig. 3.6b) along the path of avalanche and allowed to differentiate between undisturbed snow cover, the deposits of a fluidized layer that formed at the lookers-left (South) side of avalanche \#2 and the dense core.

\section{Internal temperature distribution of deposits}

The observed maximum temperatures in the dense core area did not only exist on the surface in lateral extension (Fig. 3.7) but also vertically in the deposits. This could be measured for both avalanches for which lateral investigations were conducted. Figure 3.8 shows the lateral temperature measurements conducted in the deposition zone of avalanche \#2 and \#3. Measurement $P_{\text {depo }}$, corresponding to $0 \mathrm{~m}$, was located in the middle of the deposition and marked the position of the full snow profile in the deposits (Fig. 3.2). Temperature measurement locations $\mathrm{R}$ and $\mathrm{L}$ were leading laterally from the center to the, looking uphill, 


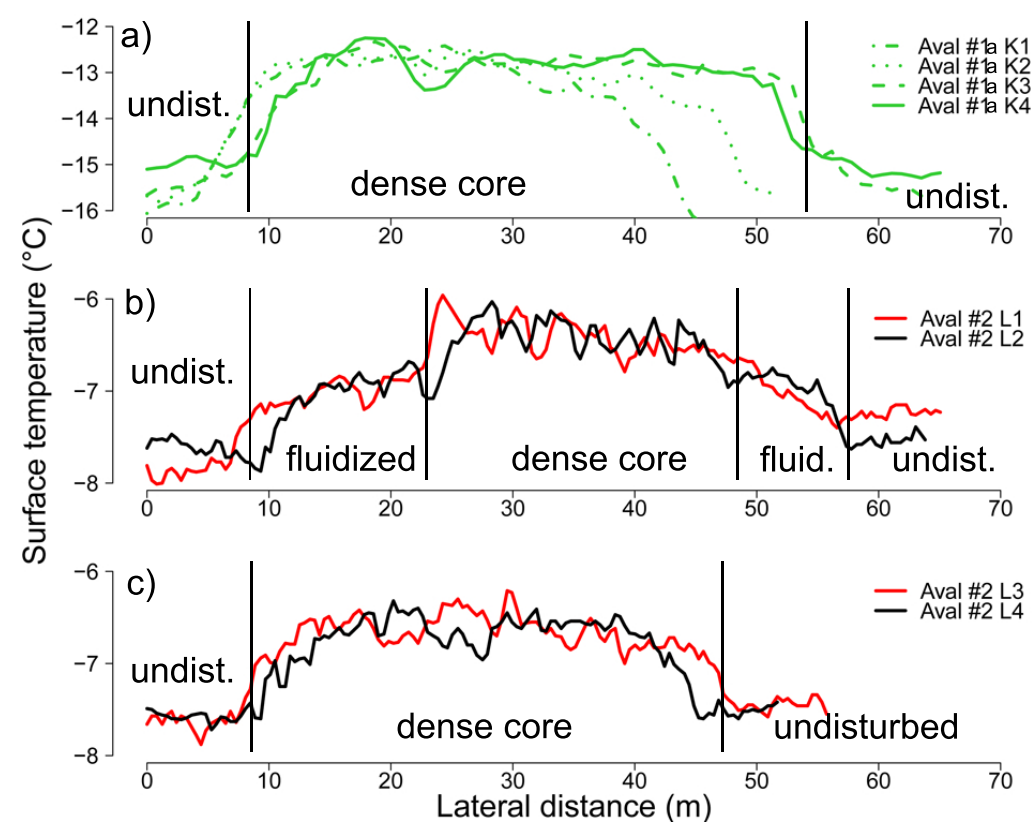

Figure 3.7: Snow surface temperatures acquired with IRT along lateral transects for avalanche \#1 (a) and in the path (b) and the deposition area (c) of avalanche \#2. Extent of undisturbed snow cover, area of fluidized layer and dense core are indicated.

right and left side of the avalanche deposits. Furthermore, the top of the avalanche deposits (solid line), the bottom of the deposits (dashed line) and the terrain (pointed line) are indicated. For better distinction the area of the undisturbed snow cover is additionally indicated by softened colors. Even though the transect shown in Fig. 3.8a only represents one half of the avalanche deposits from avalanche \#2, the extent of the dense core (area between solid and dashed line) could clearly be observed in the measured snow temperature. Similar measurements were recorded for avalanche \#3 where again the highest temperatures were recorded in the center of the deposits (Fig. 3.8b) with decreasing values towards the side of the deposits.

\subsubsection{Thermal energy sources}

To explain the observed increased snow temperatures in the deposits of the investigated avalanches and to assign and order of magnitude estimation of the sources of thermal energy, we partitioned the total warming into (i) warming due to entrainment of snow and (ii) friction. Other potential sources of thermal energy, e.g. entrainment of air or adiabatic warming, were not considered in this calculation since their influence on the temperature of the dense core were estimated as negligibly small and in the presented work. 

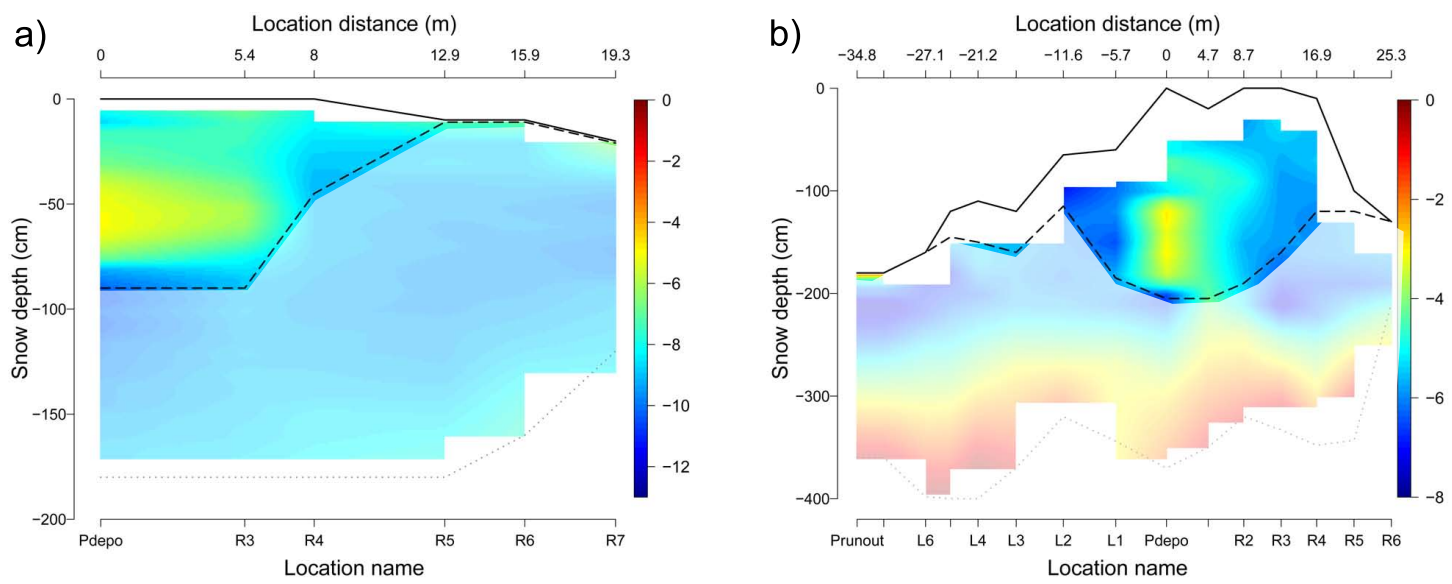

Figure 3.8: Lateral snow temperature profiles in the avalanche deposits of (a) avalanche \#2 and (b) avalanche \#3. $P_{\text {depo }}$ and $0 \mathrm{~m}$ indicate the center of deposits and the index L and R represent left and right, looking uphill, measurement locations towards the lateral sides of the avalanches. Lines indicate the top of the avalanche deposit or snow cover (solid), bottom of avalanche deposit (dashed) and bottom of snow cover (pointed). Colors of undisturbed snow cover were softened for better distinction with avalanche deposits.

\section{Entrainment}

The snow profiles (see locations in Fig. 3.2) enabled a quantification of the properties of the released and entrained snow. Figure 3.9 shows snow temperature profiles in the center of the deposition zone $T_{-} P_{\text {depo }}$ (solid violet line) and compares them to measurements conducted in the release zone $T_{-} P_{\text {release }}$ (blue line), along the path in the undisturbed snow $T_{-} P_{\text {track }}$ (orange) and the undisturbed snow cover in the run out zone $T_{-} P_{\text {runout }}$ (gray). Comparing $T_{-} P_{\text {depo }}$ and $T_{-} P_{\text {release }}$ reveals that a significant warming took place.

Depth-averaging the deposition profile (violet line) yielded a snow temperature of $-6.8^{\circ} \mathrm{C}$ for avalanche $\# 2$ and $-4.1^{\circ} \mathrm{C}$ for avalanche \#3. Temperature values from the upper and lowermost layers were excluded from the calculations because of adaption of the temperature with the surrounding air and undisturbed snow cover (gray areas in Fig. 3.9). Averaging, both spatially and vertically, the temperature for the snow that was released and entrained along the track results in $-8.7^{\circ} \mathrm{C}$ and $-5.8^{\circ} \mathrm{C}$ for the two avalanches (Table 3.2). This resulted in a difference in snow temperature between entrained and deposited snow of $\Delta T 1.9^{\circ} \mathrm{C}$ and $1.7^{\circ} \mathrm{C}$, respectively. The temperature of the released and entrained snow could therefore not be the exclusive source of thermal energy. 

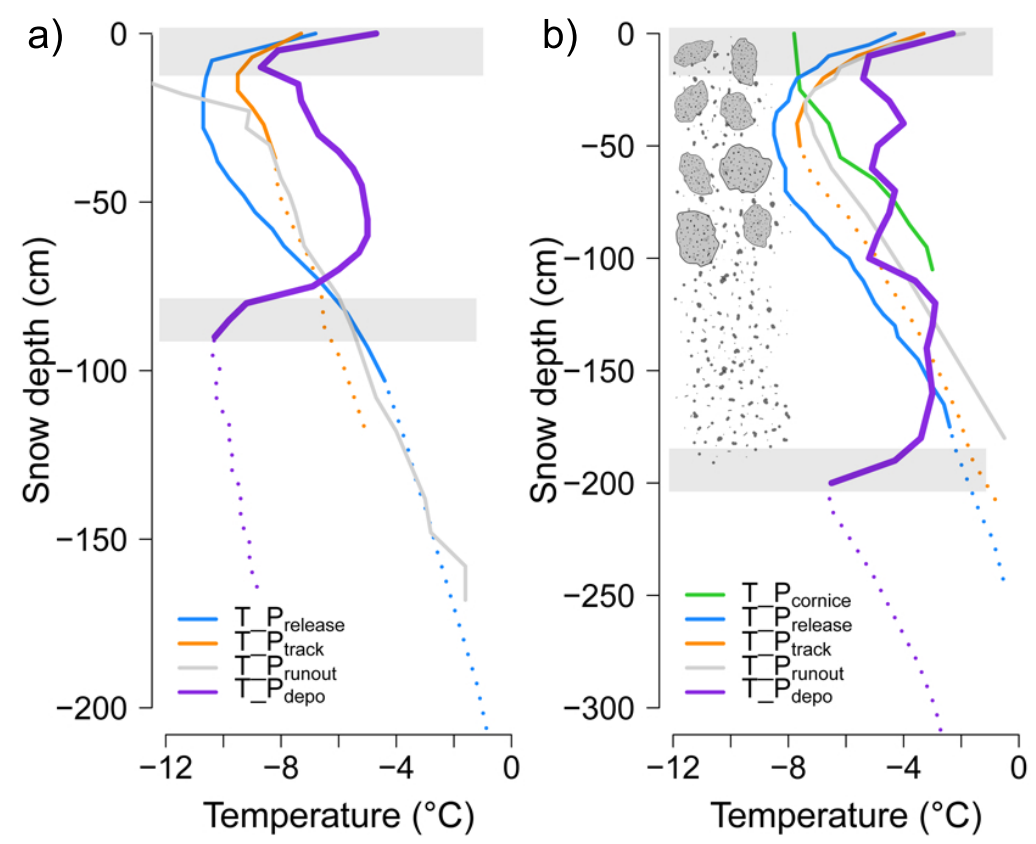

Figure 3.9: Snow temperature measurements conducted in the release zone $\left(T_{-} P_{\text {release }}\right)$, along the path in the undisturbed snow $\left(T_{-} P_{\text {track }}\right)$, in the undisturbed snow cover in the run out zone $\left(T \_P_{\text {runout }}\right)$ and in the deposition zone $\left(T_{-} P_{\text {depo }}\right)$ of (a) avalanche $\# 2$ and (b) avalanche \#3. Release, entrainment and deposition depths are indicated by solid lines whereas the undisturbed snow cover is represented by pointed lines. Gray areas indicate parts of the temperature profiles that were neglected in the calculations because of expected changes in temperature over time due to the boundary conditions of the surface and the undisturbed snow cover. Composition of deposits (granules and fine grains) are indicated for avalanche \#2.

\section{Friction}

The increase in temperature due to friction was calculated by assuming that all potential energy is transformed to heat. Starting with potential energy

$$
E_{\text {pot }}=m g h,
$$

where $m$ is the mass, $g$ is the gravitational acceleration $\left(9.81 \mathrm{~m} \mathrm{~s}^{-2}\right)$ and $h$ is the difference in elevation, we equated $E_{p o t}$ to the thermal energy $E_{t h e r m}$ resulting in

$$
E_{\text {pot }}=m g h=E_{\text {therm }}=m c_{p} \Delta T \text {, }
$$

where $m$ is the mass, $c_{p}$ is the specific heat capacity of snow $\left(2116 \mathrm{~J} \mathrm{~kg}^{-1} \mathrm{~K}^{-1}\right)$ and $\Delta T$ is the 
Table 3.2: Depth averaged temperatures of release $\left({\bar{T} \_P_{\text {release }}}\right)$, track $\left(\overline{T \_}_{-}\right.$track $)$and deposition profile $\left(\bar{T} \__{\text {depo }}\right)$ with the corresponding release and erosion depths (in brackets). The mean temperature mean $(T)={\overline{\overline{T \_}_{-}}}_{\text {cornice }}+{\bar{T} \_P_{\text {release }}+\bar{T}_{-} P_{\text {track }}}_{\text {in comparison to }} \bar{T} \__{-}{ }_{\text {depo }}$ results in the temperature difference between released and deposited snow $\Delta T$ which can not be explained by the entrained snow.

\begin{tabular}{lcc}
\hline Avalanche & $\# \mathbf{2}$ & $\# \mathbf{3}$ \\
\hline $\bar{T}_{-} P_{\text {cornice }}$ & - & $-5.3^{\circ} \mathrm{C}(1.05 \mathrm{~m})$ \\
$\overline{T \_}_{\text {release }}$ & $-8.6^{\circ} \mathrm{C}(1.03 \mathrm{~m})$ & $-6.3^{\circ} \mathrm{C}(1.75 \mathrm{~m})$ \\
$\overline{T \_}_{\text {track }}$ & $-8.7^{\circ} \mathrm{C}(0.37 \mathrm{~m})$ & $-5.8^{\circ} \mathrm{C}(0.3 \mathrm{~m})$ \\
mean $(T)$ & $-8.7^{\circ} \mathrm{C}$ & $-5.8^{\circ} \mathrm{C}$ \\
\hline$\overline{T \_P}_{\text {depo }}$ & $-6.8^{\circ} \mathrm{C}(0.9 \mathrm{~m})$ & $-4.1^{\circ} \mathrm{C}(1.95 \mathrm{~m})$ \\
\hline$\Delta T$ & $1.9^{\circ} \mathrm{C}$ & $1.7^{\circ} \mathrm{C}$ \\
\hline
\end{tabular}

change in snow temperature. Solving for $\Delta T$ resulted in

$$
\Delta T_{\text {friction }}=\frac{g h}{c_{p}} .
$$

Note that $m$ can be dropped if the mass is not assumed to change along the path (i.e. no erosion or deposition takes place). Calculating for an elevation drop of $300 \mathrm{~m}$, corresponding to the slope below the rock face until the run out zone, resulted in an increase in temperature due to friction of approximately $1.5^{\circ} \mathrm{C}$.

The calculated $\Delta T_{\text {friction }}$ can be seen as a maximum value in our order of magnitude estimation since in nature not all mass is released and entrained at the maximum elevation $h$. Furthermore, lateral temperature gradients in the deposition area are not taken into account.

\subsection{Discussion}

It has been noted in other studies [Vera et al., 2012] that potential sources of thermal energy in snow avalanches are friction processes or entrainment of snow with differing temperatures. Our results confirm that for the investigated avalanches the thermal energy increase due to friction is mainly depending on the elevation drop of the avalanche and thus a rather constant value (for a specific avalanche path and typology). The basic calculation does not take changes in mass into account. Yet, it is well known that avalanches can significantly increase their mass along the path via entrainment [Sovilla, 2004]. Therefore, the calculated value of $0.5^{\circ} \mathrm{C}$ per 100 altitudinal meters has to be adapted to consider the actual mass that enters the avalanche at a certain point along the track. For dry and cold snow avalanches far away from the melting point, the warming due to friction alone is therefore not expected 
to have a substantial influence on flow dynamics. Yet, if the overall avalanche temperature is already close to the critical temperature threshold of $-1^{\circ} \mathrm{C}$ [Steinkogler et al., 2014b] the warming by frictional processes can cause drastic changes of the granular structure inside the avalanche and consequently affect flow behavior.

Contrary, the warming due to entrainment is very specific to the individual avalanche and can vary significantly depending on the erosion depth as shown in the profiles along the avalanche track (Fig. 3.9) and the IRT pictures (Fig. 3.6). The alpine snow cover typically shows a positive temperature gradient towards the ground [Armstrong and Brun, 2008]. Except for areas with permanent permafrost the temperature at the soil-snow interface can be assumed to be approximately $0^{\circ} \mathrm{C}$ if there has been a significant snow cover for several weeks. Consequently, the erosion of deeper snow layers leads to warmer snow temperatures. Also altitudinal changes of snow temperature along the slope have been proven to be quite variable and directly influence flow dynamics [Steinkogler et al., 2014a].

Our temperature measurements on the surface (Fig. 3.7) and in depth (Fig. 3.8) of the deposition zone indicate that the highest temperatures are located in the dense core of the avalanche. The interface between the bottom of the avalanche deposits and the subjacent undisturbed snow cover featured a very clear and sharp transition (violet lines in Fig. 3.9). The shape of the temperature curve indicates the warmest temperatures in the lower parts of the deposits profile ( -40 to $-80 \mathrm{~cm}$ and -120 to $-190 \mathrm{~cm}$ for avalanches \#2 and \#3, respectively) and close to the sliding surface. This would support the expectation of the most pronounced friction at the bottom of the flow, typical for this kind of avalanche. Unfortunately, a cooling of the lowest deposition layers to the temperature of the subjacent undisturbed snow cover has to be expected and thus prevents a definite conclusion on this observation. The upper part of the temperature profiles resemble more the shape of a plug-like flow. Also, whether the temperature variations in the upper part of the deposition profile between 0 and $-100 \mathrm{~cm}$ of avalanche \#3 (violet line in Fig. 3.9) are a result of a mixture of broken parts of the eroded snow cover, with varying temperatures, and formed granules could not be fully answered. Yet, granules embedded in fine grained snow were still clearly observable in this area of the deposition.

It is without question that reaching the deposits after an avalanche release to measure the snow surface temperature with traditional methods, e.g. thermometers, takes too long and the surface as well as the upper most layers would have changed their temperature already. It could be observed in the video of avalanche \#1 (see supplementary material) that right after the dense core stopped it started to cool. In all those cases for which a real-time measurement is necessary IRT technology provides a valuable addition to traditional measurements. Even though in our study we only applied the IRT camera in a qualitative way, the presented basic verification (Fig. 3.4) with manually measured snow surface temperatures showed a fairly good agreement with an accuracy of about $\pm 1^{\circ} \mathrm{C}$. Although further investigations are necessary to define whether absolute values of surface temperature can be acquired without significant uncertainties, the relative accuracy of the IRT cameras are usually high, around $0.05^{\circ} \mathrm{C}$ in our 
case as specified by the manufacturer. This facilitates to track relative changes in temperatures even if the absolute value might not be accurate.

Recently IRT was mainly tested and evaluated for snow profile applications at short distances [Schirmer and Jamieson, 2014]. Possible influences of the large distances between camera and avalanches, viewing angle, liquid water content in snow or at its surface [Snyder et al., 1998] and surface roughness of the deposits [Danilina et al., 2006; Mushkin et al., 2007] demand detailed studies. In general, low signal attenuation can be expected for (peak) winter month atmospheres, especially for clear sky conditions, due to relatively low humidity levels.

Dozier and Warren [1982] investigated the effect of viewing angle on the infrared brightness temperature of snow and found differences of up to $3^{\circ} \mathrm{C}$. Similar values have been found by Hori et al. [2013], yet they concluded that for viewing angles less than $40^{\circ}$ from the nadir the error in temperature is less than $-0.8^{\circ} \mathrm{C}$.The effect of moisture has been studied extensively $[\mathrm{Wu}$ et al., 2009, and references therein], basically concluding that the presence of water causes a strong absorbance and consequently a decrease in reflectance in the near-infrared spectra of soils.

An effect that still illustrates challenges for the interpretation of IRT images is due to the roughness of the investigated surface [Wu et al., 2009]. In most studies the assumption that the scene elements are isothermal, smooth and homogenous is used [Danilina et al., 2006]. Consequently supposing that the object of interest is Lambertian, i.e. behaves as a perfect diffuser and emits and reflects radiation isotropically. Mushkin et al. [2007] observed that the effective emissivity spectra of rough surfaces are different from those of perfectly smooth surfaces of the same composition due to multiple scattering among roughness elements. Yet, they only found an up to 3\% reduction in the spectral contrast due to sub-pixel surface roughness variations.

Also whether the surface temperature, and possibly even the composition, of the aerosol mixture of the powder cloud can be measured is an open question. Visualization of air flows on the qualitative level is common practice for various applications [Carlomagno and Cardone, 2010; Narayanan et al., 2003] and, as presented in this study, provides impressive footage of powder snow avalanches. Usually a tracer is injected into the flow field. In our case the tracer is already present by snow particles of the entrained snow which are transported into the powder cloud. Similar concepts as applied for satellite remote sensing of high-level clouds, such as cirrus [Fu et al., 1998], might be transferable to avalanche powder clouds.

A possible further application of IRT could be the differentiation of flow regimes in the deposition area. As shown earlier the warmest part of an avalanche is located in the dense core, e.g. center (red and pink) of avalanche \#2 in Fig. 3.6b, whereas layers with less mass or where less friction occurred are cooler (yellow and orange areas in Fig. 3.6b). Especially the lookers-left (South) side of the deposition in Fig. 3.6b appears to be the deposits of a fluidized layer. The IRT observations are in agreement with the field observation criteria for fluidized layers as described by Issler et al. [2008]: (1) rapid decrease of deposit thickness, (2) snowballs of various 
sizes embedded in a matrix of compacted fine-grained snow, (3) large snowballs lying on top of the deposit and (4) fewer snowballs per unit area than on the dense deposit.

Deposits from the powder cloud have consistently lower temperatures than the warm dense core despite the fact that the powder cloud (at least from one avalanche) traveled as far downhill as the dense core. Two distinct processes may contribute to this fact: (i) A preferential ejection of colder and lighter surface snow layers already initiates suspension with colder snow while the dense core may have a higher fraction of snow from lower layers in the profile and therefore with a higher temperature. (ii) The particle concentration in the suspension layer is low and therefore molecular dissipation of kinetic energy and exchange of sensible and latent heat happens largely between air and snow and not between snow and snow particles as in the dense core. This leads to a rapid adoption of temperatures close to the air temperature for the suspended snow.

Furthermore, the IRT results can be qualitatively interpreted in a similar way as a laser scan to identify areas where deeper or shallower erosion occurred, e.g. see step-down entrainment below the rock face for avalanche \#2 (Fig. 3.6b). For this avalanche we exemplary calculated the release mass solely by using information from the IRT pictures and manually measured snow profiles in the release. Therefore, the IRT picture was georeferenced in a GIS software and shallower and deeper release layers were identified. The (IRT) surface temperature of these layers were combined with the snow height of the corresponding temperature in the conducted snow profile in the release. This resulted in a calculated release mass of $457 \mathrm{t}$ which is similar to the mass measured with the terrestrial laser scan ( $502 \mathrm{t}$ ). This depicts a rough yet quick and efficient method to estimate the release mass of an avalanche. As shown in this study, the release and entrainment depth doe not only define the overall mass of snow but equally important its temperature. IRT pictures and videos provide an intuitive and easy to acquire measure to identify these relevant erosion processes (Fig. 3.6).

\subsection{Conclusions}

We conducted full-scale avalanche experiments at the Flüelapass field site above Davos (Switzerland) to investigate the distribution of snow temperatures in avalanche deposits and identify the sources of thermal energy in dry avalanches. A further goal was to test the usability of infrared radiation thermography (IRT) in this context.

For the investigated similar avalanches the temperature increase due to friction was mainly dependent on the elevation the avalanche dropped. The contribution to the total temperature increase by erosion processes was shown to be quite variable, depending on the release depth and snow temperatures of the entrained snow. The warmest temperatures were observed in the center of the avalanche deposits and thus represented the dense core of the flowing avalanche.

The IRT camera allowed to observe the avalanche phenomenon 'with different eyes' and 
provides a lot of potential for more detailed research in the field of avalanche dynamics, both quantitative and qualitative. It is still necessary to further verify the measurements and define to which extent absolute snow surface temperatures can be measured. Then, the spatial distribution of surface temperatures can help in the interpolation of profile temperatures measured by hand.

Our results allow for a more comprehensive understanding of snow temperatures in avalanche flow and their consequences on flow regimes. This information can directly be used to verify and enhance the performance of avalanche dynamics models and is thus of great interest for practitioners.

\section{Acknowledgment}

Funding for this research has been provided through the Interreg project STRADA by the following partners: Amt für Wald Graubünden, Etat du Valais, ARPA Lombardia, ARPA Piemonte, Valle d'Aosta, Regione Lombardia. The authors would like to thank all the people who helped gathering the data during the field experiments. Thanks to Vali Meier from the SOS Service Jakobshorn (Davos) and his team for the great support. 



\section{Granulation of snow: experiments and discrete element modeling}

Steinkogler W., Gaume, J., Löwe, H., Sovilla B., Lehning M. (Submitted) Granulation of snow: from tumbler experiments to discrete element simulations. Journal of Geophysical Research Earth Surface.

\subsection{Introduction}

Snow avalanches can exhibit many different behaviors, such as a sheared and fluid-like layer, a plug flow or a dilute suspended powder cloud [Gauer et al., 2008]. In most cases different regimes exist at the same time at different locations inside an avalanche [Sovilla et al., 2008]. The flow dynamical behavior of the dense core of snow avalanches is often approximated as a granular flow [Roche et al., 2011] but a comprehensive understanding of the conditions that define the particle size distribution and their properties and the consequent influence on flow dynamics of avalanches is still lacking.

Recent studies show that the properties of the snow entrained by an avalanche during its downward motion, especially snow temperature, significantly affect flow dynamics [Naaim et al., 2013; Sovilla and Bartelt, 2002; Steinkogler et al., 2014a], mostly by changing the granular structure of the flow. An improved understanding of the driving factors causing certain granule size distributions could help to better understand the hypermobility often observed in landslides and avalanches [Pudasaini and Miller, 2013] as well as the dynamics of powder snow avalanches [Turnbull and Bartelt, 2003].

The relation between particle size distribution and mobility of a granular flow, i.e. its ability to move faster and further, has been shown in multiple studies on mono- and bi-disperse materials [GDR MiDi, 2004; Moro et al., 2010]. Additionally, numerous investigations on particle sizes in real-scale avalanche deposits (Figure 4.1) were conducted [Bartelt and McArdell, 2009; De Biagi et al., 2012]. By collecting particles in the deposition zone of full-scale avalanches, these studies could show that wet avalanches tend to produce more large granules than dry avalanches [Bartelt and McArdell, 2009; Kobayashi et al., 2000]. However, the link between snow cover properties and a certain size distribution were never quantified. 
Because of the difficulties to investigate in full-scale field campaign, experiments are mainly performed in laboratory. Most laboratory experiments on granular flow dynamics are conducted with artificial grains, e.g. glass ballotini [Schaefer and Bugnion, 2013], and generally do not take inter-particle cohesion or changes in size distribution into account. These limitations are particularly relevant for snow avalanches where the properties and distributions of the granules are fundamental parameters influencing the flow dynamics, thus highlighting the limits of such an approach. However, up to now, very few investigations exist [Nohguchi et al., 1997; Turnbull, 2011] which address the granulation of snow, i.e. the generic name for particle size enlargement [Walker, 2007].

Granulation in rotating drums is a key process in many industrial applications including medicinal and pharmaceutical [Kristensen and Schaefer, 1987; Vervaet and Remon, 2005], ceramics [Reed, 1995] and mineral processing as well as fertilizers production. Extensive research on granulation processes [Pietsch, 2003] and the characterization on the granule properties and size distributions took place in the last five decades [Ennis et al., 1991; Ouchiyama and Tanaka, 1975].

From a modeling view point, numerical studies of cohesive powder flows in rotating drums generally use the discrete element method [Cundall and Strack, 1979] and mainly focus on the mixing behavior [Chaudhuri et al., 2006; Sarkar and Wassgren, 2010, 2009] rather than the evolution of granule sizes. DE simulations were also used recently to model the dense flow of cohesive granular materials by Rognon et al. [2008a] who studied the effect of cohesion on the flow mobility and showed that a plug region could develop if the cohesion is high enough. However, to our knowledge, DE modeling has never been used to describe granulation effects in snow avalanches which are often described using cohesionless granular materials [Faug et al., 2009].

It is the aim of the present paper to describe relevant snow cover parameters and thresholds that control the size and properties of granules for different types of snow that formed in a rotating tumbler by ways of laboratory experiments (Section 4.2.1) and numerical simulations (Section 4.2.2). We then compare those results to measurements in the deposition of real-scale avalanches and suggest a diagram of the granulation regimes (Section 4.3). We discuss our results in view of the commonly used terminology of granulation processes [Iveson et al., 2001]. The paper discusses applications of the results and future avenues of research (Section 4.4).

\subsection{Methods}

\subsubsection{Experimental setting}

To investigate the granulation potential of different snow types a standard, unmodified concrete tumbler (Figure 4.2) was used. The tumbler measured $0.6 \mathrm{~m}$ at the largest diameter and held $0.4 \mathrm{~m}^{3}$ of snow. The tumbler has two blades acting as mixing elements (Figure 4.2) and rotated with constant velocity at 0.5 revolutions per second. 


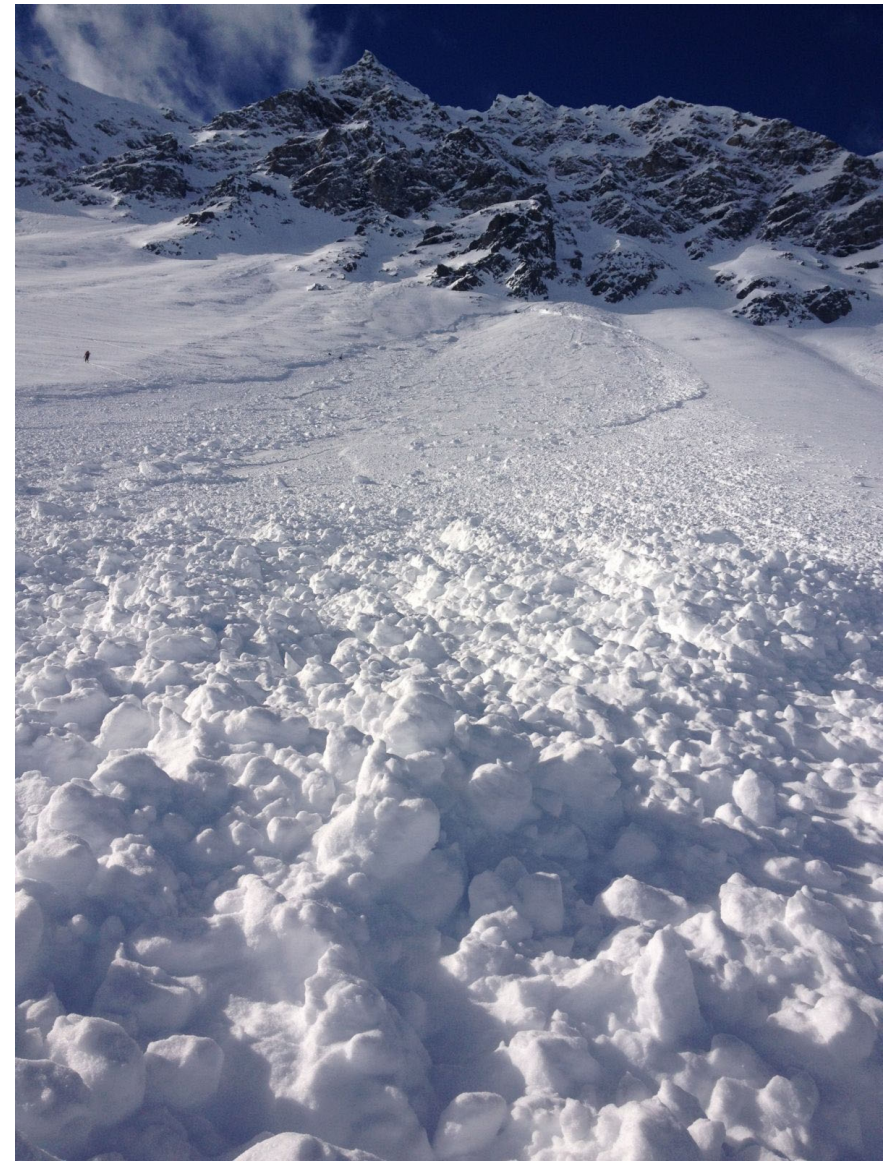

Figure 4.1: Granular structures in the deposition zone of an artificially released avalanche.

All experiments were conducted in an open-door but roofed laboratory, that granted easy and direct access to natural and undisturbed snow, under varying environmental conditions, i.e. different air temperatures and sunny or cloudy skies. A total of 23 experiments with varying initial snow types were conducted and resulted in measurements at 97 time steps (Table 4.1). Snow of different types (e.g. new snow particles or melt forms) with different properties (e.g. temperature or density) was used for the experiments. An overview is given in Table 4.1. To assess the initial conditions of the investigated snow (temperature, density, grain shape, grain size, moisture content, hardness) a regular snow profile following the guidelines of Fierz et al. [2009] was conducted before every experiment. Consequently snow layers with similar properties were collected and a defined volume $\left(0.1 \mathrm{~m}^{3}\right)$ was shoveled into the tumbler.

After defining the initial conditions of the added snow the tumbler was started. According to Mellmann [2001], who identified different flow regimes in rotating cylinders as a function of the Froude number, our experiments fall into the cascading regime $(F r=0.275)$ for cohesionless particles, where a large part of the particles was transported upwards by solid body rotation with a downward flow of particles at the surface (Figure 4.3a). However, the presence of the blades and of cohesion forced the regime into a cataracting motion, i.e. individual particles 


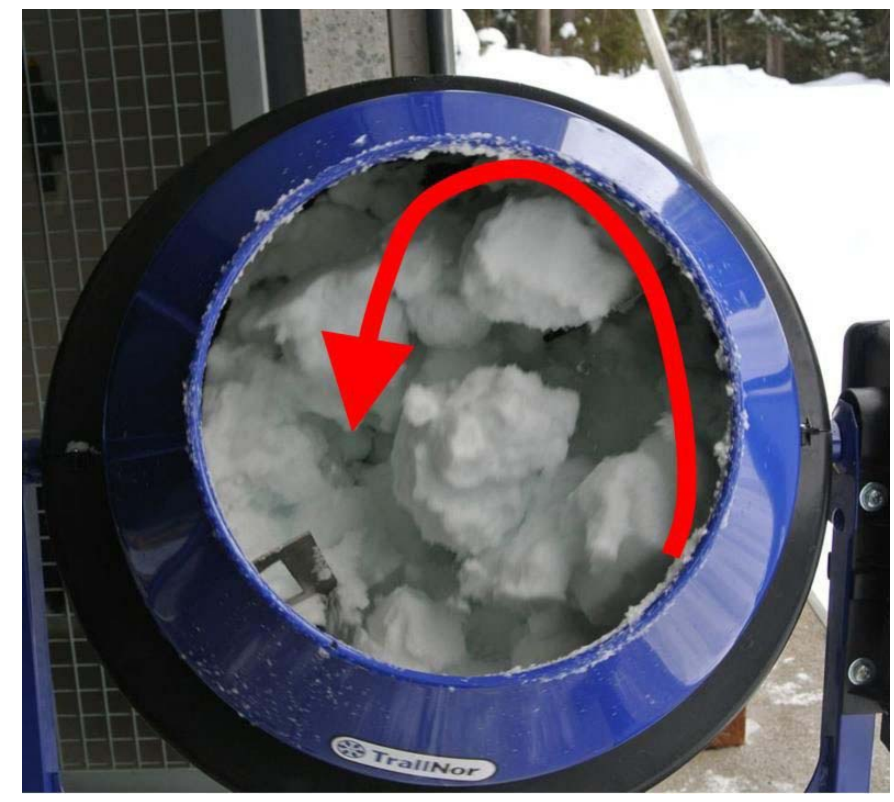

Figure 4.2: Granules in motion in rotating tumbler. One (of the two) mixing blades can be seen at lower left corner.

detach from the bed and were thrown off into the free space of the tumbler (Figure 4.2 and $4.3 \mathrm{~b})$.

The tumbler was stopped at regular intervals, typically every 5 minutes which corresponds to 150 rotations, and the properties of the snow or the formed granules were measured. Again the same procedures and measurement devices as for standard snow profiles [Fierz et al., 2009] were used. Snow temperature was measured with a digital thermometer to an accuracy of $0.1^{\circ} \mathrm{C}$. Snow densities of the granules or fine material in the tumbler were measured with a $100 \mathrm{~cm}^{3}$ snow shovel and a digital scale. If the granules were too small and no sample could be taken with the density shovel their diameter was measured and they were weighed. This was repeated for multiple granules and an average mass of that sample granules was taken. The liquid water content (LWC) was visually estimated by using a $8 \mathrm{x}$ magnification glass to identify water and squeezing the snow by hand. An LWC classification was then assigned according to Fierz et al. [2009]. Grain shape and size were identified by using a crystal card and a magnifying glass.

Additionally, the experiments were filmed with normal and high-speed cameras (videos are provided as supplementary material). Videos nicely reveal the motion of snow inside the tumbler and the interaction of snow and granules during collisions among themselves and with the tumbler.

We defined the initiation of granulation as soon as the snow started to form small snow balls, with a size of approximately $1 \mathrm{~cm}$. If they were not hard enough to sustain collisions amongst themselves or were destroyed upon touching they were defined as non-persistent granules 
a)

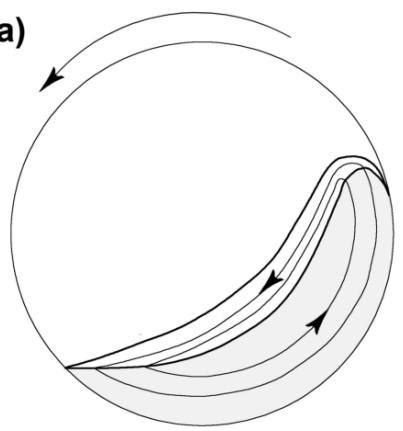

b)

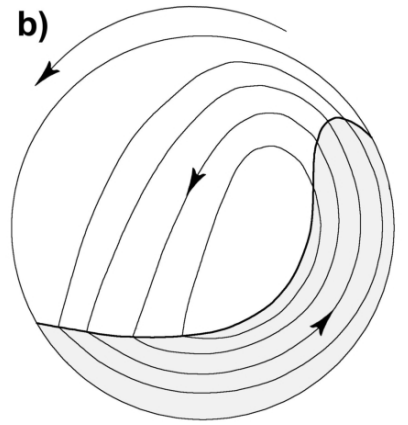

Figure 4.3: Cascading (a) and cataracting regimes (b) for a cohesion less granular material. These regimes mainly depend on the Froude number, particles and wall friction and the filling degree for a cohesionless granular material. According to Mellman (2001).
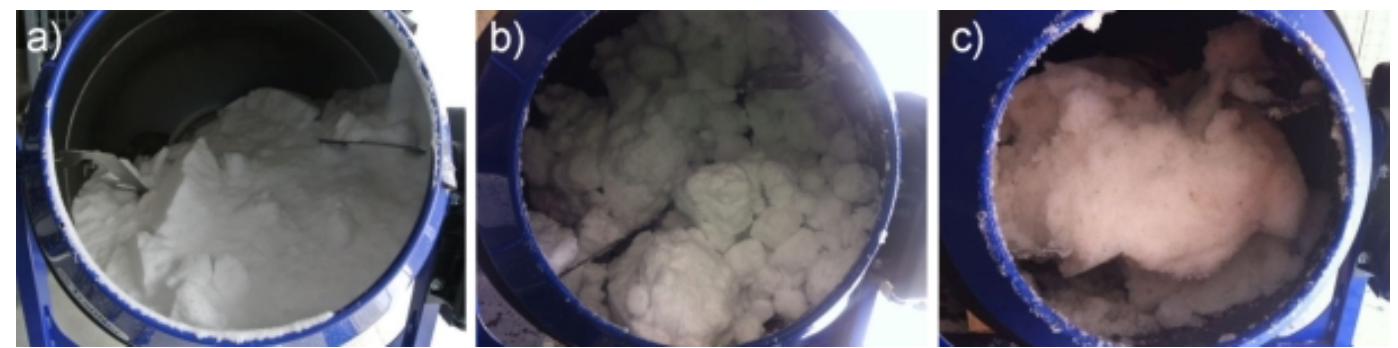

Figure 4.4: Snow inside tumbler for different experiments where (a) no persistent granules formed, (b) persistent-moist granules formed and (c) persistent-wet granules formed.

(Figure 4.4a)). On the other hand, hard granules were classified as persistent. Furthermore, we distinguished between persistent-moist granules (Figure 4.4b)), according to snow class $d r y$ or moist in Fierz et al. [2009], and persistent-wet granules (Figure 4.4c)), according to wet, very wet or soaked snow [Fierz et al., 2009]. The experiments were continued and suspended in regular intervals until the formation of new granules could be observed. Experiments were stopped either if no granules formed after an extensive time, i.e. more than 100 minutes, or the system reached a stationary state where no further changes in the measurement variables could be observed.

Measurements of the size distribution is an elaborate task in the field [Bartelt and McArdell, 2009] and in the tumbler. For our experiments we restrict ourselves to cases where granulation occurred and characterized the full size distribution at the end of the experiment by carefully emptying the tumbler and manually evaluating the particle ensemble (Figure 4.5). 


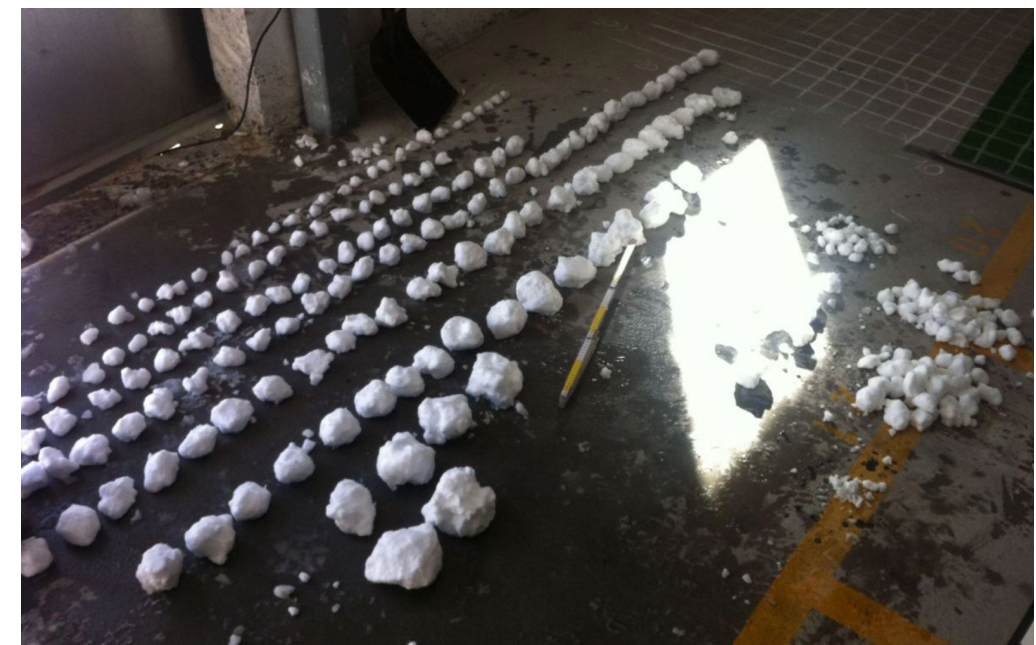

Figure 4.5: Small example set of different granule sizes.

Table 4.1: Measurement summary of tumbler experiments.

\begin{tabular}{ll} 
Nr. of experiments: & 23 \\
Nr. of measurement time steps: & 97 \\
Initial snow types: & Decomposed forms, small rounds, faceted forms, melt forms \\
(Snow) measurements: & Temperature, density, moisture, hardness, grain shape, grain size \\
\hline
\end{tabular}

\subsubsection{Discrete Element Modeling}

\section{Motivation and Objectives}

Discrete element simulations allow to assess mechanical quantities such as stresses, displacements, shear rates at each point within the sample. This is a hardly or even impossible experimental task. Hence, the rheological behavior of the material can be explored locally by using discrete elements (DE) regardless of spatial heterogeneities. It therefore implies a better understanding of physical processes at play. Once validated against experimental data, the DE method can help performing new simulations which can viewed as veritable numerical experiments.

Our objective is to use DE to characterize the link between the macroscopic behavior of dense cohesive granular materials and micro-mechanical properties of the grains to further investigate the granulation processes of snow. Hence, a cohesive contact law characterized by the inter-particle strength (tensile and shear) and a sintering parameter for the bond creation is accounted for. The parameters of the model are varied in a range of realistic values for snow in order to reproduce the different granulation regimes observed experimentally. The resulting size distribution is then compared to that obtained from the rotating tumbler experiments. 


\section{Formulation of the model}

The discrete element simulations were performed using the commercial software PFC2D (by Itasca) which implements the original soft-contact algorithm described in Cundall and Strack [1979]. To capture the essential details of snow granulation we carried out two dimensional simulations of a cohesive granular material taking into account the tumbler geometry (Figure 4.2). The simulated system consists of a two dimensional outer cylinder of radius $R=0.3 \mathrm{~m}$ and blades of length $l_{b}=0.35 R$. This configuration corresponds to the experimental setup. The granular samples are composed of about 8000 circular particles of average diameter $d=4.5 \mathrm{~mm}$ (thus $R / d \sim 67$ ), with a grain size distribution polydispersity of $\pm 30 \%$ (diameters ranging from 3 to $6 \mathrm{~mm}$ ) and a particle density $\rho_{p}=300 \mathrm{~kg} / \mathrm{m}^{3}$. The loading is applied by gravity and rotation of the walls (outer cylinder and blades). The simulations were performed in the same conditions as the experiments so as to keep the same Froude number

$$
F r=\frac{\omega^{2} R}{g}
$$

which is equal to $F r=0.275$ in our case $\left(\omega=3 \mathrm{rads}^{-1}\right.$ and $\left.g=9.81 \mathrm{~m} \mathrm{~s}^{-2}\right)$. As stated before, this Froude number would correspond to a cascading regime with a cohesionless granular material (Figure 4.3a, [Mellmann, 2001]). However, the presence of the blades and of interparticle cohesion will considerably modify and force the flow regime, from the cascading to the cataracting regime (Figure 4.3b).

The interparticle contact laws used in the simulations are classical [Radjai et al., 2011]. The normal force is the sum of a linear elastic and of a viscous contribution (spring-dashpot model), and the shear force is linear-elastic with a Coulombian friction threshold (cf Figure 4.6). In detail, let's consider two grains $i$ and $j$ in contact as in Figure 4.6. We denote by $\mathbf{n}_{\mathbf{i j}}$ the unit normal vector, pointing from sphere $i$ to sphere $j$ and $\mathbf{s}_{\mathbf{i j}}$ a perpendicular unit "shear vector". Any contact force exerted on grain $j$ by grain $i$ can be decomposed according to

$$
\mathbf{F}_{\mathbf{i j}}=N_{i j} \mathbf{n}_{\mathbf{i j}}+S_{i j} \mathbf{s}_{\mathbf{i j}} .
$$

The normal force comprises an elastic and a viscous contribution according to

$$
N_{i j}=N_{i j}^{e}+N_{i j}^{v}=k_{n} \delta_{i j}^{n}+g_{n} \dot{\delta}_{i j}^{n}
$$

where $k_{n}$ is the normal stiffness, $\delta_{i j}^{n}$ the normal interpenetration distance between grains $i$ and $j$ (Figure 4.6) and $g_{n}$ the viscous damping coefficient. The latter is directly linked to the restitution coefficient $e$, which is the ratio between the restituted and initial velocities in a 
Table 4.2: Mechanical parameters used in the simulations. $k_{n}$ : normal contact stiffness; $k_{t}$ : tangential contact stiffness; $\mu$ : intergranular friction; $e$ : normal restitution coefficient; $\rho_{p}$ : particle density; $\sigma_{t}$ : contact bond tensile strength; $\sigma_{s}$ : contact bond shear strength; $\alpha$ : contact bond creation coefficient.

\begin{tabular}{cccccccc}
\hline$k_{n} / P$ & $k_{n} / k_{s}$ & $\mu$ & $e$ & $\rho_{p}$ & $\sigma_{t}$ & $\sigma_{t} / \sigma_{s}$ & $F_{c}^{s i} / F_{c}^{t}$ \\
\hline $1.10^{3}$ & 2 & 0.5 & 0.1 & $300 \mathrm{kgm}^{-3}$ & $0-5 \mathrm{kPa}$ & 2 & $0-20$ \\
\hline
\end{tabular}

binary collision. The shear force is given by

$$
S_{i j}=k_{s} \delta_{i j}^{s} \quad \text { if } \quad\left|k_{s} \delta_{i j}^{s}\right|<\mu\left|N_{i j}^{e}\right|
$$

or

$$
S_{i j}=\mu N_{i j}^{e} \text { if }\left|k_{s} \delta_{i j}^{s}\right| \geq \mu\left|N_{i j}^{e}\right|
$$

with $k_{s}$ the tangential stiffness and $\delta_{i j}^{s}$ the shear interpenetration.

The corresponding mechanical parameters are summarized in Table 4.2. The value of the normal stiffness $k_{n}$ was chosen in a way that the normal interpenetrations $\delta$ at contacts are kept small, $\delta / d<10^{-3}$, i.e. to work in the quasi-rigid grain limit [da Cruz et al., 2005; Roux and Combe, 2002]. Concerning the normal restitution coefficient $e$, we checked that the results presented below, and more generally all the macroscopic mechanical quantities obtained from the simulations, are actually independent of this parameter (in the range 0.1 to 0.9 ), in agreement with previous studies [da Cruz et al., 2005; Gaume et al., 2011].

Cohesion was added to the particles by adding a bond to each contact. A contact bond can be envisioned as a pair of elastic springs (or a point of glue) with constant normal and shear stiffnesses acting at the contact point. These two springs have specified shear and tensile strengths $F_{c}^{s}$ and $F_{c}^{t}$ respectively. If the magnitude of the tensile normal contact force equals or exceeds the contact bond tensile strength, the bond breaks, and both the normal and shear contact forces are set to zero. If the magnitude of the shear contact force equals or exceeds the contact bond shear strength, the bond breaks, but the contact forces are not altered, provided that the shear force does not exceed the friction limit, and provided that the normal force is compressive.

At the beginning of the simulation, the cohesion is applied to the whole sample. However, during the experiment, some bonds may break but a new bond may also be created at a new contact point. The following criterion for bond creation was used:

$$
\sqrt{N_{i j}^{2}+S_{i j}^{2}}>F_{c}^{s i}
$$


where $F_{c}^{s i}$ is the bond creation force, which represents sintering.

The contact law which is used in the model is summarized schematically in Figure 4.6 in which the elastic part is on the right side and the cohesive part on the left side and the ranges of the used parameters are shown in Table 4.2.

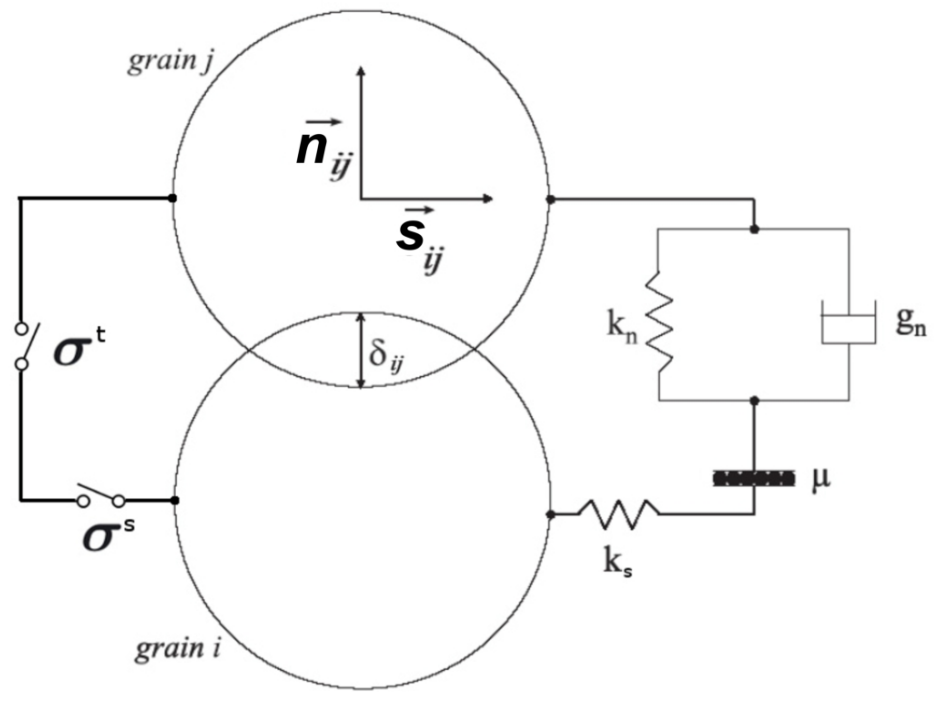

Figure 4.6: Schematic of the used contact law.

Different models of cohesive interaction could also have been used such as the cohesive potential model of Rognon et al. [2008b] (attractive force for short interpenetrations between the grains followed by repulsive force for higher interpenetrations). However, due to the complexity of snow, it would have been difficult, in practice, to link the parameters of this model to snow properties. Our model simpler but also more straightforward to apply to snow. Its model parameters, namely the tensile strength and the sintering force, can be evaluated from laboratory experiments such as tension [Hagenmuller et al., 2014; Sigrist, 2006] and sintering [Podolskiy et al., 2014; Szabo and Schneebeli, 2007] tests.

\section{Dimensional analysis}

Snow is a material generally characterized in terms of stresses rather than forces. Hence, the tensile and shear strengths $F_{c}^{t}$ and $F_{c}^{s}$ (forces) are scaled by the bond surface to obtain the tensile and shear strengths $\sigma^{t}$ and $\sigma^{\mathcal{s}}$ (stresses):

$$
\sigma^{t}=\frac{4 F_{c}^{t}}{\pi d^{2}} \quad \text { and } \quad \sigma^{s}=\frac{4 F_{c}^{s}}{\pi d^{2}}
$$

Realistic values of the tensile and shear strengths for cohesive snow can be found in the 
literature [Gaume et al., 2012; Jamieson and Johnston, 1990, 2001; Mellor, 1974] and belong to the range $[0 \mathrm{kPa} ; 5 \mathrm{kPa}]$.

Furthermore, following Rognon et al. [2008b] different dimensionless numbers are used to quantify the intensity of the inter-particle strength. These numbers compare the contact bond tensile strength $F_{c}^{t}$ and the sintering (new bond) force $F_{c}^{s i}$ to two typical forces of the system. The first number $B o_{\text {coll }}$ (bond strength number) characterizes the survival potential of a bond after a collision due to the cataracting regime of the tumbler:

$$
B o_{\text {coll }}=\frac{F_{c}^{t}}{\sqrt{m_{p} k_{n}}\langle v\rangle},
$$

where $m_{p}$ is the particle mass and $\langle\nu\rangle=\left\langle R_{p}\right\rangle \omega$ the average particle velocity $\left(\left\langle R_{p}\right\rangle\right.$ is the average particle radial position). The bond strength number thus compares $F_{c}^{t}$ to the impact force of an elastic body. This number is nevertheless different from that used in Rognon et al. [2008b] for a gravitational shear flow which compares $F_{c}^{t}$ to the gravitational force $m g$. In our case, the main source of granule breakage are granule collisions, so our bond strength number was modified accordingly.

The second number $S i_{p}$ (sintering number) characterizes the potential of creation of a new bond inside a granular assembly submitted to a pressure $P$ :

$$
S i_{p}=\frac{F_{c}^{S i}}{P d^{2}}
$$

This number compares $F_{c}^{s i}$ to the average normal force $P d^{2}$ due to pressure. According to this definition and to Rognon et al. [2008b], a transition between different cohesive flow regimes should depend on these two numbers $B o_{c o l l}$ and $S i_{p}$ and should occur for values close to unity. In our study, $F_{c}^{t}$ was varied between 0 and $0.05 \mathrm{~N}$ and $F_{c}^{s i}$ between 0 and $1 \mathrm{~N}$. The collisional force is equal to $\sqrt{m_{p} k_{n}} v \approx 0.023 \mathrm{~N}\left(\left\langle R_{p}\right\rangle \approx 0.2\right)$ and the average pressure force is equal to $P d^{2} \approx 0.027 \mathrm{~N}$ by taking $P=1 / 2 \rho v^{2}$ the pressure due to the blades which is higher than the hydrostatic pressure in this case. Consequently, the bond strength number $B o_{\text {coll }}$ varies in the range $0-2.2$ and the sintering number $S i_{p}$ in the range $0-40$.

\section{Simulation procedure}

Simulations were performed for 6 different values of $F_{c}^{t}$ and 15 of $F_{c}^{S i}$ (and thus different values of $B o_{c o l l}$ and $S i_{p}$ ) for a total of 90 simulations. At the beginning of each simulation cohesion is applied to the whole sample so it forms a single large block similar to a cohesive slab in the release zone of an avalanche. The simulations were stopped after 30 revolutions, corresponding to an apparent steady state (almost constant size distribution). At each quarter 
revolution, the size of all the granules, defined as a granular assembly linked by cohesive bonds, was computed. As the granules may not be perfectly circular, the maximum transverse length was retained, similarly to what was measured experimentally. Hence, for each simulation, the complete granules size distribution was available as a function of time. In addition to the granules size, the average number of cohesive bonds per granule was computed.

\subsection{Results}

In this section we discuss the measured snow cover parameters and their temporal evolution during the experiments and identify the most relevant parameters for the granulation process (Section 4.3.1). Depending on the persistence of the formed granules all conducted experiments are then assigned to three granulation classes (Section 4.3.2). This classification also provides the basis for the discrete element model simulations which supplement the measurements (Section 4.3.3). We summarize the main results of experiments and modeling in Table 4.3 and finally present a combined view of experimental, modeled and real-scale avalanche size distributions (Section 4.3.4).

\subsubsection{Evolution of snow parameters}

The following graphs (e.g. Figure 4.7) display all individual experiments (gray lines), the time of each measurement (gray and colored markers) and whether non-persistent (gray circles), persistent-moist (colored squares) or persistent-wet (colored triangles) granules were recorded.

Most experiments were initialized with a snow density between $200-350 \mathrm{~kg} \mathrm{~m}^{-3}$ (Figure 4.7). Densities of persistent granules reached similar values as observed in the deposition of real-scale avalanches $\left(400 \mathrm{kgm}^{-3}\right)$. Densities larger than $550 \mathrm{~kg} \mathrm{~m}^{-3}$ were only observed for persistent-wet granules. For the slush experiment (snow density of $951 \mathrm{~kg} \mathrm{~m}^{-3}$ ) water was added after persistent-wet granules had formed. In many experiments with no persistent granulation the density of the remaining fine, ungranulated snow also reached values up to $450 \mathrm{kgm}^{-3}$.

A strong dependency of granulation on snow temperature could be observed (Figure 4.8) Once a temperature of $-1^{\circ} \mathrm{C}$ was reached, granulation occurred very fast (colored markers in Figure 4.8). Multiple experiments below the threshold of $-1^{\circ} \mathrm{C}$ were run for an extensive duration (more than 100 minutes), yet no persistent granules could be observed (gray circles in Figure 4.8).

Following the classification of Fierz et al. [2009] water could neither be recognized by eye nor by magnification for persistent-moist granules yet the snow showed a distinct tendency to stick together (Figure 4.9). Liquid water was only observed for persistent-wet granules. Most experiments with non persistent granules could be observed for dry snow conditions. Even though many persistent-moist experiments were at or close to $0^{\circ} \mathrm{C}$ they never reached the wet 


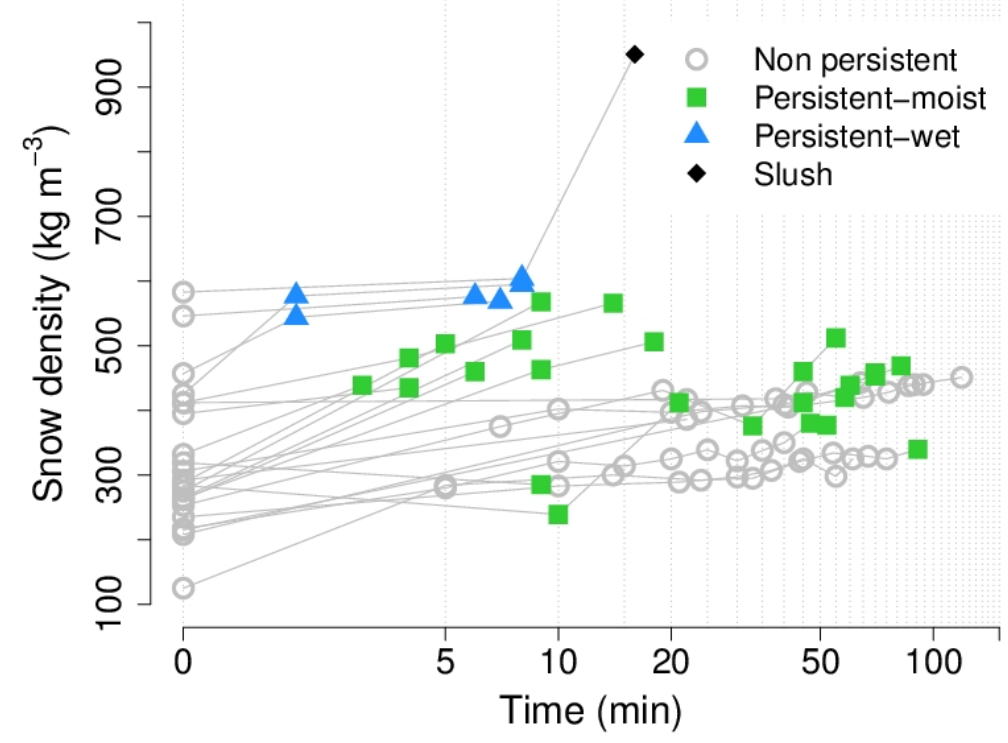

Figure 4.7: Snow density measurements (bulk density from $100 \mathrm{~cm}^{3}$ shovel) for all individual experiments (gray lines) and time of each measurement (gray and colored markers) for persistent-moist (colored squares) and persistent-wet (colored triangles) granules.

class. Persistent-wet granulation only occurred if the initial snow was already wet or water was added to the tumbler.

For most experiments with persistent granules the hardness (Figure 4.10) increased to pencil or knife [Fierz et al., 2009] in short time and the granules did not break apart anymore at this stage upon collisions inside the tumbler. In many cases persistent-wet granules were softer then persistent-moist granules. Less hard granules usually were not persistent and got destroyed by consequent rotations of the tumbler (see videos in supplementary material).

No distinct correlation between grainsize and granulation potential could be observed (Figure 4.11). Generally no large variations in grainsize during the experiments could be observed. Persistent-wet granules showed larger grainsizes since the initial snow in those cases contained mostly large melt forms.

Persistent-wet granules were only observed when melt forms were used as initial snow (Figure 4.12). No significant rounding or changing to melt forms due to friction of crystals could be observed. Decomposed forms that were rapidly mechanically transformed to rounded grains were most efficient to create persistent-moist granules. However, melt forms also resulted in persistent-moist granules in some cases.

\subsubsection{Granulation classification}

Out of all conducted tumbler experiments, 4 experiments developed no persistent granules (Figure 4.4a), in 15 experiments persistent-moist granules formed (Figure 4.4b) and in 3 


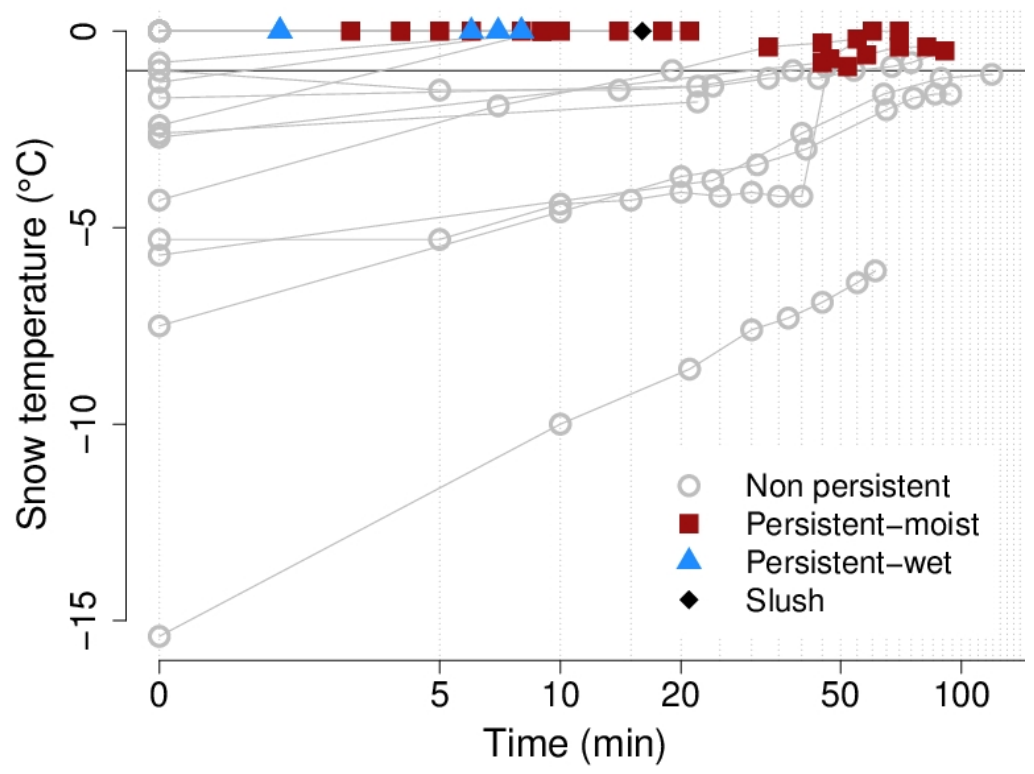

Figure 4.8: Snow temperature measurements for all individual experiments (gray lines) and time of each measurement (gray and colored markers) for persistent-moist (colored squares) and persistent-wet (colored triangles) granules.

experiments persistent-wet granules were observed (Figure 4.4c). For 1 experiment liquid water was added to the tumbler to create a slushy flow. The snow or granules that formed inside the tumbler are classified depending on their properties and snow cover parameters:

Non persistent granules easily broke upon collisions and always occurred for experiments with snow temperatures below $-1^{\circ} \mathrm{C}$ and dry snow conditions.

Persistent-moist granules were very hard and even resisted direct impacts on the mixing blades (see videos). They started to form as soon as the snow temperature exceeded $-1^{\circ} \mathrm{C}$ and the snow was dry to moist.

Persistent-wet granules were softer and deformed upon impacts. The snow was at $0^{\circ} \mathrm{C}$, liquid water could be observed at $8 \mathrm{x}$ magnification and the snow had a clear tendency to stick together but the formed granules often broke apart again.

Slush experiments did not show distinct granules and the snow behaved similar to a pasty flow inside the tumbler. A significant amount of liquid water was present and in many cases the snow was soaked.

The granulation process for persistent-moist granules was observed to take places in two stages. As soon as the temperature threshold of $-1^{\circ} \mathrm{C}$ was reached individual granules (Figure 4.13a) were observed to grow until a size of approximately 1 to $4 \mathrm{~cm}$. For most experiments these initial granules also rapidly densified (Figure 4.7) and increased in hardness (Figure 4.10). In a second stage these individual granules started to form larger agglomerates (Figure 


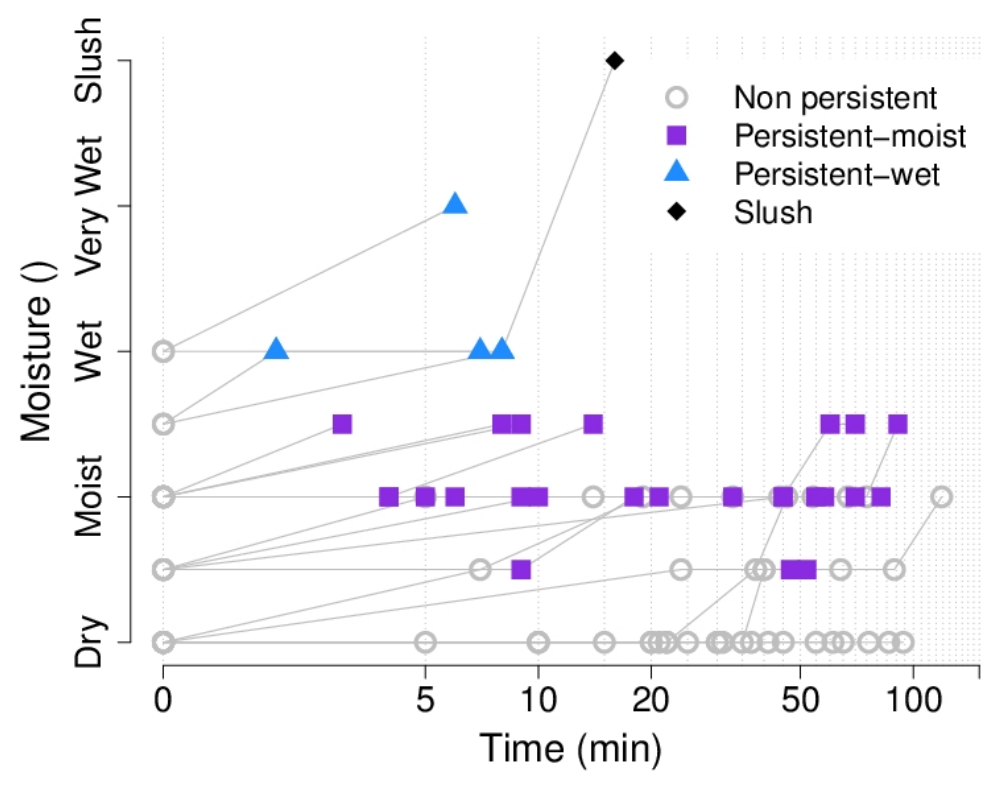

Figure 4.9: Snow moisture measurements for all individual experiments (gray lines) and time of each measurement (gray and colored markers) for persistent-moist (colored squares) and persistent-wet (colored triangles) granules.

4.13b). At the final stage of granulation for moist experiments a mixture of individual granules, agglomerates and left-over fine material existed inside the tumbler.

Depending whether persistent-moist or persistent-wet granules were created, significant differences in the collisions between individual granules could be observed (see slow-motion videos supplementary material). The videos show that the granules are lifted and consequently collide with the outer wall of the tumbler, other granules or the blades after falling the entire diameter of the tumbler. Moist granules showed a much more elastic behavior whereas the interpenetration upon collision for wet granules was much higher and inelastic. This indicates a very different energy dissipation depending on the granule type (Further discussed in Section 4.4). Non persistent granules were usually destroyed and completely fragmented at every rotation of the tumbler. For persistent-moist granules a localized disintegration [Subero and Ghadiri, 2001], i.e. the damage is restricted to the impact area, was observed. Those granules were only destroyed if they were dropped from 1-2 $\mathrm{m}$ on the concrete floor. In those cases they showed a semi-brittle behavior [Cheong et al., 2005], i.e. the fracture is preceded by limited plastic deformation. Persistent-wet granules showed a ductile behavior.

\subsubsection{Numerical results}

The conducted DE simulations allow to discuss the different, observed granulation classes and relevant snow parameters (Section 4.3.1) in more detail with respect to the determining physical processes, i.e. cohesion and sintering. The discussion (Table 4.3) is necessary since brittle failure of the bond at the microscopic scale in combination with sintering may lead to 


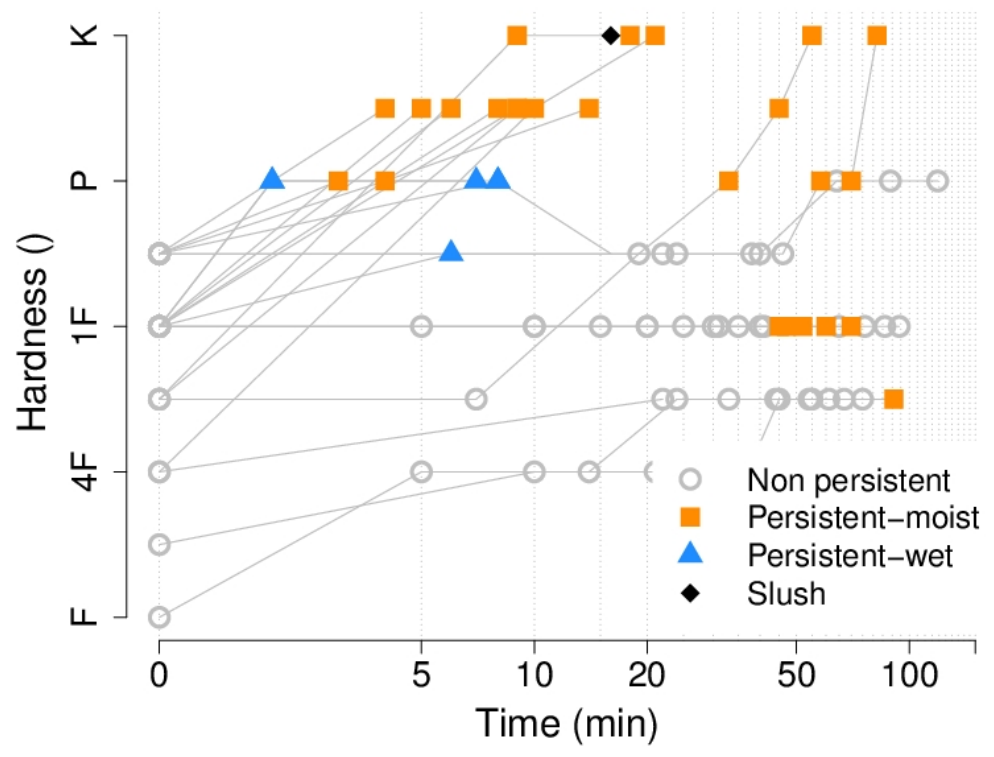

Figure 4.10: Hardness measurements for all individual experiments (gray lines) and time of each measurement (gray and colored markers) for persistent-moist (colored squares) and persistent-wet (colored triangles) granules.

macroscopic ductile behavior of the granules.

Figure 4.14 represents the average granule radius $\left\langle r_{g}\right\rangle$ as a function of the two dimensionless numbers $B o_{\text {coll }}$ and $S i_{p}$ at the end of the simulation. The simulated range of bond strengths and sintering numbers allows to observe average granule radii ranging from almost zero the particle radius $\left.r_{p}=2.25 \times 10^{-3} \mathrm{~mm}\right)$ to the radius of the tumbler $(R=30 \mathrm{~cm})$ corresponding to one single large granule.

If the sintering number $S i_{p}$ is high enough, typically higher than 5 , then only the bond strength number has an influence on the granules size distribution. In this case, the force required to create a new bond is too high compared to the force due to pressure. Hence, the only possible process is the breakage of the existing bonds due to possible dynamic collisions. In this regime $\left(S i_{p}>5\right)$ and for $B o_{c o l l}<1$ (zone A) the average granule radius $\left\langle r_{g}\right\rangle$ is approximately equal to the particle radius $r_{p}$. The bond strength is then not high enough to resist the dynamic collisions imposed by the system and thus no granules persists. If the bond strength increases so that the bond strength number $B o_{\text {coll }}$ becomes higher than 1 (zone B), then some persistent granules appear. The average granule radius therefore increases with increasing strength. Note also that for $B o_{\text {coll }}>4$ (not represented on the diagram), the cohesive bonds never break leading to one single and large granule whose radius is a little bit lower than the tumbler radius $\left(r_{g} \approx 28 \mathrm{~cm}\right)$.

For $S i_{p}<1$, the evolution of the average granule size with $S i_{p}$ and $B o_{\text {coll }}$ becomes more complex. For constant values of the bond strength number, the average granule radius $\left\langle r_{g}\right\rangle$ increases with decreasing sintering number $S i_{p}$ (Figure 4.14 and top panel) up to the tumbler 


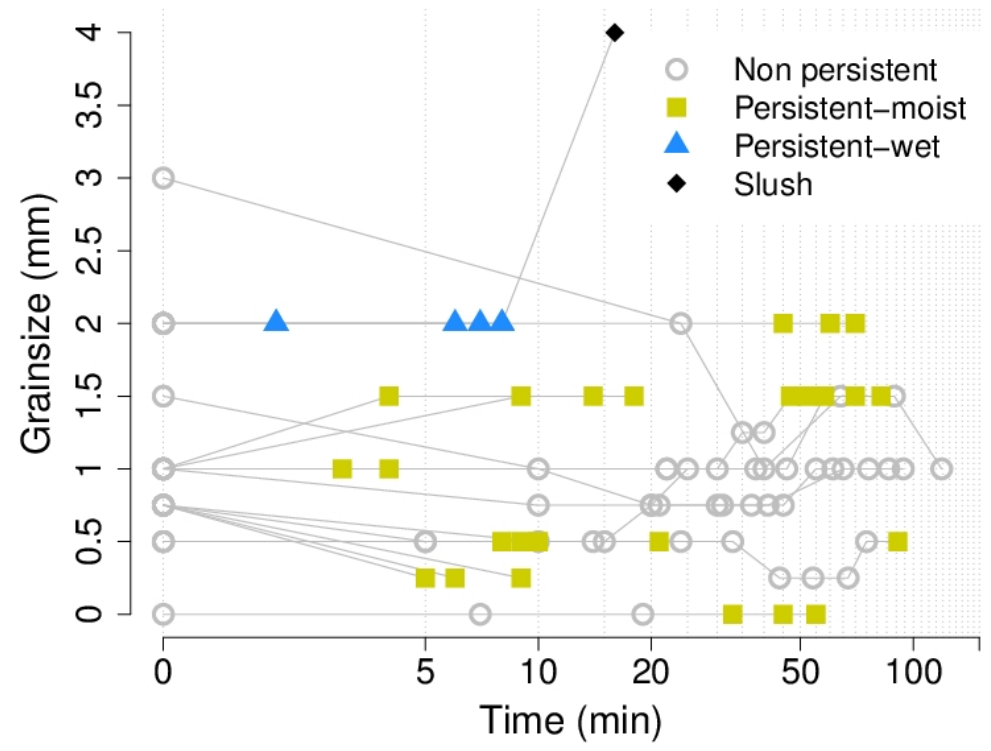

Figure 4.11: Grainsize measurements for all individual experiments (gray lines) and time of each measurement (gray and colored markers) for persistent-moist (colored squares) and persistent-wet (colored triangles) granules.

radius. The rate of change of $\left\langle r_{g}\right\rangle$ with $S i_{p}$ is independent of $B o_{\text {coll }}$. The average granule size strongly depends on the bond strength number $B o_{\text {coll }}$, lower values corresponding to lower granule sizes (Figure 4.14 and right panel). Hence, for $S i_{p}<1$ a competition between bond creation and breakage determines the average granules size. Inside the zones delimited by dashed lines (corresponding to $0.5<B o_{\text {coll }} / S i_{p}<2$, zones C and D) on Figure 4.14 , the average granule size is a linear function of the ratio between the bond strength number and the sintering number:

$$
\left\langle r_{g}\right\rangle \approx 12\left(\frac{B o_{\text {coll }}}{S i_{p}}\right)^{4 / 3}
$$

If $B o_{\text {coll }} / S i_{p}<0.5$ then the average granule radius depends only on the bond strength number as detailed before. The difference between zone $\mathrm{C}$ and zone $\mathrm{D}$ is therefore linked to the strength of the granules, stronger in $\mathrm{C}$ and weaker in $\mathrm{D}$ but leading to the same granules sizes. On the other hand, if $B o_{c o l l} / S i_{p}>2$ then the average granule radius is equal to the tumbler radius which is the limiting size of the system. Hence, zone F corresponds to a regime with a unique strong (high bond strength number) and large granule whereas zone E corresponds to a pasty-like flow regime in which new bonds are created at each contact point every time step but whose strength is very small.

The model results were added to the experimentally defined granulation classes in Table 4.3. Videos of the simulations are provided as supplementary material for the four main 


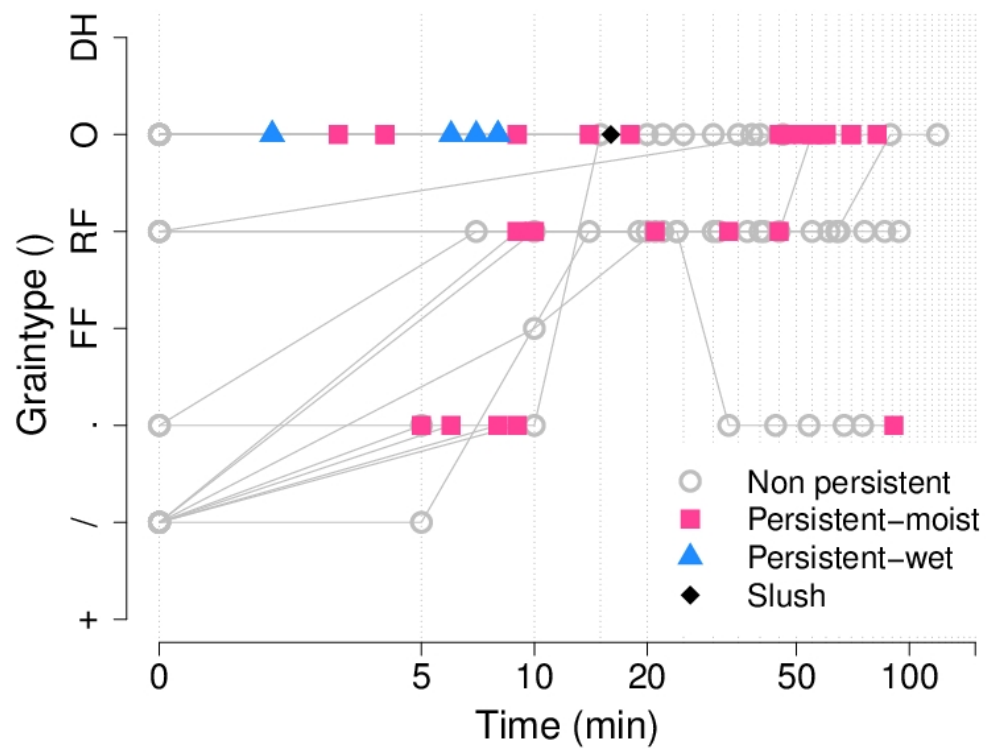

Figure 4.12: Graintype measurements for all individual experiments (gray lines) and time of each measurement (gray and colored markers) for persistent-moist (colored squares) and persistent-wet (colored triangles) granules.

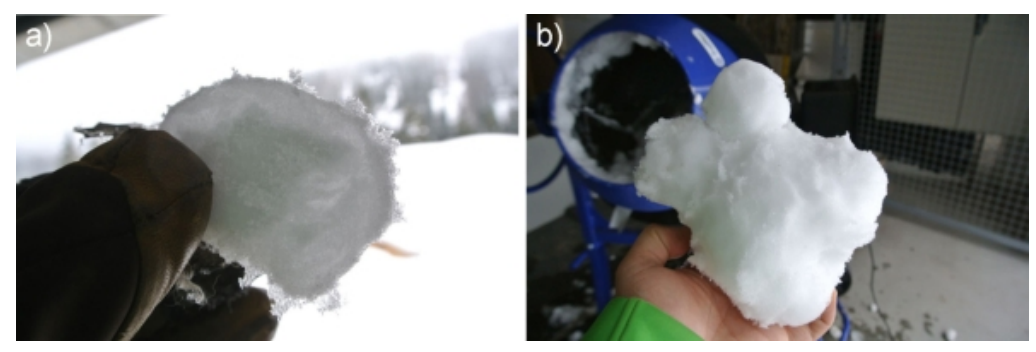

Figure 4.13: Persistent-moist granules at a very initial stage (a) and agglomerates of multiple individual granules (b) at the end of the experiment.

granulation regimes (non-persistent, persistent-moist, persistent-wet, slush).

\subsubsection{Granule size distribution}

Eventually, a stationary state is reached where there is a balance between collisions, which dislodge particles and those which add particles to them [Kapur, 1971; Walker, 2007]. At this point, a stable granule size distribution is attained.

Figure 4.15 compares the granule size distributions for two tumbler experiments, persistentmoist (violet filled circles) and persistent-wet (filled green squares), the corresponding DE simulations (violet and green lines) and a distribution as observed in avalanche deposits (blue triangles) (see Steinkogler et al. [2014c] for more information on the real-scale avalanches). Note that for the sake of the comparison with experiments the lowest values of granule sizes 


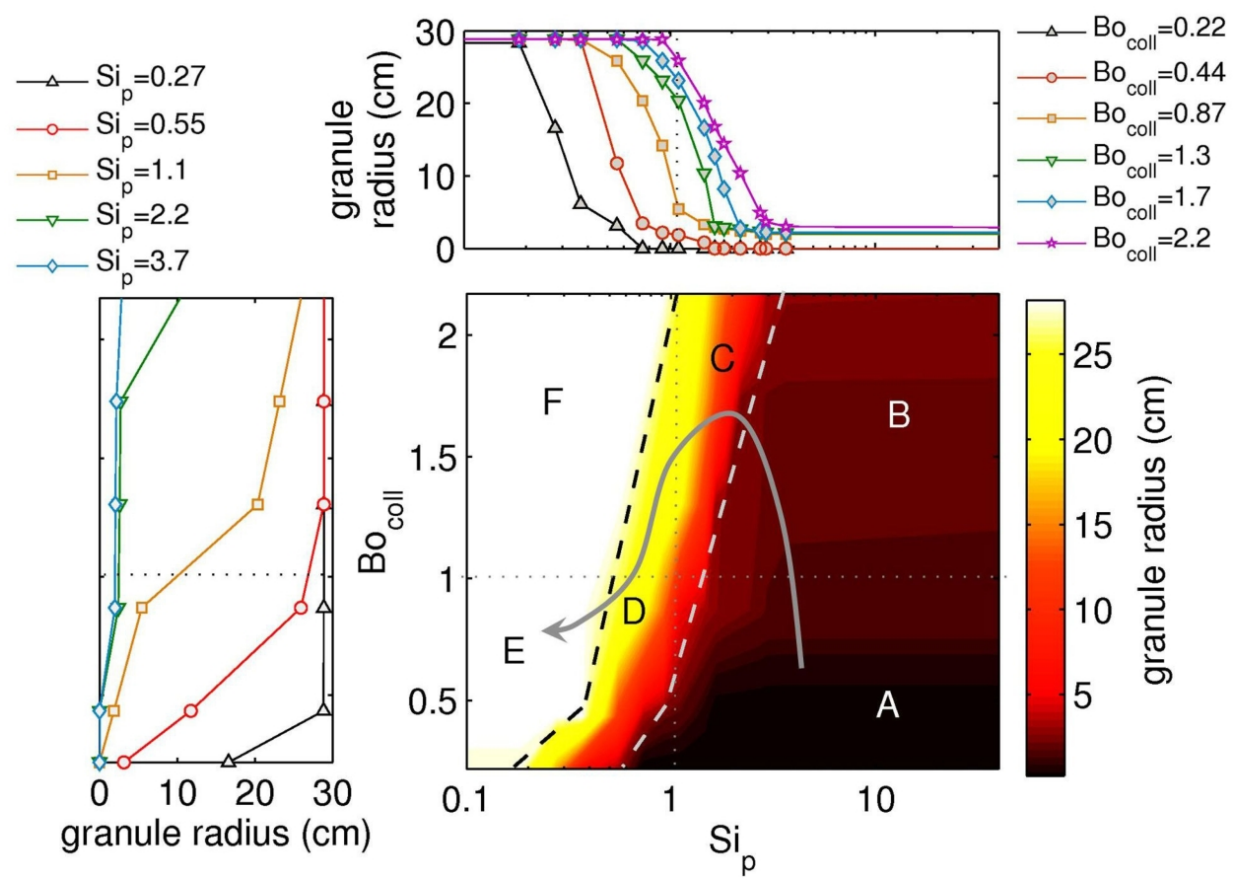

Figure 4.14: Contour plot of the granule radius as a function of bond strength number $B o_{\text {coll }}$ and sintering number $S i_{p}$ showing the different granulation regimes. Zone A: No granules, zone B: granules due to breakage, zone C: persistent-moist granules, zone D: persistent-wet granules, zone E: slush (or pasty flow) and zone F: one large granule. The domain between the dashed lines corresponds to $0.5<B o_{\text {coll }} / S i_{p}<2$. The gray curved arrow represents a qualitative path of snow temperature and liquid water content increase.

were excluded to compute the size distribution. Indeed, experimentally the very fine particles could not be measured. Hence for size distributions obtained through DE, only granule sizes larger than the smallest size observed experimentally were retained explaining the sharp tail in Figure 4.15.

The granule size showed a typical log-normal distribution [Bartelt and McArdell, 2009], although with a shift towards smaller granule sizes compared to real-scale avalanches and the DE model results are in good agreement with the measurements.

\subsection{Discussion}

The present approach (cf. summary in Table 4.3) suggest that granulation, as observed in natural avalanches can be reproduced and studied within concrete tumbler experiments and cohesive discrete element modeling. In the following we first discuss the main effects during snow granule formation (Section 4.4.1-4.4.5) and address the limitations of our experimental and model setup (Section 4.4.6). Finally we turn to the application of our results and discuss possible implications for flow dynamics (Section 4.4.7). 
Table 4.3: Summary of experiments and discrete element modeling.

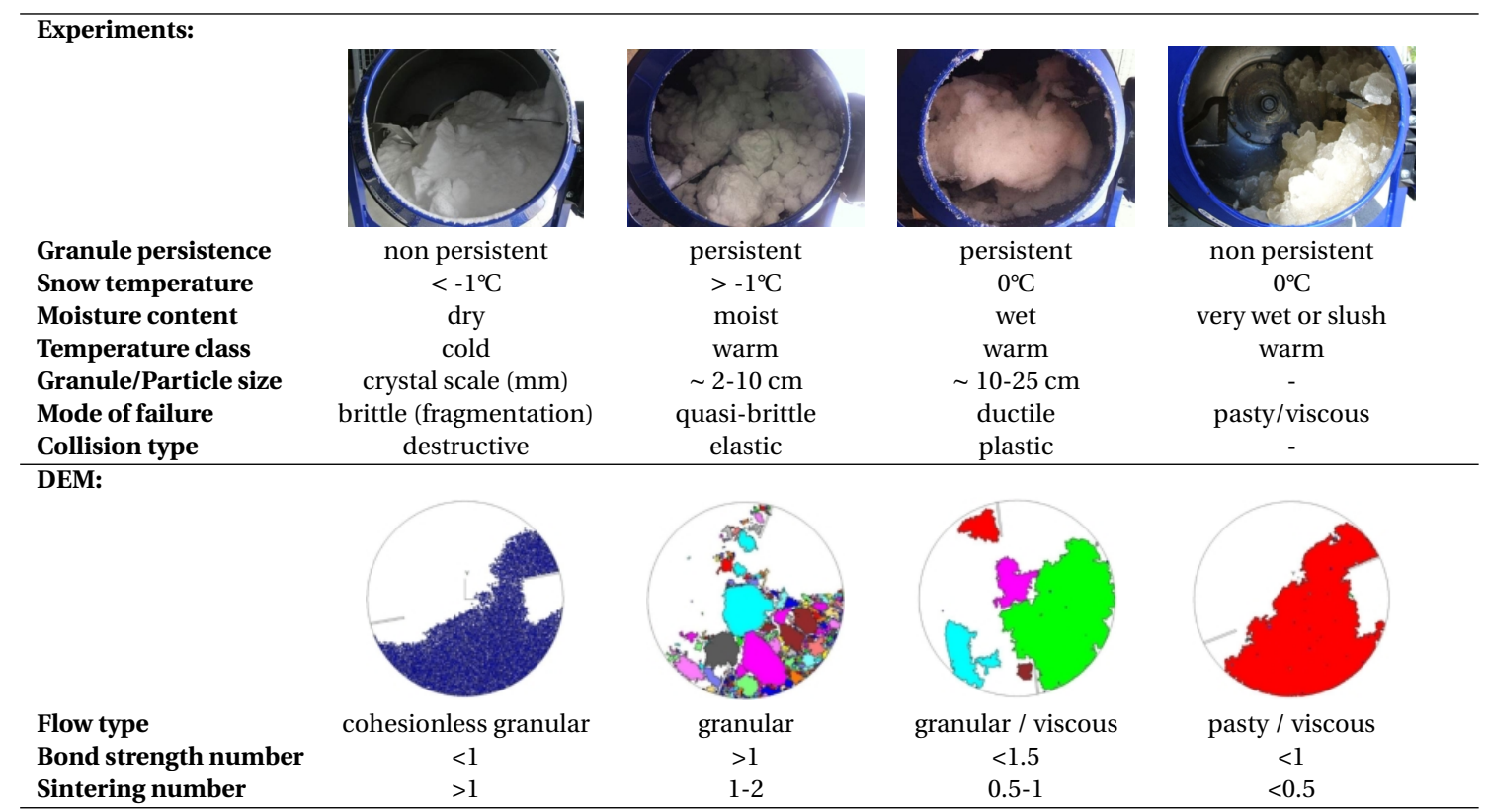

\subsubsection{Granulation process}

For the discussion it is illustrative to recap the phenomenology and main mechanisms underlying the snow granulation process. The main features are well described in literature for other examples [Hapgood et al., 2007; Iveson et al., 2001]. From the initial ensemble of constituent snow "particles", larger granules form and grow due to the presence of attractive, i.e. cohesive forces between the particles. The original, fine-grained snow (Figure 4.13a) agglomerates upon collision of two or multiple granules which stick together to form a single large granule (Figure 4.13b). Once formed, granules may consolidate during the collision by mechanical compaction or may likewise fragment again if the overall strength of the granule is too small. Energy is continuously supplied to the system via the rotation of the tumbler. The mechanical input is determined by the tumbler frequency which is constant in our experiments and simulations. Overall, the emergence, stability and size characteristics of the granule system is the result of a competition between agglomeration and fragmentation of snow particles upon collision.

\subsubsection{Main results}

As a main experimental result we found that the emergence of granules occurs at a distinct temperature threshold of $-1^{\circ} \mathrm{C}$ (Figure 4.8). In all cases we observed an abrupt change and a transition from non-persistent to persistent granule types (Table 4.3) while all other measured snow parameters, like density, hardness evolve in a continuous, monotonic manner. Although the densities are similar for all cases (Figure 4.7), our results show that granules vary in strength which are used as a main classification criterion (Table 4.3). The high-speed videos 


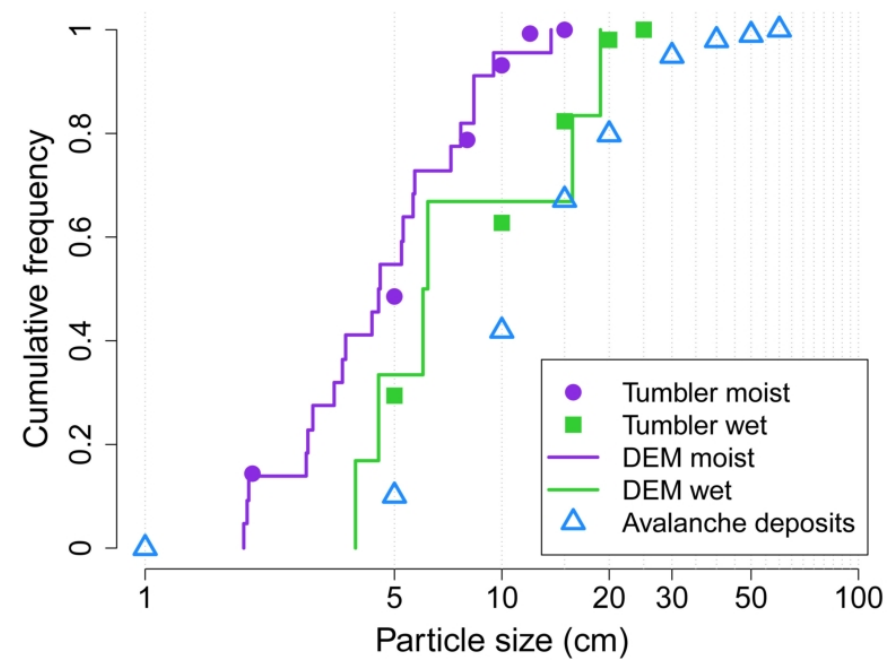

Figure 4.15: Granule size distributions conducted for selected tumbler experiments, persistentmoist (violet filled circles) and persistent-wet (filled green squares), DE simulations (violet and green lines) and in the deposition area of an artificially released avalanche (blue triangles).

(supplementary material) allow for a qualitative interpretation of the strength of the granules and are in agreement with multiple studies on breakage patters of agglomerates [Mishra and Thornton, 2001]. Granule strengths range from soft and non-persistent, which fracture completely upon touching or particle collisions, to very hard and persistent-moist granules which even resist the impact on the sharp side of the blade inside the tumbler.

From a modeling perspective it is unfeasible to couple the temperature evolution to the granular flow. Our results suggest that this is not even required to capture the main mechanisms. We have set-up a DE model and solely varied the probability of establishing a cohesive bond and the strength of these (Figure 4.14). In the following we will address the expected role of temperature on the physical interactions in the real system and their translation to the parameters of the DEM approach. Given a threshold of $-1^{\circ} \mathrm{C}$ and the additional introduction of water in some cases we are dealing with both types of forces, dry cohesive forces which are mediated by fast sintering processes [Szabo and Schneebeli, 2007] and wet cohesive forces mediated by the presence of liquid bridges and capillary effects [Mitarai and Nori, 2006].

\subsubsection{Dry cohesion}

For dry cohesion, the attractive forces by fast sintering processes [Szabo and Schneebeli, 2007] are known to be temperature dependent. The "pull-off" force of an ice-ice contact after a certain contact time shows a monotonic increase with temperature. For dry cohesion alone, a temperature increase can be directly translated to a strong increase of the bond strength number and a decrease of the sintering number in the simulations. Sintering becomes particularly fast close to the melting point, potentially due to the onset of surface melting and the emergence of a quasi-liquid layer [Dash et al., 2006]. We also observe a pronounced effect 
and the most distinct persistent-moist granulation close to $0^{\circ} \mathrm{C}$.

Concerning fragmentation in the dry case, Subero and Ghadiri [2001] noted that the fracture of agglomerates (Figure 4.13b) is more complicated than that of their homogeneous counterpart. The fracture of homogeneous snow is yet not fully understood [Sigrist et al., 2005]. For agglomerates, the strength of an agglomerate is expected to depend on the bonding mechanism as discussed by [Mishra and Thornton, 2001]. Indeed, the densification during tumbler rotation (Figure 4.7) plays a role since fracture toughness of snow depends on density [Bazant et al., 2003; McClung, 2009]. Hapgood et al. [2007] observed that the extent of consolidation depends on the intensity of agitation in the tumbler and resistance of the granule to deformation. This can also be observed in our experiments as snow that was initially soft, e.g. hardness class 1 finger, granulated into consolidated granules with a hardness of knife (Figure 4.10) and also rapidly densified (Figure 4.7). The increase of temperature should tend to shift the mechanical behavior of the agglomerates from ductile to brittle. The rate of the deformations should be controlled by the typical velocities of the particles. Typical velocities are, in turn, controlled by the tumbler frequency which is left constant in the present approach.

\subsubsection{Wet cohesion}

Effects of dry cohesion might be masked by capillary effects close to the melting point. As soon as a temperature reaches $0^{\circ} \mathrm{C}$ the amount of liquid water clearly dominates the formation and properties of the granules. Note that we only measured liquid water content by traditional methods (Figure 4.9). Since the system is not in thermal equilibrium, it possible that small amounts of liquid water are present which are not detected. Thus capillary effects may become important. In particular for the class of persistent-wet granulation (Table 4.3) the presence of liquid water and capillary forces play an important role. For the wet case, the temperature dependence of the cohesion is different from the dry case. The attractive force of a single capillary bridge of liquid water will hardly be influenced by temperature, since the relevant parameter, namely the surface energy of water, shows only a weak temperature dependence in that regime [Pruppacher and Klett, 1997]. However, the temperature influences the amount of liquid water and thus the number of capillary bonds. The snow granules then display the full non-monotonic behavior of the mechanical stability of a wet granular assembly, which is a non-monotonic function of water content (cf. Mitarai and Nori [2006, and references therein]). Initially the strength increases with increasing water content and then sharply decreases. If the material becomes fully saturated, the strength vanishes. Only the presence of small amounts of a wetting liquid, which is the case for our persistent-wet regime, can dramatically change granule properties [Hornbaker et al., 1997; Mitarai and Nori, 2006; Nowak et al., 2005; Schiffer, 2005]. 


\subsubsection{Translation to DEM and phase diagram}

In the presented DE simulations a new bond is created and two particles become an agglomerated cluster, if the contact force between two particles exceeds a threshold. This is controlled by the sintering criterion. On the other hand if the normal (or shear) force exceeds the tensile (or shear) bond strength, the bond does not persist. The DEM model contains two different dimensionless parameters, the sintering and strength of the bonds (Section 4.2.2), which mimics the main physical ingredients of temperature and liquid water content. As a consequence, we find that the main "phases" of the flow can be represented by the "phase diagram" (Figure 4.14). The regions in the diagram correspond to the observed classes in our experiments (Section 4.3.2)

\section{Non persistent granules (Zone A):}

In the experiment the snow was always below $-1^{\circ} \mathrm{C}$ and dry and the formed non-persistent granules easily broke upon collisions. This resulted in a cohesionless granuler flow inside the tumbler. The DE simulations reproduce this behavior in zone A (Figure 4.14) where the formation of new bonds is not very likely, i.e. $S i_{p}>1$ and the bond strength is too small to sustain the collisions imposed by the system, i.e. $B o_{\text {coll }}<1$.

In zone B granules are only the result of a breakage process $\left(B o_{\text {coll }}>1\right.$ and $\left.S i_{p}>1\right)$ which was not observed in the tumbler experiments since in those cases the snow was already fragmented by the process of shoveling into the tumbler. Yet, this is similar to observations in dry, cold avalanche where granular structures in the deposits are remaining parts of the slab and the eroded snow cover.

Persistent-moist granules (Zone C): As soon as the temperature threshold of $-1^{\circ} \mathrm{C}$ was reached and the snow was observed to be dry to moist, hard granules formed. Szabo and Schneebeli [2007] noted that the impact between two ice particles can cause the temporary melting of the interfacial region, thus possibly explaining the threshold for granulation to be already at $-1^{\circ} \mathrm{C}$. The DE simulations (Figure 4.14) indicate that the bond strength number $B o_{\text {coll }}$ needs to be larger than 1, i.e. the granules resist collisions, and the sintering number $S i_{p}$ to be between 1 and 2 , i.e. allowing a slight growth, to ultimately facilitate the formation of persistent-moist granules (zone C). It is worth noting that the measured maximum snow densities in this around $450 \mathrm{~kg} \mathrm{~m}^{-3}$ are very similar to the ones observed in the deposition area of real-scale avalanches [Sovilla et al., 2007]. This indicates that the formation of granules in general and the observed maximum densities are defined by the snow properties itself and not due to pressure or forces inside an avalanche.

Persistent-wet granules (Zone D): As the snow reached $0^{\circ} \mathrm{C}$ and was observed to be wet to very wet the formed granules were softer and deformed or broke upon impacts. To obtain a persistent-wet granulation regime (zone D) with the DE simulations, the bond strength number $B o_{\text {coll }}$ needs to lower than 1.5, i.e. breakage through collisions can occur but due to the lower sintering number $S i_{p}(0.5-1)$ new bonds are easily formed, ensuring large granule sizes but a lower strength than for persistent-moist granules (zone $\mathrm{C}$ ). 
Slush (Zone E): The snow is at $0^{\circ} \mathrm{C}$ and saturated with water. Instead of granules a pasty-like (viscous) flow was observed. In this case the sintering number is very low, $S i_{p}<0.5$, causing the particles to bond almost at every time step. However, the bond strength number being also low, $B o_{\text {coll }}<1$, these bonds immediately break again leading to complex interactions and the observed pasty-like flow.

Upon temperature increase and the associated increase of liquid water content we expect to transit from a cold and dry regime (zone A and B), to a persistent-moist regime with a maximum granule strength (zone C), to a persistent-wet regime (zone D) and finally to a slushy and water saturated regime (zone E) with a very low strength. This should correspond to a path in parameter space which is qualitatively represented by the gray line in Figure 4.14. The abrupt transition from non-persistent to persistent granules observed in the experiments at a certain temperature should roughly correspond to the sharp transition on that path when crossing the phase boundary in $S i_{p}-B o_{\text {coll }}$ parameter space.

The geometry of the tumbler with the blades seem to be an unnecessary complication for the DEM approach, which is clearly absent in real avalanches. The blades are required to promote granular mixing. The inclusion of the geometry in the simulation is facilitated by the dimensional analysis of the DEM model (Section 4.2.2) which allows to simulate realistic parameter regimes, even by explicitly including the geometry and blades in the tumbler. This enables a direct comparison of the simulation with the experiments. Even though some relevant, qualitative features of the granulation process are well captured by the DEM model, some experimental and model limitations must be acknowledged.

\subsubsection{Limitations of experimental and modeling setup}

One of the main shortcomings of the experimental setup is the limited control of heat supply to the system. This prevents us to detect potential temperature increase by internal friction. An improved experimental setup should envisage thermal insulation of the tumbler, potentially with a controlled heat flux to vary the temperature. Thereby a lumped capacitance analysis should be able to indicate effects from internal heating. When approaching $0^{\circ} \mathrm{C}$, precise measurements of the liquid water content will be important to discern effects of liquid and dry cohesion in the granular system. An additional helpful modification of the tumbler would be a less "singular" geometry of the mixing elements to avoid the cutting impact of the blades on the granules.

While our experiments have thus far provided a broad overview about the influence of various quantities, future experiments should focus on dedicated parameter studies. A crucial parameter which could be easily varied is the tumbler frequency which influences collision rates, contact times and breakage probabilities.

To further constrain the parameters of the model, the visco-elastic properties of the granules and the strength of the bonds needs to be known. A large body of experimental work on the 
static strength of liquid-bound granules [Iveson et al., 2001] already exists. These have been measured either by direct tensile tests or uniaxial compression tests where the granule or compact is assumed to fail due to tensile stress. Also the mechanical response of agglomerates at high and low strain rates [Cheong et al., 2005] has not been investigated yet. Schubert [1977] has described the different methods available to measure the strength of moist agglomerates. There are two main parameters of interest that are usually reported: peak yield stress and the maximum strain before brittle failure. At least bounds on mechanical properties could be easily obtained by including mechanical tests of the snow before and after granule formation at the beginning and end of the experiment.

On the modeling side, the process of granule growth in the simulation always starts from agglomerating constituent particles. The initial particles with size $(d=4.5 \mathrm{~mm})$ must be already regarded as as small granules (Figure 4.13). Using smaller sizes of $<1 \mathrm{~mm}$, similar to realistic snow grains, would however require considerable computational effort. So the effect of using different initial conditions in the simulation remains to be addressed in the future. Furthermore, the time-dependence of the sintering force and the strength as observed in Podolskiy et al. [2014]; Szabo and Schneebeli [2007] as well as densification effects are not accounted for in our model, but might affect the persistency and the strength of the granules due to progressive consolidation.

Being aware of the present limitations of the approach, the observed differences in the properties of non-persistent and persistent granules are of relevance for flow dynamics since the macroscopic behavior of a granular material is determined by the nature of the interactions between the grains [Andreotti et al., 2013].

\subsubsection{Implications for flow dynamics}

Granulation can influence flow dynamics in two possible ways: by changing the size distribution of the flowing particles [Pouliquen, 1999] and by a change of their properties [Alexander et al., 2006; Rognon et al., 2008a].

Multiple studies [Andreotti et al., 2013; Moro et al., 2010; Phillips et al., 2006] show that the size distribution can fundamentally affect the flow dynamics. Our results show that the granule size distribution is determined by snow cover properties. For avalanches consisting of cold snow, i.e. $<-1^{\circ} \mathrm{C}$, a fine-grained structure with non-persistent granules can be expected. Even though granular structures are often observed in the deposit of avalanches in this temperature range [Bartelt and McArdell, 2009] these granules are likely to be fragments of the released or eroded snow cover (Figure 4.1). Furthermore, these observations are only performed on top of the surface of the deposits and only represent $10-20 \%$ of the overall flowing mass. Multiple studies [Andreotti et al., 2013; Moro et al., 2010; Phillips et al., 2006] show that the size distribution can fundamentally affect the flow dynamics. Our results show that the granule size distribution is defined by the snow cover properties. For avalanches consisting of cold snow, i.e. $<-1^{\circ} \mathrm{C}$, a fine-grained structure with non-persistent granules can be expected. Even 
though granular structures are often observed in the deposit of avalanches in this temperature range [Bartelt and McArdell, 2009] these granules are likely to be fragments of the released or eroded snow cover (Figure 4.1). Furthermore, these observations are only performed on top of the surface of the deposits and only represent $10-20 \%$ of the overall flowing mass.

On the contrary, we expect that avalanches consisting of warm snow, i.e. $>-1{ }^{\circ} \mathrm{C}$ and possibly containing liquid water, to consist entirely of persistent granules. Also Kobayashi et al. [2000] noted that the particle size distribution of snowballs in dry granulation was wider than that in wet agglomeration. This was also found in our study since both, tumbler experiments and DE simulations, showed much larger but less granules for persistent-wet experiments than for persistent-moist granules. Further, our results also suggest that in real scale avalanches segregation processes and the resulting levée/channel morphology [Bartelt et al., 2012b] in the deposition zone are processes which are mostly relevant for avalanches where the snow temperature is above $-1^{\circ} \mathrm{C}$.

The properties of the granules also significantly influence flow dynamics and define the flow regime of avalanches, e.g. whether a plug or a sheared flow forms. In real scale avalanches, these two flow regimes are found in warm and cold avalanches, respectively [Kern et al., 2010; Sovilla et al., 2008]. Full-scale warm snow avalanches measured at the Vallée de la Sionne field site in the Western Swiss Alps [Sovilla et al., 2008] are characterized by plug flow of several meters in depth and slide over a thin basal layer of snow grains. Our experiments suggest that the large values of cohesion and sintering acting inside and between granules when the snow temperature exceeds $-1^{\circ} \mathrm{C}$ enhance the resistance of particle to shear in analogy to granular experiments by Rognon et al. [2008a]. In contrast, dry and cold avalanches, which are expected to consist of non-persistent granules, fine grains without cohesion and/or remaining fragments of the released and eroded snow cover, typically develop a sheared flow.

Moreover, the different granular structures between wet and dry dense avalanches may also explain the significantly different pressures measured in the two flow typologies [Baroudi et al., 2011; Sovilla et al., 2010b]. Recently, it has been postulated that the pressure exerted by a wet-snow avalanche can be attributed to the formation and collapse of force-chain structures forming when the avalanche interact against an obstacle. Our results indicate that these chains seem to be more developed and persistent when the snow temperature rises above $-1^{\circ} \mathrm{C}$ and persistent granules form.

\subsection{Conclusions}

The granular properties, i.e. the size distribution and mechanical properties, significantly influence the flow dynamics of avalanches. It is therefore necessary to identify the determining factors which define the granulation process, i.e. the formation of particles larger than their initial size, of snow. In this study we present a simple, but promising experimental setup, along with discrete element simulations that successfully reproduced the different granule classes observed in the experiments and conclude that: 
a) granulation of snow is highly temperature dependent with a snow temperature threshold at $-1^{\circ} \mathrm{C}$. Below this temperature no persistent granules were observed. If the snow temperature exceeded $-1^{\circ} \mathrm{C}$ granulation occurred very fast and was most effective for new snow or decomposed forms close to $0^{\circ} \mathrm{C}$;

b) persistent granules can be further differentiated into moist or wet granules. These two (persistent) granule types showed significantly different mechanical properties upon collision;

c) granulation is only relevant for snow with a temperature warmer than $-1^{\circ} \mathrm{C}$ and therefore for warm or wet avalanches. At lower temperatures the potential for the formation of persistent granules is very low. Therefore, granular structures as often observed (at the surface) in the deposition zone of cold avalanches are more likely to be fragments of the released or eroded snow cover;

d) the presented modeling approach provides a first step towards more complex and realscale modeling of flowing cohesive snow with varying properties;

e) a quantification to which extent granulation and thus the granule size distribution depends on snow temperature is possible;

To gain a better understanding and link the effect of the snow cover on flow dynamics further interdisciplinary research is necessary. The main challenge will be to accurately define the linking processes between the microscopic (crystal) scale, e.g. sintering, the mesoscopic scale, e.g. energy dissipation during granule interaction, and the macroscopic scale, e.g. flow dynamics. To accurately model snow avalanches for different snow temperatures and consequently different flow dynamics [Vera et al., 2012], it is necessary to reproduce the temperature dependent granule size distribution as good as possible. Model calculations as shown in Section 4.2.2 represent a first approach in this direction.

\section{Acknowledgment}

Funding for this research has been provided through the Interreg project STRADA by the following partners: Amt für Wald Graubünden, Etat du Valais, ARPA Lombardia, ARPA Piemonte, Valle d'Aosta, Regione Lombardia. The data is available on request. 


\section{Overall summary and conclusions}

The main purpose of this dissertation was to improve the understanding of the influence of snow properties on avalanche dynamics. Real-scale avalanche data, laboratory experiments and numerical simulations offered valuable information on the involved processes, both in a qualitative and quantitative way, and allowed the definition of important thresholds. The three chapters presented in this thesis treat several individual topics to address this goal:

(1) identification of most relevant snow cover parameters influencing avalanche dynamics;

(2) quantification of thermal sources in snow avalanches and

(3) temperature dependency of granulation of snow.

In Chapter 2 [Steinkogler et al., 2014a] data on real-scale avalanches were used to identify snow cover properties which have most influence on flow dynamical parameters such as run-out distance and front velocity. To achieve the best possible comparability of the data, five avalanches with similar initial mass and topography, but varying flow dynamics were selected from the Vallée de la Sionne test site (Western Swiss Alps) database (Fig. 2.3). Due to the absence of complementary or representative manual snow cover observations, the snow stratigraphy was reconstructed for each of the investigated avalanches using the threedimensional surface process model Alpine3D and the snow cover model SNOWPACK (Fig. 2.5). The combination of SNOWPACK and Alpine3D allowed the reproduction of the variations in the snow cover due to the prevailing meteorological conditions and additionally to account for elevation-dependent gradients, e.g. of snow depth and snow temperature. The results illustrate the capability of Alpine3D/SNOWPACK to supplement and extend historical avalanche data sets with snow cover information, given that the necessary input from automatic weather stations is available. Our data showed that:

- The total mass defined the run-out distance (Fig. 2.11) and was mainly controlled by the entrained mass. However, no correlation with front velocity could be observed (Fig. 2.12). Despite the differences in total mass all investigated avalanches reached a maximal front velocity of $44 \mathrm{~m} \mathrm{~s}^{-1}$ to $52 \mathrm{~m} \mathrm{~s}^{-1}$ in the upper part of the avalanche path (Fig. 2.4). 
- Observed differences in front velocities, powder clouds and deposition structures (Fig. 2.3) in the lower part of the path, i.e. below 1700 m.a.s.l., were caused by a change in the temperature of the entrained snow (Fig. 2.5).

- The critical threshold at which the snow temperature causes changes in flow dynamics was identified at approximately $-2^{\circ} \mathrm{C}$.

- Other snow cover parameters, e.g. density or the type of entrained snow, did not show direct correlations with flow dynamical parameters.

The investigation showed that, in addition to total mass, the temperature of the entrained snow determined the avalanche dynamic behavior especially if it approached the melting point. This is in agreement with other studies [Naaim et al., 2013] which showed based on model calculations that the static friction coefficient increases with increasing snow temperature. Our data set was limited in the number of cases and the accuracy of the determining conditions, e.g. entrainment depths and modeled snow cover properties. Additional and more detailed case studies are necessary to better quantify the influence of snow temperature on avalanche dynamics and thus provide universally applicable rules or thresholds.

Therefore, in Chapter 3 [Steinkogler et al., 2014c], the distribution of snow temperatures in avalanche deposits and sources of thermal energy in dry avalanches were investigated and quantified. Large-scale avalanche experiments at the Flüelapass field site above Davos (Switzerland) were conducted (Fig. 3.1). The artificial release of the avalanches and the application of remote and non-contact infrared radiation thermography (IRT) allowed to perform temperature measurements in the fastest possible way. Manually measured snow temperature profiles along the avalanche track and in the deposition area facilitated the quantification of the temperature of the eroded snow layers. The applied IRT camera was used to assess the snow surface temperature before, during (Fig. 3.5) and shortly after (Fig. 3.6) the avalanche occurred with high spatial resolution. This data set enabled the calculation of the thermal balance, from release to deposition and showed that:

- The highest temperatures were located in the deposits of the dense core (Fig. 3.8). This confirms the general concept that most heat is created in the center part of the flow where most mass is concentrated and it flows the fastest, resulting in the highest friction.

- In a second step we found that for the investigated dry avalanches, the thermal energy increase due to friction was mainly depending on the elevation drop of the avalanche with a warming of approximately $0.5^{\circ} \mathrm{C}$ per 100 vertical meters.

- Contrary, warming due to entrainment was very specific to the individual avalanche. Depending on the temperature of the snow along the path and the erosion depth the it ranged from nearly no increase to $1^{\circ} \mathrm{C}$ (Fig. 3.9).

The results showed that the temperature of an avalanche is determined by the temperature of the released and entrained snow but also increases by frictional and collisional processes with 
time. Especially close to the melting point this addition of heat can cause the snow to undergo significant changes in its granular structure (Fig. 2.3). These variations in granular properties, i.e. the size distribution and mechanical properties, appear to significantly influence the flow dynamics of avalanches.

In Chapter 4 [Steinkogler et al., 2014b] a simple, but promising experimental setup, along with discrete element simulations is presented which aims to identify the determining factors controlling the granulation of snow, i.e. the formation of particles larger than their initial size. The rotating concrete tumbler (Fig. 4.2) allowed to produce different granule classes which were grouped depending on their persistency and the snow cover parameters (Table 4.3). The experimental results confirmed the observations in the deposits of real-scale avalanches (as presented in Chapter 2):

- That the granulation of snow is temperature dependent with a threshold at $-1^{\circ} \mathrm{C}$.

- Once the snow temperature exceeded $-1^{\circ} \mathrm{C}$ granulation occurred very fast (Fig. 4.8) and was most effective for new snow or decomposed crystals with a temperature close to $0^{\circ} \mathrm{C}$.

- Below this temperature threshold no persistent granules were observed, even for experiments that were run for an extensive amount of time, i.e. more than 60 minutes.

- Since the potential for the formation of persistent granules at lower temperatures is very low, the granular structures as often observed (at the surface) in the deposition zone of cold, dry-snow avalanches (Fig. 3.1) are more likely to be fragments of the released or eroded snow cover. Further investigations on the properties of these fragments would allow to extend our data set for non-persistent cold granules and fragments which were not investigated in the tumbler experiments.

- Since granulation only occurred for snow temperatures warmer than $-1^{\circ} \mathrm{C}$ it is most relevant for warm, i.e. close to the melting point, or wet-snow avalanches.

- For snow temperatures higher than the threshold, the formed persistent granules were further differentiated into persistent-moist or persistent-wet granules depending on the amount of liquid water (Fig. 4.9). The significantly different mechanical properties, e.g. persistence and rebounding behavior, upon collision for these two granule types could be well observed in high-speed videos.

- The applied discrete element (DE) model emulated the competition between cohesive forces and impact forces and supported the interpretation of the granule classes observed in the experiments (Fig. 4.14).

- DE simulations were successfully used to reproduce the granule size distribution as observed in the tumbler and depositions area of avalanches. 
- Additionally, the discrete element modeling approach illustrates a cornerstone towards more complex and real-scale modeling of flowing cohesive snow with varying properties.

To accurately model snow avalanches for different snow temperatures and consequently different flow dynamics, it will be necessary to reproduce the temperature dependent granule size distribution and their properties as well as possible (further discussed in Chapter 6).

The research results presented in this dissertation are another step towards a successful link between snow properties and avalanche flow dynamics. Further interdisciplinary research is necessary to describe relevant processes between the microscopic scale, e.g. sintering or capillary processes between crystals, the mesoscopic scale, e.g. energy dissipation upon granule collisions, and the macroscopic scale, e.g. the consequence on run-out distance and flow velocity. 


\section{Outlook}

As for many investigations on snow avalanches we have to base our conclusions on a very limited number of measurements. This requires additional field campaigns to confirm the observations and verify them for other topographies and climates. Despite the existence of extensive data sets on documented avalanches, the restriction to only use comparable situations, e.g. same path and similar release volume, drastically limits the available avalanches. Furthermore, detailed snow cover observations are not always recorded in avalanche dynamics investigations. Further interdisciplinary research as presented in this study is therefore necessary to improve the link between snow cover and flow dynamics.

Field measurements with artificially released avalanches, similar to the ones presented in this study at the Flüelapass, provide the necessary framework to gather data on temporal scales important for temperature measurements. Experimental data for different snow and weather scenarios would provide valuable information for avalanche dynamics model improvements. This includes not only the classical specification of cold dry or warm wet-snow avalanches but also situations where snow temperature varies from released snow to the entrained snow along the avalanche path. Supplementing the measurements of flow dynamical and snow cover parameters with direct in-flow measurements would be a significant contribution for a more sophisticated thermal energy balance calculation. Therefore, sensors fixed on obstacles in the avalanche path, such as the mast at the Vallée de la Sionne field site [Kern et al., 2009], could provide the vertical temperature distribution in an avalanche. In addition to that, lateral and longitudinal measurements at the sliding surface [Miller et al., 2003] of an avalanche would allow to draw conclusions on the heat created by shear in this relatively thin layer. Also the energy exchange between the dense core and the powder cloud (and consequently the ambient air) might significantly contribute to a change in snow temperature.

Alternative measurements such as infrared radiation thermography (IRT) provide a qualitative and very interesting unique point of view on avalanches. The question whether theses measurements can be applied in a quantitative way as well was only marginally discussed in this study. Furthermore, other studies on the application of IRT in the field of snow science, e.g. for snow pit walls, critically discuss its applicability [Schirmer and Jamieson, 2013]. Verification is 
needed for IRT measurements on (rough) avalanche deposits to answer if the assumption that the object of interest must be Lambertian is valid. Furthermore, its use to monitor the motion of avalanches and the powder cloud should be further evaluated. For various applications [Carlomagno and Cardone, 2010; Narayanan et al., 2003] the visualization of air flows on the qualitative level is common practice. Usually a tracer is injected into the flow field. In our case the tracer is already present by snow particles of the entrained snow which are transported into the powder cloud. Similar concepts as applied for satellite remote sensing of high-level clouds, such as cirrus [Fu et al., 1998], might be transferable to avalanche powder clouds. The MODIS (Moderate Resolution Imaging Spectroradiometer) system aboard the Terra and Aqua satellites is applied to assess properties of cloud tops, i.e. height, temperature, effective emissivity [Menzel and Strabala, 2002], and sea ice surface [Hall et al., 2004]. Multiple publications showed the reflected radiance of the top cloud layer to depend on cloud thickness, cloud particle number density, size and shape [Chylek et al., 2006; Yang et al., 2005]. This would allow to get a more sophisticated knowledge on the dynamics of avalanche powder clouds, such as their initiation and collapse, plume formation and their connection to (temperature of) the dense core.

In addition to field measurements, the tumbler experiments provided insight into the temperaturedependent granular structure of an avalanche. Yet, one of the main shortcomings of the experimental setup was the limited control of heat supply to the system which did not allow the estimation of the contribution of internal friction to the temperature increase. An improved experimental setup should thermally insulate the tumbler, potentially with a controlled heat flux to vary the temperature. Conducting future experiments in a cold laboratory would therefore be desirable. Especially at $0^{\circ} \mathrm{C}$, precise measurements of the liquid water content will be important to discern effects of liquid and dry cohesion in the granular system. Dielectric devices [Denoth, 1994; Denoth and Wilhelmy, 1988] provide the potential of a continuous measurement of liquid water content during the experiments. An additional helpful modification of the tumbler would be a less complex geometry of the mixing elements to avoid the cutting impact of the blades on the granules. Smaller but multiple rectangular friction elements placed on the walls could simplify the system and promote a cascading regime for all individual granule classes. While our experiments have thus far provided a broad overview about the influence of various quantities, future experiments should focus on dedicated parameter studies. A crucial parameter which could be easily varied is the tumbler frequency which influences collision rates, contact times and breakage probabilities.

The presented DE model successfully reproduced the observed granule classes by taking the two main physical ingredients, i.e. the sintering and strength of the bonds, into account. For computational reasons we did not initialize our simulations with particles at the crystal scale. The initial particles with size $(d=4.5 \mathrm{~mm})$ must be already regarded as small granules. Using smaller sizes of $<1 \mathrm{~mm}$, similar to realistic snow grains, would however require considerable computational effort. So the effect of using different initial conditions in the simulation remains to be addressed in the future. Furthermore, the time-dependence of the sintering force and the strength as observed in Szabo and Schneebeli [2007] and Podolskiy et al. [2014] 
as well as densification effects are not accounted for in our model, but might affect the persistency and the strength of the granules. To further constrain the parameters of the model, the visco-elastic properties of the granules and the strength of the bonds needs to be known. Multiple experimental studies describe the static strength of liquid-bound granules [Iveson et al., 2001]. In most cases either direct tensile tests or uniaxial compression tests where the granule is assumed to fail due to tensile stress where conducted. Also the mechanical response of agglomerates at high and low strain rates [Cheong et al., 2005] has not been investigated yet. Schubert [1977] has described the different methods available to measure the strength of moist agglomerates. There are two main parameters of interest that are usually reported: peak yield stress and the maximum strain before brittle failure. Information on the mechanical properties could be easily obtained by including mechanical tests of the snow before and after granule formation at the beginning and end of the experiment. Being aware of the present limitations of the approach, the observed differences in the properties of non-persistent and persistent granules are of relevance for flow dynamics since the macroscopic behavior of a granular material is determined by the nature of the interactions between the granules [Andreotti et al., 2013].

For the practical application of temperature effects in avalanche dynamics models, a binary switch between dry and moist/wet might already be sufficient. However, a gradual transition would allow for more sophisticated model calculations such as temperature changes along an avalanche path. Model improvements of depth-averaged models [Christen et al., 2010] already partly account for these effects. Additionally discrete element (DE) methods can be used to model cohesive granular flows [Rognon et al., 2008a] and provide valuable information about the effect of small-scale interactions on the macroscopic behavior of the flow. Yet, due to computational issues, it is currently impossible to use a DEM approach for practical applications. Today, new promising hybrid methods are currently under development such as the MPM (Material Point Method) [Stomakhin et al., 2013]. However, whether these methods are more suitable to address this challenge is still an open question.

Once avalanche dynamics models are able to successfully account for varying snow cover properties a coupling to a snow cover model, such as the presented models Alpine3D and SNOWPACK, might be feasible. Run-out distance, velocity and impact pressure could then be calculated depending on the prevailing snow conditions at that time in the avalanche path. This would allow to account for varying weather conditions or climatic regions. A further coupling to a numerical weather prediction model, such as COSMO [MeteoSwiss, 2012], would even turn this model chain from a now-casting into a forecasting system. 



\section{Bibliography}

Alexander, A. W., B. Chaudhuri, A. Faqih, F. J. Muzzio, C. Davies, and M. S. Tomassone (2006), Avalanching flow of cohesive powders, Powder Technology, 164(1), 13 -21, doi: 10.1016/j. powtec.2006.01.017.

Ancey, C. (2001), Snow avalanches, in Geomorphological Fluid Mechanics, pp. 319-338, Springer.

Ancey, C., N. Andreini, and G. Epely-Chauvin (2013), Granular suspension avalanches. i. macro-viscous behavior, Physics of Fluids (1994-present), 25(3), 033,301.

Andreotti, B., Y. Forterre, and O. Pouliquen (2013), Granular Media, 1st ed., Cambridge University Press.

Armstrong, R. L., and E. Brun (2008), Snow and Climate: Physical Processes, Surface Energy Exchange and Modeling, Cambridge University Press, Cambridge, UK, 222 pp.

Baroudi, D., B. Sovilla, and E. Thibert (2011), Effects of flow regime and sensor geometry on snow avalanche impact-pressure measurements, Journal of Glaciology, 57(202), 277-288.

Bartelt, P., and B. W. McArdell (2009), Granulometric investigations of snow avalanches, Journal of Glaciology, 55(193), 829-833.

Bartelt, P., O. Buser, and K. Platzer (2006), Fluctuation-dissipation relations for granular snow avalanches, Journal of Glaciology, 52(179), 631-643.

Bartelt, P., L. Meier, and O. Buser (2011), Snow avalanche flow-regime transitions induced by mass and random kinetic energy fluxes, Annals of Glaciology, 52(58), 159-164, doi: doi:10.3189/172756411797252158.

Bartelt, P., Y. Bühler, O. Buser, M. Christen, and L. Meier (2012a), Modeling mass-dependent flow regime transitions to predict the stopping and depositional behavior of snow avalanches, J. Geophys. Res., 117(F1).

Bartelt, P., J. Glover, T. Feistl, Y. Bühler, and O. Buser (2012b), Formation of levees and enechelon shear planes during snow avalanche run-out, Journal of Glaciology, 58(211), 980992, doi: doi:10.3189/2012JoG11J011. 
Bartelt, P., O. Buser, Y. Bühler, L. Dreier, and M. Christen (2014), Numerical simulation of snow avalanches: Modelling dilatative processes with cohesion in rapid granular shear flows, Fundamentals of Ground Engineering, p. 327.

Bates, B., C. Ancey, and J. Busson (2014), Visualization of the internal flow properties and the material exchange interface in an entraining viscous newtonian gravity current, Environmental Fluid Mechanics, 14(2), 501-518.

Bavay, M., M. Lehning, T. Jonas, and H. Löwe (2009), Simulations of future snow cover and discharge in alpine headwater catchments, Hydrological Processes, 23(1), 95-108, doi: 10. 1002/hyp.7195.

Bavay, M., T. Grünewald, and M. Lehning (2013), Response of snow cover and runoff to climate change in high alpine catchments of eastern switzerland, Advances in Water Resources, 55(0), 4 - 16, doi: http://dx.doi.org/10.1016/j.advwatres.2012.12.009, atmosphere Interactions and Hydrological Consequences.

Bazant, Z. P., G. Zi, and D. McClung (2003), Size effect law and fracture mechanics of the triggering of dry snow slab avalanches, Journal of Geophysical Research: Solid Earth (19782012), 108(B2).

Bellaire, S., J. B. Jamieson, and C. Fierz (2011), Forcing the snow-cover model snowpack with forecasted weather data, The Cryosphere, 5(4), 1115-1125, doi: 10.5194/tc-5-1115-2011.

BFF, and EISLF (1984), Richtlinien zur berücksichtigung der lawinengefahr bei raumwirksamen tätigkeiten, Bundesamt für Forstwesen (BFF), Eidgenössisches Institut für Schnee-und Lawinenforschung (EISLF).

Blattenberger, G., and R. Fowles (1995), Road closure to mitigate avalanche danger: a case study for little cottonwood canyon, International Journal of Forecasting, 11(1), 159 - 174, doi: DOI:10.1016/0169-2070(94)02008-D, probability Forecasting.

Brenning, A., S. Gruber, and M. Hoelzle (2005), Sampling and statistical analyses of bts measurements, Permafrost and Periglacial Processes, 16(4), 383-393.

Caccamo, P., B. Chanut, T. Faug, H. Bellot, and F. Naaim-Bouvet (2012), Small-scale tests to investigate the dynamics of finite-sized dry granular avalanches and forces on a wall-like obstacle, Granular Matter, 14(5), 577-587.

Canadian Avalanche Association (2007), Observational Guidelines and Recording Standards for Weather, Snowpack and Avalanches, Canadian Avalanche Association, Revelstoke, British Columbia.

Carlomagno, G., and G. Cardone (2010), Infrared thermography for convective heat transfer measurements, Experiments in Fluids, 49(6), 1187-1218, doi: 10.1007/s00348-010-0912-2.

Chaudhuri, B., A. Mehrotra, F. J. Muzzio, and M. S. Tomassone (2006), Cohesive effects in powder mixing in a tumbling blender, Powder Technology, 165(2), 105-114. 
Cheong, Y., M. Adams, A. Routh, M. Hounslow, and A. Salman (2005), The production of binderless granules and their mechanical characteristics, Chemical Engineering Science, 60(14), 4045 - 4053, doi: 10.1016/j.ces.2005.02.033.

Christen, M., J. Kowalski, and P. Bartelt (2010), Ramms: Numerical simulation of dense snow avalanches in three-dimensional terrain, Cold Regions Science and Technology, 63(1-2), 1 14, doi: DOI:10.1016/j.coldregions.2010.04.005.

Chylek, P., S. Robinson, M. Dubey, M. King, Q. Fu, and W. Clodius (2006), Comparison of near-infrared and thermal infrared cloud phase detections, Journal of Geophysical Research: Atmospheres (1984-2012), 111(D20).

Cundall, P. A., and O. D. Strack (1979), A discrete numerical model for granular assemblies, Geotechnique, 29(1), 47-65.

da Cruz, F., S. Emam, M. Prochnow, J.-N. Roux, and F. Chevoir (2005), Rheophysics of dense granular materials: Discrete simulation of plane shear flows, Physical Review E, 72(2), 021309, doi: 10.1103/PhysRevE.72.021309.

Danilina, I., A. Mushkin, A. Gillespie, M. O'Neal, L. Pietro, and L. Balick (2006), Roughness effects on sub-pixel radiant temperatures in knetically isothermal surfaces, in RAQRS II: 2 nd International Symposium on Recent Advances in Quantitative Remote Sensing.

Dash, J. G., A. W. Rempel, and J. S. Wettlaufer (2006), The physics of premelted ice and its geophysical consequences, Reviews of modern physics, 78, 695-741.

De Biagi, V., B. Chiaia, and B. Frigo (2012), Fractal grain distribution in snow avalanche deposits, Journal of Glaciology, 58(208), 340-346.

Denoth, A. (1994), An electronic device for long-term snow wetness recording, Ann. Glaciol., 19, 104-106.

Denoth, A., and I. Wilhelmy (1988), Snow dielectric devices and field applications, in Proceddings, International Snow Science Workshop, Whistler, pp. 203-206.

Dozier, J., and S. G. Warren (1982), Effect of viewing angle on the infrared brightness temperature of snow, Water Resources Research, 18(5), 1424-1434, doi: 10.1029/WR018i005p01424.

Eckert, N., H. Baya, and M. Deschatres (2010), Assessing the response of snow avalanche runout altitudes to climate fluctuations using hierarchical modeling: Application to 61 winters of data in france, Journal of Climate, 23(12), 3157-3180, doi: 10.1175/2010JCLI3312. 1.

Ennis, B. J., B., G. Tardos, G., and R. Pfeffer (1991), A microlevel-based characterization of granulation phenomena, Powder Technology, 65(1-3), 257-272.

Faug, T., R. Beguin, and B. Chanut (2009), Mean steady granular force on a wall overflowed by free-surface gravity-driven dense flows, Physical Review E, 80(2), 021305. 
Faug, T., P. Caccamo, and B. Chanut (2012), A scaling law for impact force of a granular avalanche flowing past a wall, Geophysical Research Letters, 39(23).

Fierz, C., R. Armstrong, Y. Durand, P. Etchevers, E. Greene, D. McClung, K. Nishimura, P. Satyawali, and S. Sokratov (2009), The international classification for seasonal snow on the ground, IHP-VII Technical Documents in Hydrology, 83(1).

Fischer, J.-T. (2013), A novel approach to evaluate and compare computational snow avalanche simulation, Natural Hazards and Earth System Science, 13(6), 1655-1667, doi: 10.5194/ nhess-13-1655-2013.

Forterre, Y., and O. Pouliquen (2008), Flows of dense granular media, Annu. Rev. Fluid Mech., $40,1-24$.

Fu, Q., P. Yang, and W. Sun (1998), An accurate parameterization of the infrared radiative properties of cirrus clouds for climate models, Journal of climate, 11(9), 2223-2237.

Fuchs, S., M. Thöni, M. C. McAlpin, U. Gruber, and M. Bründl (2007), Avalanche hazard mitigation strategies assessed by cost effectiveness analyses and cost benefit analyses evidence from davos, switzerland, Natural Hazards, 41(1), 113-129.

Gauer, P., D. Issler, K. Lied, K. Kristensen, H. Iwe, E. Lied, L. Rammer, and H. Schreiber (2007), On full-scale avalanche measurements at the ryggfonn test site, norway, Cold Regions Science and Technology, 49(1), 39 - 53, doi: 10.1016/j.coldregions.2006.09.010, selected Papers from the General Assembly of the European Geosciences Union (EGU), Vienna, Austria, 25 April 2005.

Gauer, P., D. Issler, K. Lied, K. Kristensen, and F. Sandersen (2008), On snow avalanche flow regimes: inferences from observations and measurements, in Proceedings, International Snow Science Workshop ISSW 2008, Whistler, Canada.

Gaume, J., G. Chambon, and M. Naaim (2011), Quasistatic to inertial transition in granular materials and the role of fluctuations, Physical Review E, 84(5), 051304.

Gaume, J., G. Chambon, N. Eckert, and M. Naaim (2012), Relative influence of mechanical and meteorological factors on avalanche release depth distributions., GRL, 39, L12401.

GDR MiDi (2004), On dense granular flows, Eur. Phys. J. E, 14, 341-365.

Glazovskaya, T. (1998), Global distribution of snow avalanches and changing activity in the northern hemisphere due to climate change, Annals of glaciology, 26, 337-342.

Gruber, U., and S. Margreth (2001), Winter 1999: a valuable test of the avalanche-hazard mapping procedure in switzerland, Annals of Glaciology, 32(1), 328-332.

Gubler, H., and M. Hiller (1984), The use of microwave fmcw radar in snow and avalanche research, Cold Regions Science and Technology, 9(2), 109 - 119, doi: 10.1016/0165-232X(84) 90003-X. 
Hagenmuller, P., T. C. Theile, and M. Schneebeli (2014), Numerical simulation of microstructural damage and tensile strength of snow, Geophysical Research Letters, 41(1), 86-89.

Hall, D. K., J. R. Key, K. A. Casey, G. A. Riggs, and D. J. Cavalieri (2004), Sea ice surface temperature product from modis, Geoscience and Remote Sensing, IEEE Transactions on, 42(5), 1076-1087.

Hapgood, K., S. lveson, J. Litster, and L. Liu (2007), Chapter 20 granulation rate processes, in Granulation, vol. 11, edited by M. H. A.D. Salman and J. Seville, pp. 897-977, Elsevier Science B.V.

Harbitz, C. (1998), A survey of computational models for snow avalanche motion.

Herminghaus, S. (2005), Dynamics of wet granular matter, Advances in Physics, 54(3), 221-261, doi: $10.1080 / 00018730500167855$.

Hestnes, E. (1998), Slushflow hazard-where, why and when? 25 years of experience with slushflow consulting and research, Annals of Glaciology, 26, 370-376.

Hirashima, H., K. Nishimura, S. Yamaguchi, A. Sato, and M. Lehning (2008), Avalanche forecasting in a heavy snowfall area using the snowpack model, Cold Regions Science and Technology, 51, 191 - 203, doi: http://dx.doi.org/10.1016/j.coldregions.2007.05.013.

Holyoake, A. J., and J. N. McElwaine (2012), High-speed granular chute flows, Journal of Fluid Mechanics, 710, 35-71.

Hopfinger, E. (1983), Snow avalanche motion and related phenomena., Annual Review of Fluid Mechanics, 15, 47-76, cited By (since 1996) 28.

Hori, M., T. Aoki, T. Tanikawa, A. Hachikubo, K. Sugiura, K. Kuchiki, and M. Niwano (2013), Modeling angular-dependent spectral emissivity of snow and ice in the thermal infrared atmospheric window, Appl. Opt., 52(30), 7243-7255, doi: 10.1364/AO.52.007243.

Hornbaker, D. J., R. Albert, I. Albert, A.-L. Barabasi, and P. Schiffer (1997), What keeps sandcastles standing?, Nature, 387(6635), 765-765.

Hutter, K., and N. Kirchner (2013), Dynamic response of granular and porous materials under large and catastrophic deformations, vol. 11, Springer Science \& Business.

Issler, D., and P. Gauer (2008), Exploring the significance of the fluidized flow regime for avalanche hazard mapping, Annals of Glaciology, 49, 193-198, cited By (since 1996) 2.

Issler, D., A. Errera, S. Priano, H. Gubler, B. Teufen, and B. Krummenacher (2008), Inferences on flow mechanisms from snow avalanche deposits, Annals of Glaciology, Vol 49, 2008, 49, 187-192.

Iveson, S. M., J. D. Litster, K. Hapgood, and B. J. Ennis (2001), Nucleation, growth and breakage phenomena in agitated wet granulation processes: a review, Powder Technology, 117, 3 - 39, doi: 10.1016/S0032-5910(01)00313-8. 
Jaedicke, C., M. Kern, P. Gauer, M.-A. Baillifard, and K. Platzer (2008), Chute experiments on slushflow dynamics, Cold Regions Science and Technology, 51(2-3), 156 - 167, doi: http://dx. doi.org/10.1016/j.coldregions.2007.03.011, international Snow Science Workshop (ISSW) 2006.

Jamieson, B., and C. Johnston (1990), In-situ tensile tests of snowpack layers, Journal of Glaciology, 36(122), 102-106.

Jamieson, J., and C. Johnston (2001), Evaluation of the shear frame test for weak snowpack layers, Annals of Glaciology, 32, 59-69.

Jones, K. W., D. Hamre, and P. Bartelt (2014), Effects of the thermal characteristics of snow entrainment in avalanche run-out at bird hill, south central alaska, in Proceedings, International Snow Science Workshop ISSW 2014, Banff, Canada.

Kapur, P. C. (1971), The crushing and layering mechanism of granule growth, Chemical Engineering Science, 26(7), 1093-1099, doi: 10.1016/0009-2509(71)80023-4.

Kern, M., F. Tiefenbacher, and J. McElwaine (2004), The rheology of snow in large chute flows, Cold Regions Science and Technology, 39(2-3), 181 - 192, doi: 10.1016/j.coldregions.2004. 03.006, <ce:title>Snow And Avalanches: Papers Presented At The European Geophysical Union Conference, Nice, April 2003. Dedicated To The Avalanche Dynamics Pioneer Dr. B. Salm.</ce:title>.

Kern, M., P. Bartelt, B. Sovilla, and O. Buser (2009), Measured shear rates in large dry and wet snow avalanches, Journal of Glaciology, 55(190), 327-338.

Kern, M. A., P. A. Bartelt, and B. Sovilla (2010), Velocity profile inversion in dense avalanche flow, Annals of Glaciology, 51(54), 27-31.

Kobayashi, T., Y. Nohguchi, and K. Izumi (2000), Comparison of dry granulation and wet agglomeration of snow, in Proceedings of the Fourth International Conference on Snow Engineering, Trondheim, Norway, pp. 93-97.

Kristensen, H., and T. Schaefer (1987), Granulation. a review on pharmaceutical wetgranulation, Drug Development and Industrial Pharmacy, 13(4-5), 803-872.

Lehning, M., and C. Fierz (2008), Assessment of snow transport in avalanche terrain, Cold Regions Science and Technology, 51, 240-252.

Lehning, M., P. Bartelt, B. Brown, C. Fierz, and P. Satyawali (2002a), A physical snowpack model for the swiss avalanche warning. partii: Snow microstructure, Cold Regions Science and Technology, 35, 147-167.

Lehning, M., P. Bartelt, B. Brown, and C. Fierz (2002b), A physical snowpack model for the swiss avalanche warning. part iii: Meteorological forcing, thin layer formation and evaluation, Cold Regions Science and Technology, 35, 169-184. 
Lehning, M., I. Völksch, D. Gustafsson, T. A. Nguyen, M. Stähli, and M. Zappa (2006), Alpine3d: a detailed model of mountain surface processes and its application to snow hydrology, HYDROLOGICAL PROCESSES, 20, 2111-2128.

Lehning, M., H. Löwe, M. Ryser, and N. Raderschall (2008), Inhomogeneous precipitation distribution and snow transport in steep terrain, Water Resources Research, 44(7), doi: 10.1029/2007WR006545.

Lewkowicz, A. G., and M. Ednie (2004), Probability mapping of mountain permafrost using the bts method, wolf creek, yukon territory, canada, Permafrost and Periglacial Processes, 15(1), 67-80.

Lied, K., and S. Bakkehøi (1980), Empirical calculations of snow-avalanche run-out distance based on topographic parameters, Journal of Glaciology, 26, 165-177.

Louge, M. Y., C. S. Carroll, and B. Turnbull (2011), Role of pore pressure gradients in sustaining frontal particle entrainment in eruption currents: The case of powder snow avalanches, Journal of Geophysical Research-earth Surface, 116, F04,030, doi: 10.1029/2011JF002065.

Magnusson, J., D. Farinotti, T. Jonas, and M. Bavay (2011), Quantitative evaluation of different hydrological modelling approaches in a partly glacierized swiss watershed, Hydrological Processes, 25(13), 2071-2084, doi: 10.1002/hyp.7958.

McClung, D. (2009), Dimensions of dry snow slab avalanches from field measurements, Journal of Geophysical Research: Earth Surface, 114(F1).

McClung, D. M., and K. Lied (1987), Statistical and geometrical definition of snow avalanche runout, Cold Regions Science and Technology, 13(2), 107-119.

McElwaine, J., and K. Nishimura (2001), Ping-pong ball avalanche experiments, Annals of Glaciology, 32(1), 241-250.

Mellmann, J. (2001), The transverse motion of solids in rotating cylinders - forms of motion and transition behavior, Powder Technology, 118(3), 251-270, doi: 10.1016/S0032-5910(00) 00402-2.

Mellor, M. (1974), A review of basic snow mechanics, US Army Cold Regions Research and Engineering Laboratory.

Menzel, W. P., and K. I. Strabala (2002), Cloud top properties and cloud phase algorithm theoretical basis document, University of Wisconsin-Madison.

Meola, C., and G. M. Carlomagno (2004), Recent advances in the use of infrared thermography, Measurement Science and Technology, 15(9), R27.

MeteoSwiss (2012), The numerical weather prediction model cosmo. http://www.meteoswiss.admin.ch/web/en/weather/models/cosmo.html. 
Miller, D., E. Adams, D. Schmidt, and R. Brown (2003), Preliminary experimental evidence of heating at the running surface of avalanching snow, Cold regions science and technology, $37(3), 421-427$.

Mishra, B., and C. Thornton (2001), Impact breakage of particle agglomerates, International Journal of Mineral Processing, 61(4), 225-239, doi: 10.1016/S0301-7516(00)00065-X.

Mitarai, N., and F. Nori (2006), Wet granular materials, Advances in Physics, 55(1-2), 1-45, doi: $10.1080 / 00018730600626065$.

Moro, F., T. Faug, H. Bellot, and F. Ousset (2010), Large mobility of dry snow avalanches: Insights from small-scale laboratory tests on granular avalanches of bidisperse materials, Cold Regions Science and Technology, 62(1), 55 - 66, doi: 10.1016/j.coldregions.2010.02.011.

Mott, R., M. Schirmer, M. Bavay, T. Grunewald, and M. Lehning (2010), Understanding snowtransport processes shaping the mountain snow-cover, Cryosphere, 4(4), 545-559, doi: $10.5194 /$ tc- $4-545-2010$.

Mott, R., M. Schirmer, and M. Lehning (2011), Scaling properties of wind and snow depth distribution in an alpine catchment, Journal of Geophysical Research: Atmospheres, 116(D6), n/a-n/a, doi: 10.1029/2010JD014886.

Mushkin, A., I. Danilina, A. R. Gillespie, L. K. Balick, and M. F. McCabe (2007), Roughness effects on thermal-infrared emissivities estimated from remotely sensed images, in Remote Sensing, pp. 67,492V-67,492V, International Society for Optics and Photonics.

Naaim, M., and Y. Durand (2012), Dense avalanche friction coefficients influence of nivological parameters, in Proceedings, International Snow Science Workshop ISSW 2012, Anchorage, Alaska.

Naaim, M., Y. Durand, N. Eckert, and G. Chambon (2013), Dense avalanche friction coefficients: influence of physical properties of snow, Journal of Glaciology, 59(216), 771-782, doi: 10. 3189/2013JoG12J205.

Narayanan, V., R. Page, and J. Seyed-Yagoobi (2003), Visualization of air flow using infrared thermography, Experiments in fluids, 34(2), 275-284.

Nishimura, K. (1991), Studies on the fluidized snow dynamics, Contributions from the Institute of Low Temperature Science, 37, 1-55.

Nishimura, K., and Y. Ito (1997), Velocity distribution in snow avalanches, Journal of Geophysical Research: Solid Earth (1978-2012), 102(B12), 27,297-27,303.

Nohguchi, Y., T. Kobayasi, K. Iwanami, K. Nishimura, and A. Sato (1997), Granulation of snow, in Snow engineering: Recent Advances.

Nowak, S., A. Samadani, and A. Kudrolli (2005), Maximum angle of stability of a wet granular pile, Nature physics, 1(1), 50-52. 
Onesti, L. (1987), Slushflow release mechanism: A first approximation, International Association of Hydrological Sciences Publications, 162, 331-336.

Ouchiyama, N., and T. Tanaka (1975), The probability of coalescence in granulation kinetics, Industrial \& Engineering Chemistry Process Design and Development, 14(3), 286-289.

Phillips, J., A. Hogg, R. Kerswell, and N. Thomas (2006), Enhanced mobility of granular mixtures of fine and coarse particles, Earth and Planetary Science Letters, 246, 466 - 480, doi: 10.1016/ j.epsl.2006.04.007.

Pietsch, W. (2003), An interdisciplinary approach to size enlargement by agglomeration, Powder Technology, 130, 8 - 13, doi: 10.1016/S0032-5910(02)00218-8.

Podolskiy, E., M. Barbero, F. Barpi, G. Chambon, M. Borri-Brunetto, O. Pallara, B. Frigo, B. Chiaia, and M. Naaim (2014), Healing of snow surface-to-surface contacts by isothermal sintering, The Cryosphere Discussions, 8(3), 2465-2490.

Pouliquen, O. (1999), Scaling laws in granular flows down rough inclined planes, Physics of Fluids, 11(3), 542-548, doi: 10.1063/1.869928.

Pruppacher, H., and J. Klett (1997), Microphysics of Clouds and Precipitation, Atmospheric and Oceanographic Sciences Library, Springer.

Pudasaini, S. P. (2012), A general two-phase debris flow model, Journal of Geophysical Research: Earth Surface (2003-2012), 117(F3).

Pudasaini, S. P., and K. Hutter (2007), Avalanche dynamics: dynamics of rapid flows of dense granular avalanches, Springer.

Pudasaini, S. P., and S. A. Miller (2013), The hypermobility of huge landslides and avalanches, Engineering Geology, 157(0), 124-132, doi: 10.1016/j.enggeo.2013.01.012.

Radjai, F., F. Dubois, et al. (2011), Discrete-element modeling of granular materials, Wiley.

Rasmus, S., J. Raisanen, and M. Lehning (2004), Estimating snow conditions in finland in the late 21st century using the snowpack model with regional climate scenario data as input, Annals of Glaciology, 38(1), 238-244, doi: doi:10.3189/172756404781814843.

Reed, J. S. (1995), Principles of Ceramics Processing, 2nd Edition, Wiley.

Roche, O., M. Attali, A. Mangeney, and A. Lucas (2011), On the run-out distance of geophysical gravitational flows: Insight from fluidized granular collapse experiments, Earth and Planetary Science Letters, 311(34), 375-385, doi: 10.1016/j.epsl.2011.09.023.

Rognon, P., J.-N. Roux, M. Naaim, and F. Chevoir (2008a), Dense flows of cohesive granular materials, Journal of Fluid Mechanics, 596, 21-47, doi: 10.1017/S0022112007009329. 
Rognon, P., F. Chevoir, H. Bellot, F. Ousset, M. Naaim, and P. Coussot (2008b), Rheology of dense snow flows: Inferences from steady state chute-flow experiments, Journal of Rheology, 52(3), 729-748.

Roux, J.-N., and G. Combe (2002), Quasistatic rheology and the origins of strain, Comptes Rendus Physique, 3(2), 131-140.

Rudolf-Miklau, F., and S. Sauermoser (2011), Handbuch Technischer Lawinenschutz, John Wiley \& Sons.

Salm, B. W., A. Burkhard, and H. Gubler (1990), Berechnung von fliesslawinen: eine anleitung für praktiker mit beispielen, Tech. rep., Eidgenössisches Institut für Schnee- und Lawinenforschung (Davos).

Sampl, P., and T. Zwinger (2004), Avalanche simulation with samos, Annals of glaciology, 38(1), 393-398.

Sarkar, A., and C. Wassgren (2010), Continuous blending of cohesive granular material, Chemical Engineering Science, 65(21), 5687-5698.

Sarkar, A., and C. R. Wassgren (2009), Simulation of a continuous granular mixer: Effect of operating conditions on flow and mixing, Chemical Engineering Science, 64(11), 2672-2682.

Schaefer, M., and L. Bugnion (2013), Velocity profile variations in granular flows with changing boundary conditions: insights from experiments, Physics of Fluids, 25(6), 063303, doi: 10.1063/1.4810973.

Schiffer, P. (2005), Granular physics: A bridge to sandpile stability, Nature Physics, 1(1), 21-22.

Schirmer, M., and B. Jamieson (2013), Limitations of an infrared camera to measure snow pit -wall temperatures, in Proceedings, International Snow Science Workshop ISSW 2013, Grenoble, France.

Schirmer, M., and B. Jamieson (2014), Limitations of using a thermal imager for snow pit temperatures, The Cryosphere, 8(2), 387-394, doi: 10.5194/tc-8-387-2014.

Schubert, H. (1977), Tensile strength and capillary pressure of moist agglomerates.

Schweizer, J., C. Mitterer, and L. Stoffel (2009), On forecasting large and infrequent snow avalanches, Cold Regions Science and Technology, 59(2-3), 234 - 241, doi: DOI:10.1016/j. coldregions.2009.01.006, international Snow Science Workshop (ISSW) 2008.

Shea, C., and B. Jamieson (2011), Some fundamentals of handheld snow surface thermography, Cryosphere, 5(1), 55-66, doi: 10.5194/tc-5-55-2011.

Shea, C., B. Jamieson, and K. W. Birkeland (2012), Use of a thermal imager for snow pit temperatures, The Cryosphere, 6(2), 287-299, doi: 10.5194/tc-6-287-2012. 
Sigrist, C. (2006), Measurement of fracture mechanical properties of snow and application to dry snow slab avalanche release, Ph.D. thesis, University of Bern.

Sigrist, C., J. Schweizer, H.-J. Schindler, and J. Dual (2005), On size and shape effects in snow fracture toughness measurements, Cold Regions Science and Technology, 43(1), 24-35.

SLF (2000), Der lawinenwinter 1999, Ereignisanalyse (588 p).

Snyder, W. C., Z. Wan, Y. Zhang, and Y.-Z. Feng (1998), Classification-based emissivity for land surface temperature measurement from space, International Journal of Remote Sensing, 19(14), 2753-2774, doi: 10.1080/014311698214497.

Sovilla, B. (2004), Field experiments and numerical modelling of mass entrainment and deposition processes in snow avalanches., Dissertation no. 15462, Swiss Federal Institute of Technology, Zürich.

Sovilla, B., and P. Bartelt (2002), Observations and modelling of snow avalanche entrainment, Natural Hazards and Earth System Science, 2(3/4), 169-179, doi: 10.5194/nhess-2-169-2002.

Sovilla, B., P. Burlando, and P. Bartelt (2006), Field experiments and numerical modeling of mass entrainment in snow avalanches, Journal of Geophysical Research-earth Surface, 111(F3), doi: 10.1029/2005JF000391.

Sovilla, B., S. Margreth, and P. Bartelt (2007), On snow entrainment in avalanche dynamics calculations, Cold Regions Science and Technology, 47(1-2), 69-79, doi: 10.1016/j.coldregions. 2006.08.012.

Sovilla, B., M. Schaer, M. Kern, and P. Bartelt (2008), Impact pressures and flow regimes in dense snow avalanches observed at the vallee de la sionne test site, Journal of Geophysical Research: Earth Surface, 113.

Sovilla, B., J. N. McElwaine, M. Schaer, and J. Vallet (2010a), Variation of deposition depth with slope angle in snow avalanches: Measurements from vallee de la sionne, Journal of Geophysical Research-earth Surface, 115, doi: 10.1029/2009JF001390.

Sovilla, B., M. Kern, and M. Schaer (2010b), Slow drag in wet-snow avalanche flow, Journal of Glaciology, 56(198), 587-592.

Sovilla, B., J. N. McElwaine, and M. Y. (submitted), The structure of powder snow avalanches.

Steinkogler, W., B. Sovilla, and M. Lehning (2013), Granulation of snow, in Proceedings, International Snow Science Workshop ISSW 2013, Grenoble, France.

Steinkogler, W., B. Sovilla, and M. Lehning (2014a), Influence of snow cover properties on avalanche dynamics, Cold Regions Science and Technology, 97, 121-131, doi: 10.1016/j. coldregions.2013.10.002. 
Steinkogler, W., J. Gaume, H. Löwe, B. Sovilla, and M. Lehning (2014b), Granulation of snow: from tumbler experiments to discrete element simulations, Journal of Geophysical Research - Earth Surface, submitted.

Steinkogler, W., B. Sovilla, and M. Lehning (2014c), Thermal energy in dry snow avalanches, The Cryosphere, submitted.

Stoffel, L. (2013), Vergleich der Sprengmethoden: Gazex, Lawinenwächter / -mast InauenSchätti, Wyssen Sprengmast, Avalancheur, WSL-Institut für Schnee- und Lawinenforschung SLF.

Stomakhin, A., C. Schroeder, L. Chai, J. Teran, and A. Selle (2013), A material point method for snow simulation, ACM Transactions on Graphics (TOG), 32(4), 102.

Subero, J., and M. Ghadiri (2001), Breakage patterns of agglomerates, Powder Technology, 120(3), 232-243, doi: 10.1016/S0032-5910(01)00276-5.

Szabo, D., and M. Schneebeli (2007), Subsecond sintering of ice, Applied Physics Letters, 90(15), 151916-151916, doi: 10.1063/1.2721391.

Takeuchi, Y., K. Yamanoi, Y. Endo, S. Murakami, and K. Izumi (2003), Velocities for the dry and wet snow avalanches at makunosawa valley in myoko, japan, Cold Regions Science and Technology, 37(3), 483 - 486, doi: DOI:10.1016/S0165-232X(03)00086-7, iSSW 2002: International Snow Science Workshop.

Turnbull, B. (2011), Scaling laws for melting ice avalanches, Physical review letters, 107, 258,001, doi: 10.1103/PhysRevLett.107.258001.

Turnbull, B., and P. Bartelt (2003), Mass and momentum balance model of a mixed flowing/powder snow avalanche, Surveys in Geophysics, 24(5-6), 465-477, doi: 10.1023/B: GEOP.0000006077.82404.84.

Vallet, J., B. Turnbull, S. Joly, and F. Dufour (2004), Observations on powder snow avalanches using videogrammetry, Cold Regions Science and Technology, 39, 153 - 159, doi: 10.1016/j. coldregions.2004.05.004.

Vera, C., T. Feistl, W. Steinkogler, O. Buser, and P. Bartelt (2012), Thermal temperature in avalanche flow, Proceedings, International Snow Science Workshop ISSW 2012, Anchorage, Alaska.

Vervaet, C., and J. P. Remon (2005), Continuous granulation in the pharmaceutical industry, Chemical Engineering Science, 60(14), 3949 - 3957, doi: http://dx.doi.org/10.1016/j.ces.2005. 02.028 .

Voellmy, A. (1955), Über die zerstörungskraft von lawinen, Schweizerische Bauzeitung, Sonderdruck aus dem 73. Jahrgang, 1-25. 
Walker, G. M. (2007), Chapter 4 drum granulation processes, in Granulation, vol. 11, edited by M. H. A.D. Salman and J. Seville, pp. 219-254, Elsevier Science B.V.

Wu, C.-Y., A. R. Jacobson, M. Laba, and P. C. Baveye (2009), Accounting for surface roughness effects in the near-infrared reflectance sensing of soils, Geoderma, 152, 171 - 180, doi: http://dx.doi.org/10.1016/j.geoderma.2009.06.002.

Yang, P., H. Wei, H.-L. Huang, B. A. Baum, Y. X. Hu, G. W. Kattawar, M. I. Mishchenko, and Q. Fu (2005), Scattering and absorption property database for nonspherical ice particles in the near-through far-infrared spectral region, Applied optics, 44(26), 5512-5523. 



\section{Walter Steinkogler}

Roitherstrasse 75

4802 Ebensee, Austria

$\square+41762718858$

w.steinkogler@gmail.com

Resume

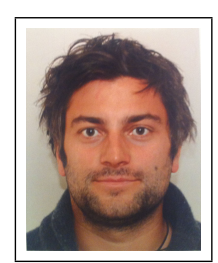

\section{Personal Information}

date of birth 11. April 1984

place of birth Gmunden

citizenship Austrian

\section{Education}

2003-2009 Master of Natural Science (Mag. rer. nat.), Meteorology and Geophysics, University of Innsbruck, Austria.

MASTER THEsis

title Systematic Assessment of New Snow Settlement in SNOWPACK

institute Institute of Meteorology and Geophysics IMGI (Innsbruck, Austria), WSL Institute for Snow and Avalanche Research SLF (Davos, Switzerland)

supervisors Dr. Friedrich Obleitner (IMGI), Dr. Charles Fierz (SLF)

\section{Experience}

\section{Research}

11/2010 - Ph.D student, WSL Institute for Snow and Avalanche Research SLF, Switzerland. present Influence of snow cover properties on avalanche dynamics

$08 / 2010-$ $10 / 2010$

$06 / 2010-$ $07 / 2010$ Scientific Assistant, WSL Institute for Snow and Avalanche Research SLF, Switzerland.

$09 / 2009-$

$12 / 2009$

Internship, WSL Institute for Snow and Avalanche Research SLF, Switzerland.

Permafrost simulations of the Dolomites using ALPINE3D

Internship, WSL Institute for Snow and Avalanche Research SLF, Switzerland. Icing frequencies for wind turbines in the Alps

Master Thesis, WSL Institute for Snow and Avalanche Research SLF, Switzerland. Systematic Assessment of New Snow Settlement in SNOWPACK

\section{Working}

03/2011 - University of Innsbruck, Institute of Meteorology and Geophysics IMGI, Innsbruck, Austria. Managing and conducting a scientific snow investigation campaign in Svalbard, Norway

02/2010 - Alaska Heliskiing, Haines, Alaska.

$04 / 2010$ Heliski Guide, weather forecaster and snow safety

01/2010 - City and Borough of Juneau, Urban Avalanche Forecasting, Juneau, Alaska.

02/2010 Assistant/intern of local urban avalanche forecaster 
02/2007 - Austrian Federal Forest Office, Department of Natural Hazards and Alpine

07/2007 Timberline BFW, Innsbruck, Austria.

Safety analysis of an avalanche endangered slope

05/2007 - University of Innsbruck, Institute of Meteorology and Geophysics IMGI, 06/2007 Innsbruck, Austria.

Setting up a weather station and ice core drilling in an ice cave in Austria

07/2006 - Central Institute for Meteorology and Geodynamics ZAMG, Salzburg, Austria.

08/2006 Weather observer at manned weather station Feuerkogel

$2003-2005$ Ski school Neuhuber, Ebensee, Austria.

Part-time skiing instructor

2002 - 2003 Austrian Army, Kirchdorf, Austria.

Military service, Alpine infantry

2000 - 2002 HEP Hard- and Software, Ebensee, Austria.

Work in computer business (disposal, repair, webdesign, network) while attending school

$2000-2006$ TILT eSports and Multimedia, Ebensee, Austria.

Multiple organisations \& realisations of (computer-) youth events for up to 100 participants

1999 - 2001 Multiple summer jobs in construction business.

\section{Teaching}

2012- present Instructor, SLF.

Presenter at the SLF IFKIS courses. Topic: Winter weather

2012 - present Instructor, SLF.

Presenter at SOS Services / Patrouilleur courses. Topic: Meteorology

2010 - present Instructor, SLF.

Member of the safety training team at SLF

02/2007 - Teaching Assistant, University of Innsbruck.

05/2007 Assistant in the exercises to The snow cover model SNOWPACK

\section{Peer-reviewed}

Granulation of snow: Experiments and discrete element modeling, Steinkogler, W., Gaume, J., Löwe, H., Sovilla, B., Lehning, M.; 2014; submitted.

Permafrost distribution modeling with the energy balance model Alpine3D in the Eastern Italian Alps, Steinkogler, W., Bavay, M., Crepaz, A., Völksch, I., Lehning, M.; 2014; in review.

Thermal energy in dry snow avalanches, Steinkogler, W., Sovilla, B., Lehning, M.; 2014; submitted.

Weblink Evaluation of a snow avalanche possibly triggered by a local earthquake at Vallée de la Sionne, Switzerland, Pérez-Guillén, C., Tapia, M., Furdara, G., Suriñach, E., McElwaine, J.N., Steinkogler, W., Hiller, M.; 2014; Cold Reg. Sci. Technol.

Weblink Influence of snow-cover properties on avalanche dynamics, Steinkogler, W., Sovilla, B., Lehning, M.; 2014; Cold Reg. Sci. Technol. 97: 121-131. 
Weblink Mapping frequencies of icing on structures in Switzerland., Grünewald, T., Dierer, S., Cattin, R., Steiner, P., Steinkogler, W., Fundel. F., Lehning, M.; 2012; J. Wind Eng. Ind. Aerodyn. 107-108: 76-82.

\section{Conference proceedings and abstracts}

\section{4:}

ISSW 2014 Linking snow cover properties and avalanche dynamics, Steinkogler, W., Sovilla, B., Lehning, M.; 2014; In Proceedings of the International Snow Science Workshop ISSW, Banff, Canada.

ISSW 2014 Granulation of snow: Experiments and discrete element modeling, Steinkogler, W., Gaume, J., Löwe, H., Sovilla, B., Lehning, M.; 2014; In Proceedings of the International Snow Science Workshop ISSW, Banff, Canada.

ISSW 2014 Modeling small and frequent avalanches, Dreier, L., Bühler, Y., Steinkogler, W., Feistl, T., Bartelt, P.; 2014; In Proceedings of the International Snow Science Workshop ISSW, Banff, Canada.

ISSW 2014 Livigno (Italy) Freeride Project, Monti, F., Steinkogler, W., Mitterer, C.; 2014; In Proceedings of the International Snow Science Workshop ISSW, Banff, Canada.

FA 2014 An integrated approach for backcountry snow sports safety and avalanche risk management., Monti, F., Steinkogler, W., Mitterer, C., Pozzi, A.; 2014; Forum Alpinum, Brescia, Italy.

FA 2014 Bringing avalanche forecasting into the 21st century: a combination of models and weather stations., Monti, F., Bellaire, S., Mitterer, C., Steinkogler, W., Pozzi, A.; 2014; Forum Alpinum, Brescia, Italy.

GF 2014 Linking snow cover properties and avalanche dynamics., Steinkogler, W., Sovilla, B., Lehning, M.; 2014; Graubünden forscht: Young Scientists in Contest, Davos, Switzerland.

GF 2014 Granulation of snow: Experiments and discrete element modeling., Steinkogler, W., Gaume, J., Löwe, H., Sovilla, B., Lehning, M.; 2014; Graubünden forscht: Young Scientists in Contest, Davos, Switzerland.

EUCOP 2014 4D Permafrost modeling with Alpine3D, Steinkogler, W., Bavay, M., Lehning, M.; 2014; 4th European Conference on Permafrost, Evora, Portugal.

\section{3:}

ISSW 2013 Granulation of Snow, Steinkogler, W., Sovilla, B., Lehning, M.; 2013; In Proceedings Weblink of the International Snow Science Workshop ISSW, Grenoble, France.

ISSW 2013 Thermal Energy in Snow Avalanches, Steinkogler, W., Sovilla, B., Jonas, T., Lehning,

Weblink M.; 2013; In Proceedings of the International Snow Science Workshop ISSW, Grenoble, France.

ISSW 2013 Toward Better Decision Tools for the Management of Frequent Avalanches, Segor, Weblink V., Pitet, L., Bovet, E., Dellavedova, P., Sovilla, B., Steinkogler, W., Veitinger, J., Maggioni, M., Chiambretti, I., Prola, M.; 2013; In Proceedings of the International Snow Science Workshop ISSW, Grenoble, France. 
ISSW 2013 The Full-Scale Avalanche Dynamics Test Site Vallée de la Sionne, Sovilla, B., Weblink McElwaine, J., Steinkogler, W., Hiller, M., Dufour, F., Surinach, E., Guillen, C., Fischer, J.-T., Thibert, E., Baroudi, D.; 2013; In Proceedings of the International Snow Science Workshop ISSW, Grenoble, France.

DACA 2013 Measuring the thermal balance of a snow avalanche, Steinkogler, W., Sovilla, B., Jonas, T., Lehning, M.; 2013; Davos Atmosphere and Cryosphere Assembly, Davos, Switzerland.

DACA 2013 Development, refinement and application of a new evaluation and comparison method for computational snow avalanche simulation, Fischer, JT., Fromm, R., Gauer, P., Sovilla, B., Steinkogler, W., Granig, M., Christen, M.; 2013; Davos Atmosphere and Cryosphere Assembly, Davos, Switzerland.

DACA 2013 The study of snow avalanches from a climate change perspective, Dellavedova, Segor, Pitet, Bovet, Steinkogler, Veitinger, McElwaine, Maggioni, Prola, Barbero, Chiambretti, Sovilla; 2013; Davos Atmosphere and Cryosphere Assembly, Davos, Switzerland.

DACA 2013 Observed and modelled snow structure at the glacier Kongsvegen (Svalbard), Obleitner, Jacobi, Karner, Bilgeri, Steinkogler, Kohler; 2013; Davos Atmosphere and Cryosphere Assembly, Davos, Switzerland.

2012:

ISSW 2012 How snow cover properties influence avalanche dynamics, Steinkogler, W., Sovilla, B., Weblink Lehning, M.; 2012; In Proceedings of the International Snow Science Workshop ISSW, Anchorage, USA.

ISSW 2012 The role of thermal temperature in avalanche flow, Valero, C., Feistl, T., Steinkogler, Weblink W., Buser, O., Bartelt, P.; 2012; In Proceedings of the International Snow Science Workshop ISSW, Anchorage, USA.

ISSW 2012 Objective Comparison of Two Numerical Avalanche Dynamics Models, Fischer, J.-T., Weblink Steinkogler, W., Granig, M., Christen, M.; 2012; In Proceedings of the International Snow Science Workshop ISSW, Anchorage, USA.

EGU 2012 Influence of snow-cover properties on avalanche dynamics, Steinkogler, W., Sovilla, B., Lehning, M.; 2012; European Geoscience Union, Vienna, Austria.

EGU 2012 Permafrost simulations in the Dolomites using Alpine3D, Steinkogler, W., Bavay, M., Lehning, M.; 2012; European Geoscience Union, Vienna, Austria.

EGU 2012 Snow micro-structure at Kongsvegen glacier, Svalbard, Bilgeri, F., Karner, F., Steinkogler, W., Fromm, R., Obleitner, F., Kohler, J.; 2012; European Geoscience Union, Vienna, Austria.

EGU 2012 Large-scale modelling permafrost distribution in Ötztal, Pitztal and Kaunertal (Tyrol), Hoinkes, S., Sailer, R., Lehning, M., Steinkogler, W.; 2012; European Geoscience Union, Vienna, Austria.

2010:

IGS 2010 A new map of icing potential for Switzerland, Grünewald, Steinkogler, Dierer, Cattin, Steiner, Lehning; 2012; International Symposium on Snow, Ice and Humanity in a Changing Climate, Sapporo, Japan. 
2009:

ISSW 2009 Systematic Assessment of New Snow Settlement in SNOWPACK, Steinkogler, W., Fierz,

Weblink C., Lehning, M., Obleitner, F.; 2009; In Proceedings of the International Snow Science Workshop ISSW, Davos, Switzerland.

SGM 2009 A systematic approach to quantify the performance of SNOWPACK., Steinkogler, W., Fierz, C., Lehning, M., Obleitner, F.; 2009; 7th Swiss Geoscience Meeting, Neuchatel, Switzerland.

\section{Non peer-reviewed}

Le site expérimental de la vallée de la Sionne dédié à l'étude de la dynamique des avalanches., Sovilla, B., McElwaine, J., Steinkogler, W., Veitinger, J., Köhler, A., Bühler, Y., Scharr, M., Hiller, M., Dufour, F., Suriñach, E., Perez Guillen, C., Fischer, J.-T., Thibert, E., Baroudi, D.; 2014; Neige et avalanches 145, avril: 28.

Granulation de la neige, Steinkogler, W., Sovilla, B., Lehning, M.; 2014; Neige et avalanches 145, avril: 28 .

Numerische Simulation von gravitativen Naturgefahren mit RAMMS (Rapid Mass Movements), Christen, M.; Gerber, W.; Graf, C.; Bühler, Y.; Bartelt, P.; Glover, J.; McArdell, B.W.; Feistl, T.; Steinkogler, W., 2012; Wildbach- Lawinenverbau 76, 169: 282-292.

\section{Additional Education/Certifications}

2011 (Airborne/Helicopter) Avalanche Control Blasting Permit, Innsbruck, Austria, WIFI Tirol.

2010 CAA Avalanche Operations Level II - Mod I, Revelstoke, Canada, Canadian Avalanche Association.

2010 Certified Explosives Expert, Innsbruck, Austria, WIFI Tirol.

2010 CAA Avalanche Operations Level I, Smithers, Canada, Canadian Avalanche Association.

2010 Heliski Guide Level II, Haines, Alaska, Alaska Heliskiing.

2010 Wilderness Advanced First Aid (WAFA) - $\mathbf{3 6}$ hours, Haines, Alaska, Wilderness Medical Associates.

2010 American Avalanche Association Level III, Juneau, Alaska.

2009 Artificial Avalanche Release using Pyrotechnical Thrower Systems, Kaprun, Austria, Explosive Engineering.

2003 Austrian Skiing Instructor I, Obertauern, Austria, Snowsport Austria.

Diving License (CSMA Brevet*).

Paraglider License.

Austrian driver's license.

\section{Languages}

German Native

English Fluent 


\section{Spanish Novice}

Computer skills

scientific Matlab, ArcGIS, R

job related SNOWPACK, Alpine3D

typography ATE $_{\mathrm{E}} \mathrm{X}$, Microsoft Office

tools Photoshop

RAMMS, SamosAT

Hardware, Networks

Personal Interests

Traveling, surfing, climbing, diving, reading, enjoying life and snow.

References

References available on request.

Updated

September 19, 2014 